\title{
A Study of the Contaminant Mixture of Lead, Cadmium and Methylmercury for Their Effects on Endothelial Function Under Conditions Typifying Specific Diets and Lifestyles for Northern Populations
}

\author{
By \\ Saad Ulhaq, B.Sc.H \\ A thesis submitted to \\ the Faculty of Graduate Studies and Research \\ in partial fulfillment of the requirements for the degree of
}

Masters of Science

Biology Department

Ottawa-Carleton Institute of Biology

Ottawa, Ontario

November 2012

Copyright $\mathbb{C}$ Saad Ulhaq 2012 
Library and Archives

Canada

Published Heritage

Branch

395 Wellington Street

Ottawa ON K1A ON4

Canada
Bibliothèque et

Archives Canada

Direction du

Patrimoine de l'édition

395 , rue Wellington

Ottawa ON K1A ON4

Canada
Your file Votre référence

ISBN: 978-0-494-94286-4

Our file Notre référence

ISBN: $978-0-494-94286-4$
NOTICE:

The author has granted a nonexclusive license allowing Library and Archives Canada to reproduce, publish, archive, preserve, conserve, communicate to the public by telecommunication or on the Internet, loan, distrbute and sell theses worldwide, for commercial or noncommercial purposes, in microform, paper, electronic and/or any other formats.

The author retains copyright ownership and moral rights in this thesis. Neither the thesis nor substantial extracts from it may be printed or otherwise reproduced without the author's permission.
AVIS:

L'auteur a accordé une licence non exclusive permettant à la Bibliothèque et Archives Canada de reproduire, publier, archiver, sauvegarder, conserver, transmettre au public par télécommunication ou par l'Internet, prêter, distribuer et vendre des thèses partout dans le monde, à des fins commerciales ou autres, sur support microforme, papier, électronique et/ou autres formats.

L'auteur conserve la propriété du droit d'auteur et des droits moraux qui protege cette thèse. $\mathrm{Ni}$ la thèse ni des extraits substantiels de celle-ci ne doivent être imprimés ou autrement reproduits sans son autorisation.
In compliance with the Canadian Privacy Act some supporting forms may have been removed from this thesis.

While these forms may be included in the document page count, their removal does not represent any loss of content from the thesis.
Conformément à la loi canadienne sur la protection de la vie privée, quelques formulaires secondaires ont été enlevés de cette thèse.

Bien que ces formulaires aient inclus dans la pagination, il n'y aura aucun contenu manquant. 


\section{ABSTRACT}

Northern populations of Canada have recently seen increases in cardiovascular disease. Shifting from traditional protein-rich diets to western-diets and/or exposure to persistent environmental contaminants within those regions may be possible causes. Endothelial dysfunction is a primary event capable of initiating processes ultimately leading to cardiovascular disease. This study aims to understand changes occurring in endothelial function by exposure of human coronary artery endothelial cells (HCAEC), in vitro, to factors like high sugar/fat, alcohol and Northern contaminant heavy metals cadmium, lead and methylmercury. We found that endothelin-1 (ET-1), plasminogen activitor inhibitor-1 (PAI-1), 6-keto-Prostaglandin F1 $\alpha$ (6-keto) and endothelial nitric oxide synthase (eNOS) were significantly altered with exposure to high fat/sugar and contaminant mixture. Furthermore, high concentration of $\mathrm{MeHg}$ exposure significantly decreased HCAEC cell viability and reduced eNOS protein. Results suggest $\mathrm{MeHg}$ exposure, more so than diet, may cause endothelial dysfunction and puts Northern populations of Canada at increased risk of cardiovascular disease. 


\section{ACKNOWLEDGEMENTS}

I would like to express my heartfelt gratitude and appreciation to Dr. William Willmore for not only accepting me as one of his graduate students, but for providing guidance, moral support, encouragement and insight during my thesis. His passion, attitude and intellect are an understatement of his scientific prowess. His character, belief in his students and patience are virtues which have left an indelible mark on me not only as a student of science but as a person. I am extremely grateful.

My thesis was also made possible by Dr. Dawn Jin and her continuous drive for success and excellence with humility and understanding. I am extremely indebted to her patience and allowing me the opportunity to work within her lab. Dr. Jin gave me the first opportunity I needed for obtaining experience within a real-world setting; eventually leading to my masters. I would also like to extend gratitude and thanks to my co-lab members/mentors Melanie Coughlan, Jin Yan, Maria Florian and laziyan Mahemuti; I have learned much from all their experiences.

I would like to thank Drs. Kenneth Storey and John Arnason for their guidance and being committee members for my thesis. I would also like to thank Drs. John Vierula and David Miller for attending my thesis defense.

I am extremely grateful to my family and friends for being very patient and supportive, understanding my frustrations, easing my burdens and praying for my success. I could not have done this without them.

I owe all that I have achieved and will achieve to God and his blessings. He has allowed me opportunities that many do not get and only dream of. I can only hope that I may produce the best results for whatever I am faced with in the future. I am humbled. 


\section{TABLE OF CONTENTS}

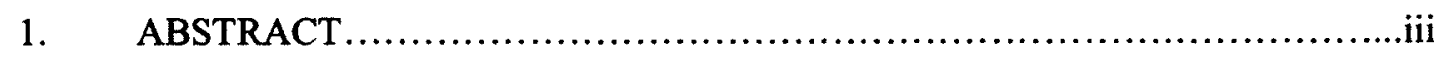

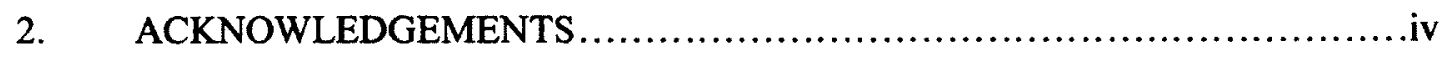

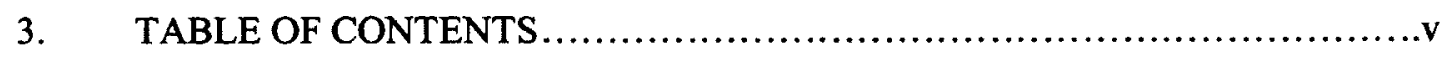

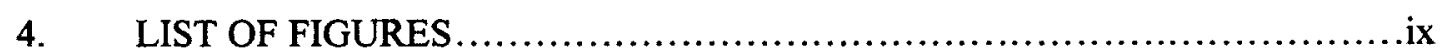

5. LIST OF ABBREVIATIONS .............................................

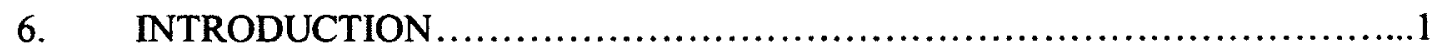

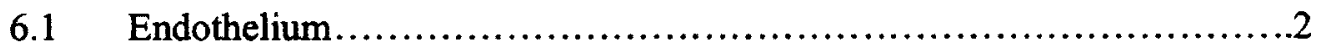

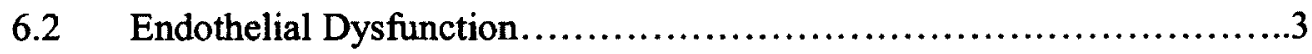

6.3 Inuit Populations and Northern Contaminant Exposure..................5

6.4 Contaminant Metals: Lead, Cadmium and Mercury....................

6.4.1 Metals........................................................

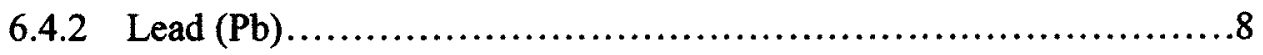

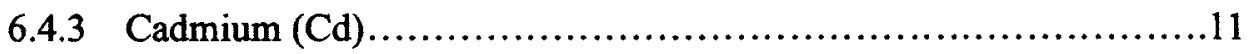

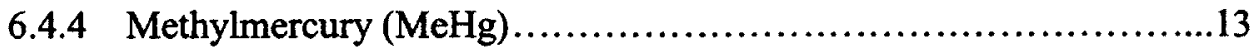

6.5 The Role of Oxidative Stress in Endothelial Dysfunction................16

6.6 Nuclear Factor-kB (NF-kB) and Inflammation......................22

6.7 Keap1-Nrf2 Cellular Defense Pathway............................24

6.8 Endothelial Nitric Oxide Synthase (eNOS) and Nitric Oxide (NO).......25

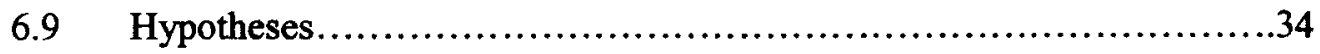




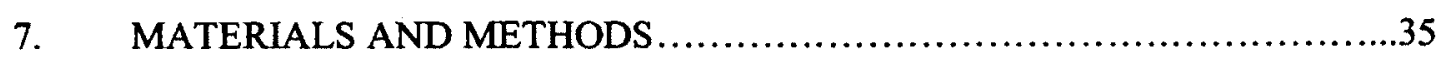

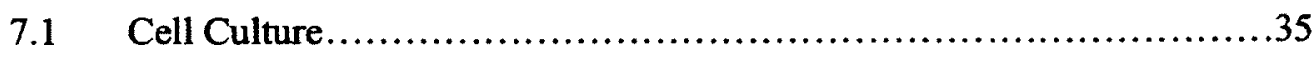

7.2 Preparation of Chemical Dosing Solutions...........................36

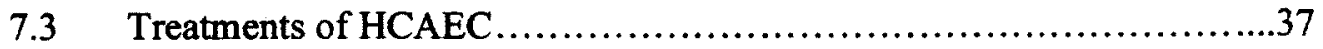

7.3.1 Cell Preparation.............................................37

7.3.2 Experimental Design and Dosing of HCAEC..................37

7.3.3 Supernatant and HCAEC Lysate Collection......................38

7.3.4 Determining Protein Concentration...........................39

7.4 Individual Metal Dosing and Treatments...........................39

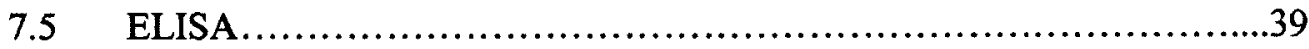

7.5.1 Endothelin-1 (ET-1) ....................................

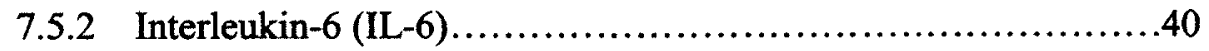

7.5.3 Plamsminogen Activator Inhibitor-1 (PAI-1) ..................40

7.5.4 6-keto Prostaglandin $F_{1 \alpha}(6-$ keto PGF $1 \alpha) \ldots \ldots \ldots \ldots \ldots \ldots \ldots \ldots . \ldots \ldots$

7.5.5 Endothelial Nitric Oxide Synthase (eNOS) ....................41

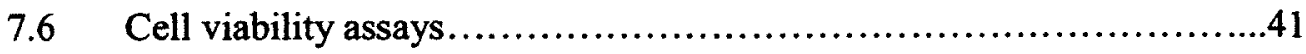

$7.7 \quad$ Western Blot Analysis........................................42

$7.8 \quad$ Statistical Data Analysis ........................................43 


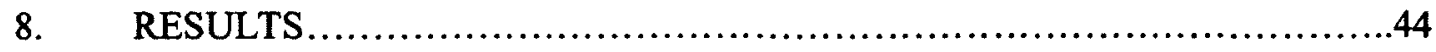

8.1 Effects of NCM3 on Markers of Endothelial Function in HCAEC Grown Under Varying LVG and EtOH Conditions.......................44

8.1.1 Multitox Data..........................................44

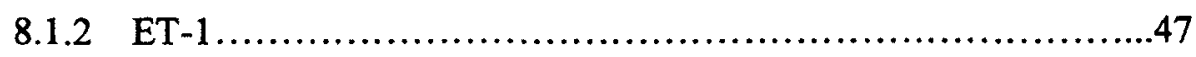

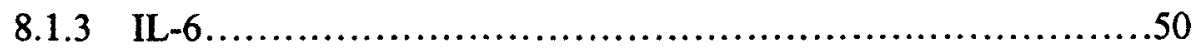

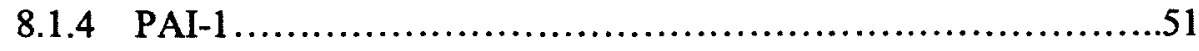

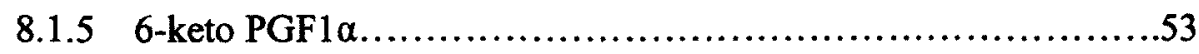

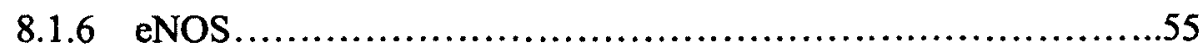

8.2 Effects of Individual Metals on eNOS ...............................58

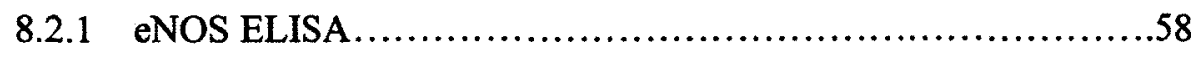

8.2.2 eNOS Protein...................................................

8.3 Effects of NCM3 and Individual Metals on Cell Morphology...........67

8.4 Cell Viability For Exposure to $\mathrm{M} 3, \mathrm{MeHg}, \mathrm{PbCl}_{2}$ and $\mathrm{CdCl}_{2} \ldots \ldots \ldots \ldots . .73$

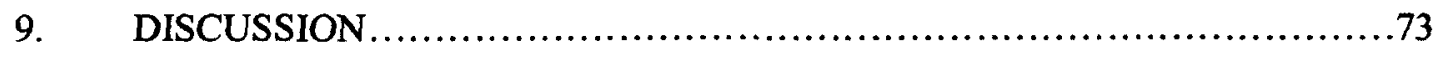

9.1 Human Coronary Artery Endothelial Cells.........................73

9.2 Effects of NCM3, Dietary Fat/Sugar and Alcohol on HCAEC Cell

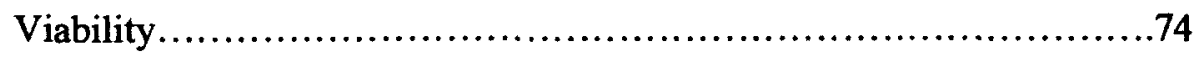


9.3 Effects of NCM3 on Markers of Endothelial Dysfunction................77

9.4 Effects of individual metals on eNOS Protein Expression in HCAEC....84

9.5 Conclusion......................................................... 85

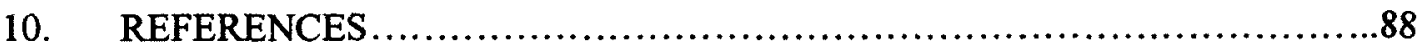




\section{LIST OF FIGURES AND TABLES}

Figure 1: Differences between the appearance of healthy and atherosclerotic endotheliums.................................................................4

Figure 2: Lead exposure and promotion of oxidative stress......................................10

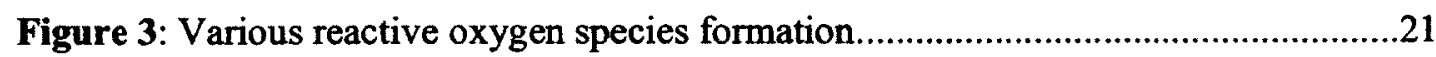

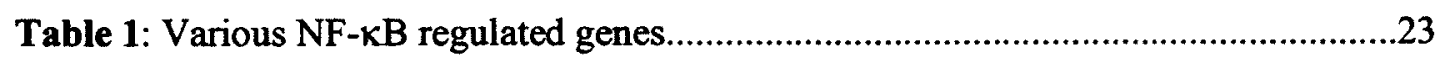

Figure 4: Full length schematic of NOS protein structure showing N-terminal oxygenase

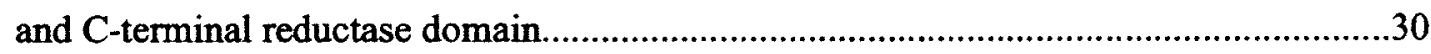

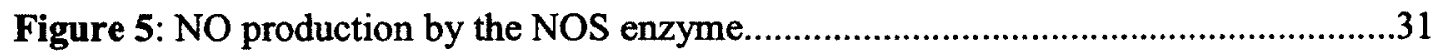

Figure 6: Schematic representation of possible mechanisms by which production of NO

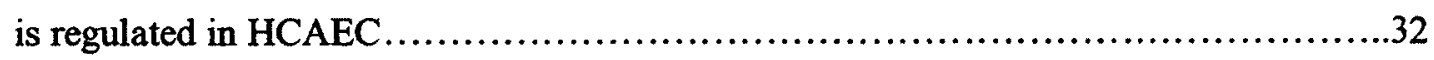

Figure 7: Schematic of a postulated G-protein mediated signal transduction processes

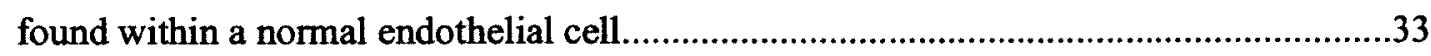

Table 2: Experimental design of treatment groups and factors......................37

Figure 8: Effects of NCM on cell viability for HCAEC cultured under varying LVG and

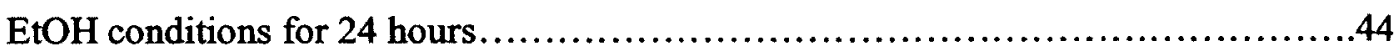

Figure 9: Effects of NCM3 on ET-1 levels in the culture media of HCAEC cultured

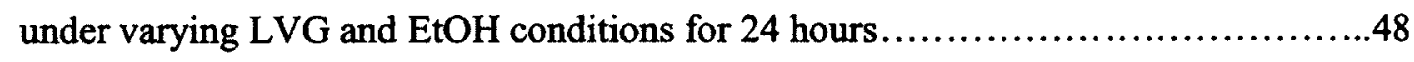

Figure 10: Effects of NCM3 on intracellular ET-1 levels in HCAEC cultured under varying $L V G$ and EtOH conditions for 24 hours .49

Figure 11: Effects of NCM3 on IL-6 levels in the supernatants of HCAEC cultured under varying LVG and EtOH conditions for 24 hours .50 
Figure 12: Effects of NCM3 on PAI-1 levels in the supernatants of HCAEC cultured under varying $L V G$ and $E t O H$ conditions for 24 hours........................... 52

Figure 13: Effects of $\mathrm{NCM} 3$ on 6-keto $\mathrm{PGF}_{1 \alpha}$ levels in the supernatants of HCAEC cultured under varying $L V G$ and EtOH conditions for $24 \mathrm{hrs} . \ldots \ldots \ldots \ldots \ldots \ldots \ldots . \ldots . \ldots . \ldots . \ldots$

Figure 14: Effects of NCM3 on eNOS levels in cell lysates of HCAEC cultured under

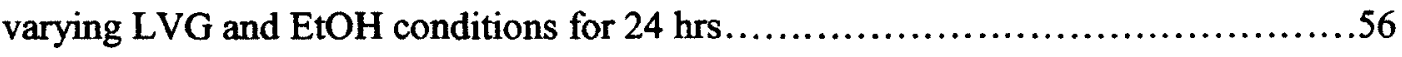

Figure 15: Dose effects of NCM3 on eNOS protein levels in HCAEC after $24 \mathrm{hr}$ of

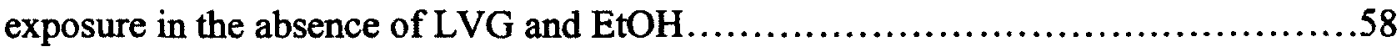

Figure 16: Effects of MeHg on eNOS levels in HCAEC after $24 \mathrm{hr}$ of exposure........59

Figure 17: Effects of $\mathrm{Pb}$ on eNOS protein levels in HCAEC after $24 \mathrm{hr}$ of exposure....60

Figure 18: Effects of Cd on eNOS protein levels in HCAEC after $24 \mathrm{hr}$ of exposure....61

Figure 19: Western blot of protein extracts of HCAEC exposed to varying doses of

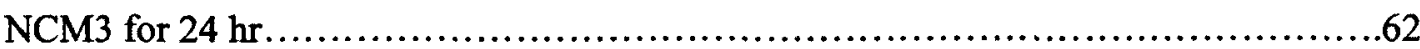

Figure 20: Western blot of protein extracts of $\mathrm{HCAEC}$ exposed to $\mathrm{MeHg}$ for $24 \mathrm{hr} . \ldots . .63$

Figure 21: Western blot of protein extracts of HCAEC exposed to $\mathrm{Pb}$ for $24 \mathrm{hr} . \ldots \ldots \ldots 64$

Figure 22: Western blot of protein extracts of HCAEC exposed to Cd for $24 \mathrm{hr} . \ldots \ldots . .65$

Figure 23: Effects of NCM3 on morphology of HCAEC after $24 \mathrm{hr}$ of exposure........67

Figure 24: Effects of $\mathrm{MeHg}$ on morphology of HCAEC after $24 \mathrm{hr}$ of exposure........69

Figure 25: Effects of $\mathrm{Pb}$ on morphology of HCAEC after $24 \mathrm{hr}$ of exposure...........70

Figure 26: Effects of Cd on morphology of HCAEC after $24 \mathrm{hr}$ of exposure............71

Figure 27: Dose response cell viability of $\mathrm{HCAEC}$ exposed to $\mathrm{M} 3, \mathrm{MeHg}, \mathrm{PbCl}_{2}$ and

$\mathrm{CdCl}_{2}$ over $24 \mathrm{hrs}$ 


\section{LIST OF ABBREVIATIONS}

6-keto PGF $1 a$ : 6-keto Prostagladin $F_{1 a}$

ADP: Adenosine Diphosphate

AP1: Activator Protein-1

ARE: Antioxidant Response Elements

ATP: Adenosine Triphosphate

bFGF: Basic Fibroblast Growth Factor

BH $_{4}$ : Tetrahydrobiopterin

CaM: Calmodulin

Cd: Cadmium

cGMP: Cyclic Guanidine MonoPhosphate

CHD: Coronary Heart Disease

DNA: Deoxyribonucleic acid

EC: Endothelial cells

ECE-1: Endothelin Converting Enzyme - 1

EDRF: Endothelium Derived Relaxing Factor

eNOS: Endothelial Nitric Oxide Synthase

EPI: (-)-Epicathechin

ET-1: Endothelin - 1

FAD: Flavin Adenine Dinucleotide

FMN: Flavin Mononucleotide

FSS: Fluid Shear Stress

HCAEC: Human Coronary Artery Eqdothelial Cells 
Hg: Mercury

HIF: Hypoxia Inducible Factor

Hsp: Heat Shock Protein

HTN: Hypertension

HUVEC: Human Umbilical Vein Endothelial Cells

IL-6: Interleukin-6

iNOS: Inducible Nitric Oxide Synthase

JAK: Janus Kinase

Keap-1: Kelch-like ECH associated protein-1

LDL: Low-density lipoprotein

LVG: Low-density lipoprotein/Very-low density lipoprotein/ Glucose

M3: Metal mixture of methylmercury/ lead/ cadmium

MCP-1: Monocyte Chemotactic Protein-1

MeHg: Methylmercury

Mn-SOD: Manganese Superoxide Dismutase

mRNA: Mitochondrial Ribonucleic Acid

NADH: Nicotinamide Adenine Dinucleotide

NADPH: Nicotinamide Adenine Dinucleotide Phosphate

NCP: Northern Contaminants Program

NCM: Northern Contaminant Mixture

NF-kB: Nuclear Factor-kB

n-LDL: Native Low-Density Lipoprotein

NLS: Nuclear Localization Signal 
NOHA: N-hydroxy-L-arginine

nNOS: Neuronal Nitric Oxide Synthase

NO: Nitric Oxide

NOS: Nitric Oxide Synthase

NOX: Nicotinamide Adenine Dinucleotide Phosphate Oxidase

Nrf2: Nuclear Factor Erythroid 2- Related Factor

OC: Organochlorine Pesticide

OH: Alcohol

ox-LDL: Oxidized-Low Density Lipoprotein

ox-VLDL: Oxidized Very-Low-Density Lipoprotein

PAI-1: Plasminogen Activator Inhibitor-1

Pb: Lead

PCB: Polychlorinated Biphenyls

PEDF: Pigment Epithelium Derived Factor

PKCa: Protein Kinase c alpha

Rac-1: Ras-related C3 Botulinum Toxic Substrate-1

RHD: Rel Homology Domain

ROS: Reactive Oxygen Species

S: Serine

Se: Selenium

SH: Sulfhydryl

SOD: Superoxide Dismutase

STAT: Signal Tranducer and Activator of Transcription 
T: Threonine

TF: Tissue Factor

TNF- $\alpha$ : Tumor Necrosis Factor- $\alpha$

VCAM-1: Vascular Cell Adhesion Molecule - 1

VEGF: Vascular Endothelium Growth Factor

VLDL: Very Low-Density Lipoprotein

VSMC: Vascular Smooth Muscle Cell

WHO: World Health Organization

Y: Tyrosine 


\section{INTRODUCTION}

The rationale and idea behind this thesis stems from the ongoing projects aimed at studying First Nations and Inuit populations in Northern Canada as part of the Northern Contaminants Program (NCP). This large collaborative project has numerous initiatives directed to the study of Inuit health as it relates to contaminant exposure to humans from the environment and other sources. Recent increases of cardiovascular disease in Inuit populations have attracted a lot of attention and raised questions of possible causes and long term contaminant exposure. This thesis specifically dealt with understanding the effects of heavy metal exposure, high levels of dietary fats and alcohol consumption on cardiovascular health in Inuit populations by studying endothelial dysfunction in cultured human coronary artery endothelial cells (HCAEC) exposed to contaminants in vitro and aims to offer insight into what may be good future directions to consider in vivo. Since in vitro conditions were tested, we have to make a few simplifying assumptions. First thing to consider is that the HCAEC cell line is an accepted cultured line to measure endothelial dysfunction in humans. Second, the method of exposure in vitro conditions are different from in vivo; cultured cells will be directly exposed to the contaminants whereas under in vivo conditions, all contaminats will be absorbed differently, metabolized differently and ultimately affect cells differently. Dietary fats, alcohol and heavy metals would undergo numerous metabolic and digestive processes before interacting with in vivo cells. Third we have to consider that in vitro cells are in culture media which causes lesser hindrance to exposed contaminants when comparing with in vivo cells since they are in blood which has various proteins and substances capable of 
interacting with contaminatns; we assume that the result in both cases would be comparable.

\subsection{Endothelium}

The endothelium is composed of a single layer of cells which lines the myocardial vasculature, from the major arteries of the heart down to capillaries, and serves as the primary interface between the blood and body tissues. It therefore regulates numerous and important aspects of vascular responses (Davidson 2010; Versari et al 2008; Atochin and Huang 2010). The endothelium controls access of surrounding cells to glucose, fatty acids and other metabolites in addition to also exerting a negative effect on smooth muscle proliferation. It regulates vascular tone and regional blood flow by producing factors involved in vasodilation (it is the primary source of nitric oxide, prostacyclin, etc), vasoconstriction (endothelin, etc), vascular derived hyperpolarizing factor as well as other secreted molecules and hormones involved in controlling smooth muscle contraction. It serves as a modulator for the adhesion and aggregation of platelets which affects the resistance to thrombosis. The endothelium expresses certain surface adhesion molecules which influence interactions with monocytes and leukocytes. This response affects the recruitment of inflammatory cells as well as atherosclerotic plaque formation. In response to vascular injury, the endothelium also serves as a modulator of vascular smooth muscle cell proliferation (Deanfield et al 2007; Atochin and Huang, 2010). With those particular essential functions, in addition to being the first line of interaction between the blood and body tissues, there is growing evidence which suggests that 
endothelial dysfunction may be an important independent predictor for the risk of cardiovascular events in the future (Versari et al, 2008).

\subsection{Endothelial Dysfunction}

Endothelial dysfunction is now accepted as an early and important mechanism which predisposes individuals to atherothrombotic damage and subsequent cardiovascular events (Atochin and Huang, 2010; Reriani et al., 2010; Ramirez-Sanchez et al., 2012). In 2004, the World Health Organization (WHO) estimated 17.1 million deaths are attributed to cardiovascular events; representing $29 \%$ of all deaths as well as being the single greatest cause of death (Versari, 2008). Endothelial dysfunction can be defined as a pathological state of the endothelium where in there exists an imbalance between the vasodilative, vasoconstrictive as well as the modulatory substances required for normal functioning (Cai and Harrison, 2000). It is also characterized by a shifting of normal actions of the endothelium towards reduced vasodilation, appearance of a more proinflammatory state and increase in prothrombotic properties - where this is an important early event in atherosclerosis pathogenesis by contributing to plaque initiation and progression (Celermajer et al 1992; Suwaidi et al 2000; Endemann and Schiffrin, 2004). Figure 1 depicts the difference between a healthy and unhealthy endothelium. 


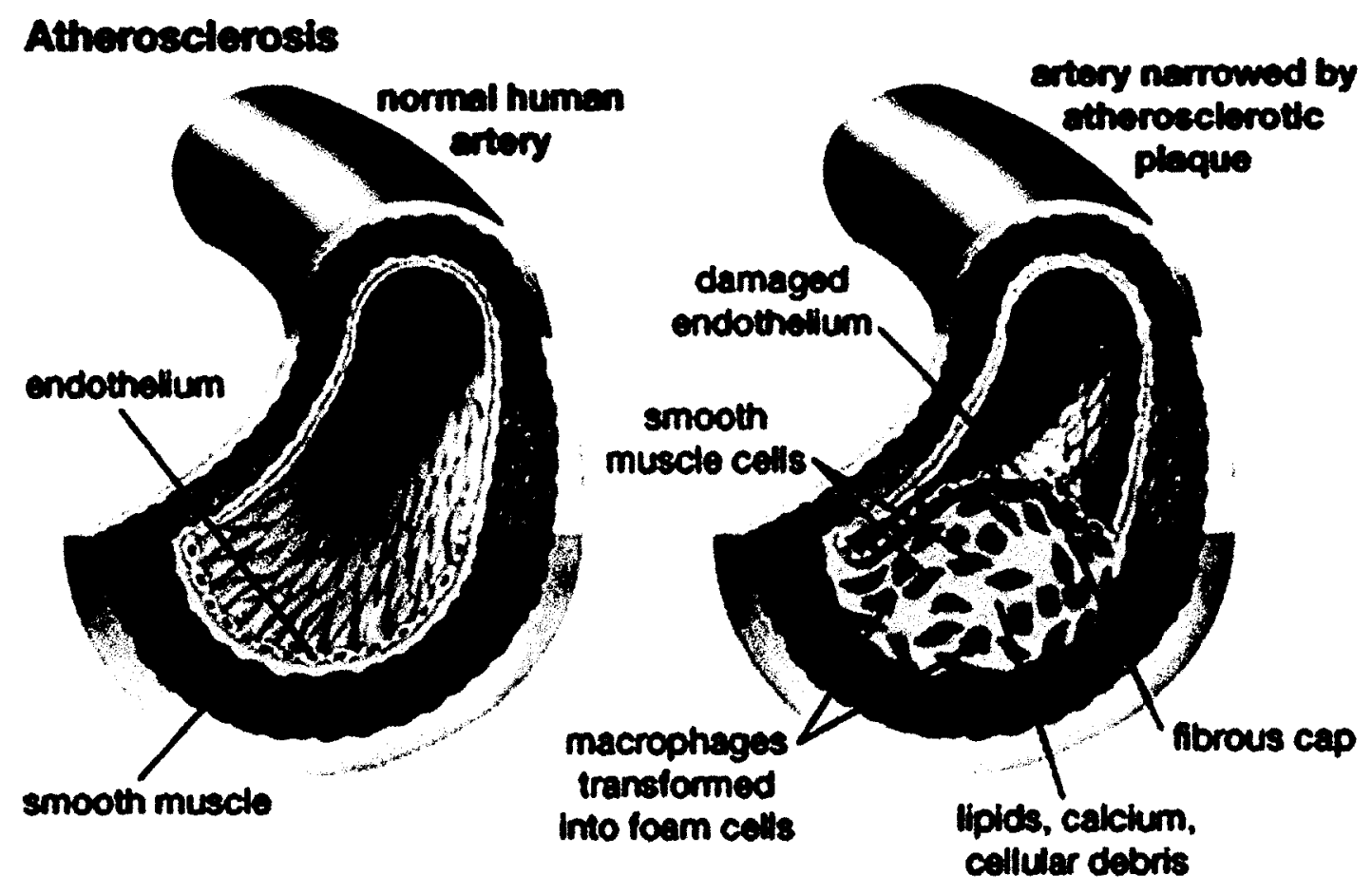

Figure 1: Differences between the appearance of healthy and atherosclerotic endotheliums. The image on the left is that of a normal and healthy artery. The image on the right is of an artery with atherosclerotic plaque. * Image Encyclopaedia Britannica, Inc., 2007 


\subsection{Inuit Populations and Northern Contaminant Exposure}

There is a common stigma that assumes lower incidences of coronary heart disease (CHD) among Inuit populations; the basis of which is that a traditional diet high in monounsaturated and polyunsaturated fatty acids from marine origins will serve to protect against $\mathrm{CHD}$ (Jorgensen and Borch-Johnsen, 2008). Unfortunately, the diet also happens to be the main route of exposure for many contaminants to these populations. Most aboriginal groups in Canada rely on fishing and hunting as part of their traditional lifestyle. Seafood consumption has both "pros and cons"; various fatty acids which are associated with beneficial health effects are the "pros" while exposure to environmental contaminants is a "con" (Sharp 2009). There are a plethora of persistent environmental toxicants which are carried from the southern towards the northern arctic areas via oceanic and atmospheric transport; these substances are biomagnified within the Arctic food web (Fontaine et al, 2008; Van Oostam et al. 2005; Sharp 2009; Pelletier et al. 2009; Dellaire et al., 2003). Heavy metals, polychlorinated biphenyls, organochlorine pesticides, polybrominated diphenyl ethers, perfluorooctane sulfonate are all part of this complicated mixture. A federal program known as the Northern Contaminants Program (NCP) was formed and began in 1991. The NCP was a response to the concerns raised over the increased levels of contaminants in fish and wildlife, both of which are considered an important part of the diets of numerous northern Aboriginal peoples (Van Oostam et al., 2005). Part of NCP's funds are allocated for research and related activities in the areas of human health research, environmental monitoring and research, education and communication and lastly, national/regional coordination and aboriginal partnerships. 
The problem arises when we consider that it is not just a single contaminant affecting the outcome of various diseases but that it is a complicated mixture. For a number of the individual substances found, there is extensive literature on animal and human exposure to single compounds; however, the data on complex mixtures are few (Pelletier et al., 2009). A study conducted by Dewailly et al. in 2006 surveyed individuals in Nunavik for blood contaminants. Plasma levels of $\mathrm{MeHg}, \mathrm{Pb}$ and $\mathrm{Cd}$ were approximately $11 \mu \mathrm{g} / \mathrm{L}, 39.4 \mu \mathrm{g} / \mathrm{L}$ and $3.04 \mu \mathrm{g} / \mathrm{L}$ respectively (Dewailly et al., 2006). A more recent study by Fontaine et al (2008), re-evaluated metals of concern found in the Inuit of Nunavik. This study involved 917 adults aged between 18 and 74 from the 14 communities of Nunavik. Collected blood samples were analyzed for metals. The mean blood concentration of total mercury was found to be $51.2 \mathrm{nmol} / \mathrm{L}$, lead $0.19 \mu \mathrm{mol} / \mathrm{L}$ and cadmium from $5.3 \mathrm{nmol} / \mathrm{L}$ for non-smokers to $40.4 \mathrm{nmol} / \mathrm{L}$ for smokers. This study indicates a decrease in concentrations of mercury between 1992 and 2004. This decrease was attributed to dietary change (Fontaine et al., 2008). It should be noted that the Inuit have the highest mean levels of cadmium compared in maternal blood with a range of 1.0 $\mu \mathrm{g} / \mathrm{L}$ to $1.9 \mu \mathrm{g} / \mathrm{L}$ (Van Oostam et al., 2005). It has been hypothesized that increased exposure to elevated levels of contaminants such as mercury, lead and cadmium may cause endothelial dysfunction, leading to metabolic and cardiovascular diseases. 


\subsection{Contaminant Metals: Lead, Cadmium and Mercury}

\subsubsection{Metals}

There is widespread exposure of humans to metals, which may induce a toxic response. While technology has been on the rise in the modern era, numerous anthropogenic processes such as industrialization, manufacture and processing caused release of chemicals into the environment. Among the numerous contaminants that are considered as potential effectors of endothelial dysfunction, heavy metals such as lead, cadmium and methylmercury are of the top concern and became the focus of this study.

\subsubsection{Lead $(\mathrm{Pb})$}

Lead is a very toxic heavy metal which naturally occurs in the earth's crust. Owing to industrialization and various anthropogenic activities of humankind, exposure to lead occurs through various means.

Sources: Sources of exposure have been found to be in construction, batteries, fusible alloys, radiations shields, lead based paints, leaded gasoline contaminated water, etc. (Sander et al, 2009; Vaziri 2008). Enforcement of industrial and environmental regulations has paralleled a decline of lead in the environment., Environmental persistence and poor enforcement of safety measures in developing countries make lead a threat to human health (Vaziri 2008).

Distribution, absorption and persistence: Lead has a biological half life of 35 days in blood and 20-30 years in bone (Writh and Mijal, 2010). Lead is found to cause a variety of adverse health effects such as encephalopathy, renal failure, impairment of 
cognitive and neuronal behavior, development of hypertension (HTN), cardiovascular disease, oxidative stress (ROS production) and atherosclerosis (Vaziri 2008; Goyer 1995; Goyer 1997; Fujiwara and Kaji, 2000; Gurer and Ercal, 2000). Lead absorption by humans occurs via the respiratory, gastrointestinal tract and occasionally via the skin (Vaziri 2008). Highest efficiency for absorption occurs via the respiratory tract; this mostly occurs due to occupational exposures such as smelting, or inhalation of lead containing dust. Following absorption, most of lead content is bound to red blood cells. The persistence of lead within the body is helped by the fact that over $95 \%$ of total body lead content resides in the bone. Therefore, gradual release of lead from their storage areas in the bone serves as a persistent source of lead exposure and toxicity (Vaziri 2008).

Metabolism: Recent studies have shown that lead causes oxidative stress by causing the generation of ROS, depleting glutathione which reduces the antioxidant defense system, inhibits sulfhydryl dependent enzymes and alters membrane integrity and fatty acid composition (Gurer and Ercal, 2000). Another study by Fujiwara and Kaji (2000) suggested that lead may cause an inhibition of the ability of endothelial cells (ECs) to repair themselves when injured. Their rationale was based on the fact that vascular ECs form a layer of cells on the inner surface of the blood vessel wall; this is to prevent vascular damage and lesions (such as in atherosclerosis) by blocking the interface between blood and tissue. Upon injury, vascular endothelium release basic fibroblast growth factors (bFGFs) which stimulate proliferation and migration of cells to the damaged site for repair (Fujiwara and Kaji, 2000). If any limitations are extended to this system, there may remain de-endothelialized areas where platelet aggregation may be induced; serving as the initial atherosclerotic event (Fujiwara and Kaji, 2000). Fujiwara 
and Kaji grew confluent cultures of bovine aortic endothelial cells, half injured, which were incubated in the presence and absence of lead nitrate. The process of repair was evaluated by monitoring for the cell numbers, of endothelial cell monolayers, appearing in the injured area. Their observations concluded that lead inhibited the repair of injured monolayer of vascular endothelial cells stimulated by exogenous bFGF, which suggested that the metal may disturb endothelial repair even when there is a release of bFGF from dead cells. Finally, lead inhibits the proliferation of vascular ECs (Fujiwara and Kaji, 2000). Lead is reported to have the ability to alter the proper functioning of antioxidant enzymes such as superoxide dismutase, catalase and glutathione peroxidase, as well as changes to concentrations of antioxidant molecules such as glutathione in exposed animals and workers (Gurer and Ercal, 2000). Figure 2 shows a schematic for the processes involved from lead exposure leading to endothelial dysfunction. Lead and other metals including mercury and cadmium have high affinities for sulfhydryl groups (SH). Lead has been shown to inhibit activities of numerous enzymes which contain functional SH groups (Gurer and Ercal, 2000). 


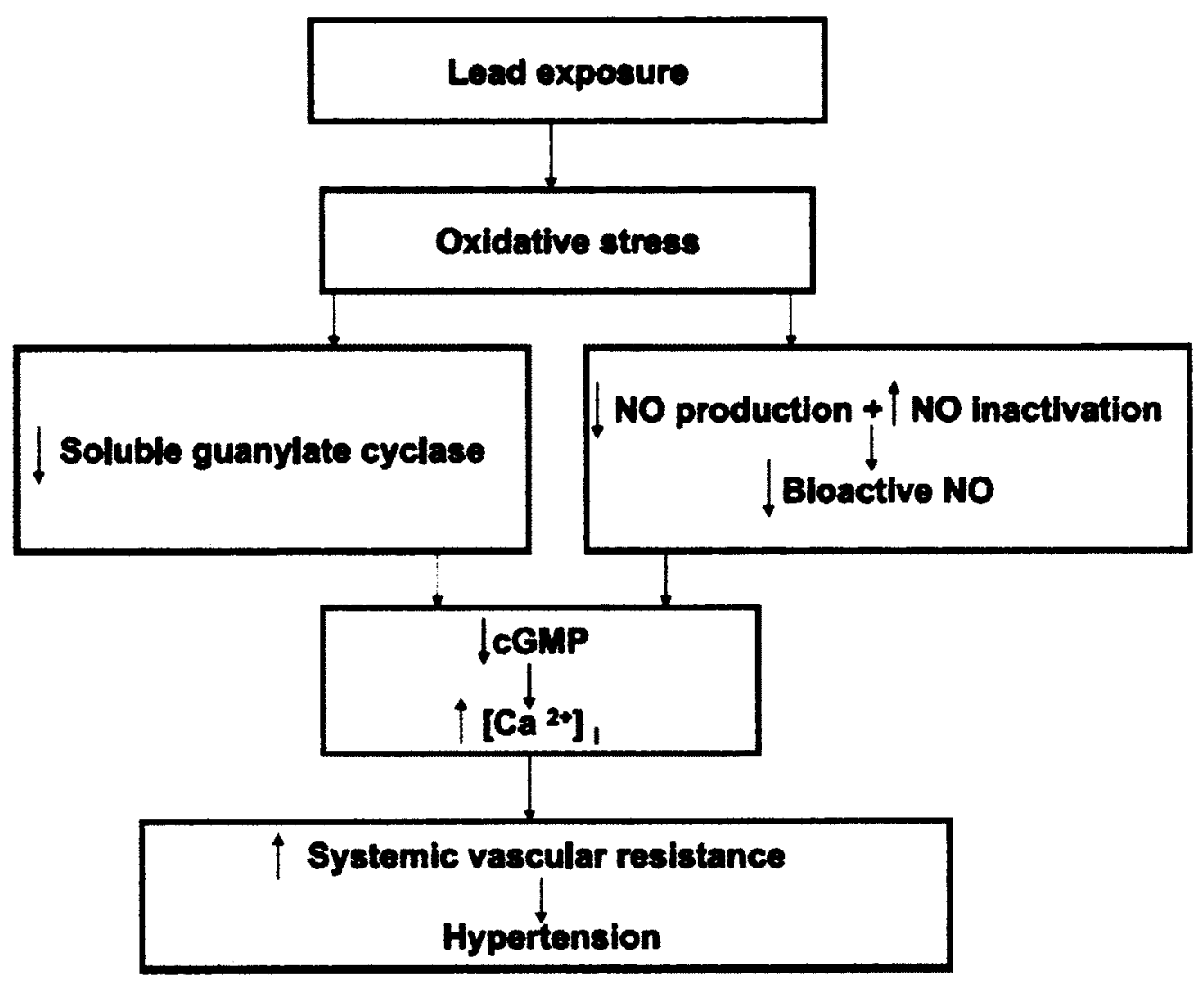

Figure 2: Lead exposure and promotion of oxidative stress. The process causes a reduction in available nitric oxide (NO), down regulation of soluble guanylate cyclase, which in turn lowers cGMP. This interaction causes intracellular calcium levels to increase, causing an increase in systemic vascular response, which will eventually cause hypertension, atherosclerosis and thrombosis. $\mathrm{NO}=$ nitric oxide, $\mathrm{cGMP}=$ cyclic guanidine mono phosphate. (Vaziri 2008 


\subsubsection{Cadmium (Cd)}

Cadmium is naturally found in the earth's crust as a mineral in combinations with other elements such as chlorine, sulfur or oxygen. $\mathrm{Cd}$ is an element and therefore cannot be degraded and its environmental concentration steadily increases.

Sources: The increased release of $\mathrm{Cd}$ into the environment is largely a result of human anthropogenic activities. The major source of $\mathrm{Cd}$ in soil is the result of the use of phosphate based fertilizers meant for agricultural purposes. Tobacco contains significant amounts of $\mathrm{Cd}$ and smoking is one of the primary sources of exposure to $\mathrm{Cd}$ in the general population (It accumulates within the food chain; spanning plants as well as animals. The carcinogenicity and toxicity of $\mathrm{Cd}$ at high doses has been recognized for a long time.. Recent epidemiological evidence suggests that long term exposure at low doses is significantly toxic and affects more people than previously thought (Moulis and Thevenod, 2010; Cuypers et al., 2010; Prozialeck et al., 2006). Cd is classified as a class1 human carcinogen by the International Agency for Research on Cancer (IARC).

Distribution, absorbance and persistence: Target organs of $\mathrm{Cd}$ include the lungs, liver, kidney, testes, bone, placenta and pancreas. In the cardiovascular system, Cd has been linked to numerous cardiovascular pathologies such as atherosclerosis, hemorrhagic injury, hypertension as well as cardiac myopathy. It is suggested that the vascular endothelium is also an important target for Cd toxicity (Prozialeck et al., 2006). If we consider the effects of $\mathrm{Cd}$ on vascular endothelium, it should be taken into account what the route of exposure was. For instance, humans are primarily exposed via airborne $\mathrm{Cd}$ in the form of cigarette smoke or occupational exposure or by the ingestion of contaminated 
water and food. This results in a chronic, yet low level, of exposure. However, the biological half life of $\mathrm{Cd}$ in humans is from 7 to 26 years in the kidney and from 3 to 4 months in blood. Cd bioaccumulates in specific organs such as the liver, kidney and heart where they may be bound to a metallothionein (Nordberg 2009).

Metabolism: It was reported that all $\mathrm{Cd}$ which reaches the systemic circulation was bound to proteins as well as other materials in blood; eventually, all Cd exposed to endothelial cells would be complexed with serum components of low affinity such as albumin, cysteine and glutathione (Prozialeck et al., 2006). Exposure to 1 to $5 \mu \mathrm{M} \mathrm{Cd}$ for 24 to 72 hours was lethal to ECs. According to a population-based survey conducted in 2005, exposure of the general population in USA was $0.412 \mu \mathrm{g} / \mathrm{L}$ and $0.403 \mu \mathrm{g} / \mathrm{L}$ for individuals 20 years and older and for all males ( 1 year and older), respectively (Writh and Mijal, 2010). Cd is not able to generate ROS directly; however, Cd-induced oxidative stress was a commonly observed phenomenon in multiple studies (Cuypers et al., 2010). Cd has a high affinity for thiols, which results in glutathione being a primary target. When the binding of this complex causes depletion in free glutathione, the redox balance is disturbed and promotes oxidative conditions within the cell. Cd has also been shown to induce NADPH oxidase (NOX). A study conducted on mice found that NOX4 gene expression was upregulated in kidneys after chronic exposure to low level $\mathrm{Cd}(10 \mathrm{mg} / \mathrm{L}$ for 23 weeks) (Thijssen et al., 2007). Additionally, studies on superoxide dismutase under $\mathrm{Cd}$ exposure has described increases as well as decreases in activity for the enzyme (Cuypers et al., 2010). 


\subsubsection{Methylmercury (MeHg)}

Virtually every person is exposed to $\mathrm{MeHg}$ at some point in their lives. While elemental mercury is toxic to humans, when it is inhaled or ingested, $\mathrm{MeHg}$ is the most toxic form of mercury (Bose-O'Reilly et al., 2010; Mahaffey 2005).

Sources: Mercury release into the atmosphere is through a combination of both natural and anthropogenic processes. Once released into the atmosphere, mercury circulates through the environment in both inorganic and organic (methylmercury) forms. It can re-deposit onto the earth via dry or wet deposition. Once it enters into the aquatic environment, biotransformation can occur. This happens when common bacteria (sulfate reducing), methylate part of the inorganic mercury, converting it into its organic methylmercury via biomethylation. $\mathrm{MeHg}$ can then bioaccumulate and biomagnify in the food chain - with higher levels found in predatory fish or mammals (Bose-O'Reilly et al., 2010; Ceccatelli et al., 2010). $\mathrm{MeHg}$ is a very potent environmental toxicant capable of causing neurological deficits such as ataxia, damage to the visual cortex and granule layers of the cerebellum in both animals and humans. Its effects for both populations have been well documented in numerous studies (Ekino et al., 2007; Yorifuji et al., 2010; McAlpine and Araki, 1958; Bond and Diamond, 2009; Faria et al., 2010; Amonpatumrat et al., 2008).

Distribution, absorption and persistence: Human exposure primarily occurs via ingestion of contaminated fish or marine mammals. Other routes of exposure include occupational exposure i.e. coal mining, smelting and refineries and/or medical uses i.e. mercury containing devices such as thermometers and multidose activated vaccines using 
ethylmercury as a preservative; though recent regulations have almost eliminated the use of mercury in therapeutics. Historically, $\mathrm{MeHg}$ was developed (1914) and widely used as a fungicide (Grandjean et al., 2010).

Because $\mathrm{MeHg}$ is lipophilic in nature, it can easily move throughout the body. Once inside the cell, it binds to sulfhydryl groups of cysteine, glutathione and/or proteins causing their deficiency or functional disruption. It may also bind to selenium leading to its deficiency. The most sensitive site of $\mathrm{MeHg}$ toxicity in humans is the developing brain, where severe neurological deficiencies can be observed in exposed individuals. Wiggers et al. (2008), have identified that low mercury concentrations can cause oxidative stress and endothelial dysfunction, in both conductance and resistance arteries. Numerous studies have revealed that mercury can generate oxygen radicals indirectly, mainly by causing glutathione depletion, results in higher levels of intracellular ROS; this in turn induces lipid, protein and DNA damage (Wiggers et al., 2008).

\section{Effects of MeHg on endothelial function}

The interaction of NO and superoxide form peroxynitrite, which reduces the availability of $\mathrm{NO}$ for smooth muscle relaxation. It was reported that $\mathrm{HgCl}_{2}$ exposure induced a concentration-dependent cytotoxic effect in ECs (in vivo) and caused a reduction in NO synthase bioavailability (Wiggers et al., 2008). The chronic effect of $\mathrm{MeHg}$ on endothelial regulation of vascular responses was unknown (Wiggers et al., 2008). Wiggers et al. (2008) was the first to show that chronic exposure to low dose mercury causes endothelial dysfunction, most likely through an increase in oxidative stress. Another possible mechanism for mercury toxicity in cardiovascular disease could 
be via the mercury-selenium interaction. Selenium $(\mathrm{Se})$ is an essential micronutrient for humans. Selenocysteine is a component of selenoproteins; some of which have very important antioxidant enzymatic functions. Glutathione peroxidase is a selenoprotein which protects against lipid peroxidation. Mercury has a high affinity for Se and could bind to it to form insoluble mercury selenide complexes, thereby causing a compromised antioxidant defense, which will eventually lead to increased oxidative damage to macromolecules such as lipids, proteins, and nucleic acids (Virtanen et al., 2007). It can be postulated that mercury may reduce the bioavailability of Se which would impair glutathione peroxidase activity, thus promoting lipid peroxidation in atherosclerosis (Virtanen et al., 2007). 


\subsection{The Role of Oxidative Stress in Endothelial Dysfunction}

All the major risk factors for heart disease such as diabetes, hyperlipidaemia, hyperglycaemia, oxidized low-density lipoprotein (oxLDL) and inflammation (among others) have the endothelium as a direct target. The increased generation of reactive oxygen species (ROS) is in all the above mentioned conditions (Davidson 2010; Kondo et al., 2009; Perez-Vizcaino et al., 2010). ROS, through their activity as second messengers at low concentrations, can initiate various processes such as the expression of vascular cell adhesion molecule-1 (VCAM-1) or monocyte chemotactic protein-1 (MCP1) which are early events in the development of atherosclerosis (Kondo et al., 2009). ROS can also induce factors such as vascular endothelium growth factor (VEGF) and angiopoietin-1 which are both involved in angiogenesis (Ushio-Fukai and Nakamura, 2008). Owing to the relative importance of ROS in vascular disease, growing interest has been directed to the enzyme sources responsible for generating these free radicals in vascular tissues, some of which are shown in Figure 3 (Harrison et al., 2003). ROS are identified as oxygen containing substances which are reactive with other biomolecules, some more reactive than others. Species of ROS vary and include substances which contain one or more unpaired electrons such as superoxide, hydroxyl, peroxyl and hydroperoxyl radicals. There also exist non-radical species such as hydrogen peroxide and other peroxides (Perez-Vizcaino et al., 2010; Suvorava and Kojda, 2009; UshioFukai and Nakamura, 2008). The production of ROS is not necessarily bad in itself. However, the regulation of the concentrations produced ultimately determines whether the effects are more beneficial or deleterious. ROS are cytotoxic, mutagenic and able to induce cell death and apoptosis at high concentrations. However, at low concentrations, 
they function as signaling molecules (Ushio-Fukai and Nakamura, 2008). Within cellular systems, there exist antioxidant enzymes, as well as other small molecular weight antioxidants, responsible for scavenging superoxides and peroxides. The pathological or negative consequences resulting from possible inhibition or gene deletions of these enzymes may point to the importance of these enzymes in preventing ROS-induced effects in cells. ROS should not be considered as a toxic by-product of cellular metabolism, since they can act as intermediates in various signaling pathways as second messengers. The sources of enzymes responsible for ROS generation are plentiful, the most common ones being: xanthine oxidase, NADPH oxidase (NOX), NADH oxidase, NO synthase, mitochondrial electron transport, cyclooxygenase, lipooxygenase, and glucose oxidase. Antioxidant enzymes are also present in vascular cells and include superoxide dismutase, catalase, glutathione synthesizing enzymes, glutathione reductase, glutathione peroxidase, the glutathione S-transferases, and others. The intracellular levels of ROS are very tightly regulated by the interplay of these enzymes based on various stimuli within the milieu of vascular cells (Harrison et al., 2003; Perez-Vizcaino et al., 2010; Suvorava and Kojda, 2009; Ushio-Fukai and Nakamura, 2008; Durackova, 2010). A large proportion of ROS generated in the vascular cells is produced by NOX. There are seven isoforms of NOX, each one with a different mechanism of activation and distribution (Zhang et al., 2010; Ushio-Fukai and Nakamura, 2008). The NOX enzymes, NOX1, NOX2, NOX4 and NOX 5, as well as the cytosolic regulatory subunits p47 $7^{\text {phox }}$, p $67^{\text {phox }}$ and Rac1, have been shown to be involved in ROS production in endothelial cells (EC). NOX1 is upregulated by shear stress, and mediates ROS-dependent leukocyte adhesion to EC.This adhesion process disrupts the initiation of EC migration and 
proliferation which, in itself, is a critical aspect of the angiogenic process. NOX 1 maybe involved in angiogenesis in ECs (Ushio-Fukai and Nakamura, 2008). NOX 1 and 2 require additional subunits in order to be activated whereas NOX 4 is independent of the requirement for additional cytosolic proteins. The importance of NOX 1 expression for increasing blood pressure and ROS production in VSMCs been shown in rodents, however, the contribution of this particular oxidase in human vascular pathology is uncertain (Schroder, 2010). NOX 2 is immensely important to humans as it is the predominant NOX in endothelial cells. Regulation of NOX 2 activation occurs via $\mathrm{p} 47^{\mathrm{phox}}$ phosphorylation. Once phosphorylated, $\mathrm{p} 47^{\text {phox }}$ may interact with cytoplasmic tail of $\mathrm{p} 22^{\mathrm{phox}}$, which would facilitate the full assembly of the NOX complex. Once NOX2 is activated, superoxide is generated by electron transfer from cytosolic NADPH to oxygen in the extracellular space (Leopold and Loscalzo, 2009). Nitric oxide (NO) is rapidly neutralized by superoxide. Since NO is a vasodilator, it is expected that NOX2 would induce contraction. A correlation between NOX2 expression and hypertension has been observed repeatedly, suggesting that NOX2 may affect blood pressure (Lassegue and Griendling, 2010). A study by Wind et al., in 2010 demonstrated that oxidative stress and endothelial dysfunction induced by NOX1 and NOX2 in the aortas of aged spontaneously hypertensive rats is reversed by inhibition of these enzymes. NOX4 appears to be the most abundant isoform in the EC when compared to other NOX proteins (Wind et al., 2010). It has been located in the endoplasmic reticulum and nucleus of EC and the focal adhesions and stress fibers of VSMC (Lessegue and Griendling, 2010; Montezano et al., 2011). In EC, it is upregulated via physiological shear stress but downregulated via pathological stress. Hydrogen peroxide seems to be the primary product derived from 
NOX4, which may be due to the rapid dismutation of superoxide to hydrogen peroxide. Various molecular mechanisms of NOX4 induction have been proposed which include activator protein-1 (AP1), JAK (Janus Kinase)/STAT (signal transducer and activator of transcription), E2F, pigment epithelium derived factor (PEDF) and protein kinase c alpha (PKC $\alpha$ ) (Montezano et al., 2011). Recently, NOX4 nuclear ROS production has been implicated in oxidative DNA damage. A study by Lener et al. (2009) also suggested that NOX4 activity increases oxidative DNA damage in human umbilical vein endothelial cells (HUVECs) which leads to a loss of replicative potential (Lener et al., 2009). The stimuli, which can activate NOX, especially NOX4, include G-protein coupled receptor agonists (angiotensin II, thrombin, endothelin, serotonin and thromboxane $A_{2}$ ), cytokines (tumor necrosis factor alpha and transforming growth factor beta), and changes in oxygen levels (Perez-Vicaino et al., 2010). NOX5 is a very different protein from the others, owing to its different requirement for activation. NOX5 contains EF hand domains at the $\mathrm{N}$-terminal region and binds to calcium for activation. It does not require the other NOX subunits for its activation. The C-terminal domain possesses sites which are for binding FAD and NADPH. Owing to a polybasic region on the protein, it is localized on the plasma membrane but is also found in the cytoskeletal fraction and endoplasmic reticulum (Lasseuge and Griendling, 2010; Montezano et al., 2011; Guzik et al., 2008). NOX5 is not present in rodents and experimental models have been limited to cultured cells and isolated tissues. The study by Guzic et al. (2008) showed alterations of vascular functions during coronary artery disease. As a vasoactive agonist, calcium concentration in both EC and VSMC normally increases during the development of coronary artery disease. In EC, this promotes NO flease, while in VSMC it triggers the contractile 
apparatus. NOX5 induction could negate NO release due to simultaneous superoxide and hydrogen peroxide production; superoxide binds to NO to produce peroxynitrite - this mechanism is enhanced in an atherosclerotic condition. It was also observed that during early lesions, NOX5 seemed to colocalize within EC; suggesting that the cytokines present during early atherosclerosis could promote NOX5 expression in EC (Guzic et al., 2008).

Mitochondria are also a very well known source of ROS in vascular cells. Modulation of mitochondrial ATP and superoxide production by tissue oxygen concentration is of particular relevance to the cardiovascular system. Mitochondria generate superoxide during oxidative phosphorylation at several sites within the electron transport chain. Roughly 0.2 to $2.0 \%$ of electrons leak to form superoxide as they are transferred from NADH to complexes I-IV for ATP generation. Majority of the superoxide is converted to hydrogen peroxide by manganese superoxide dismutase (MnSOD) located in the mitochondrial matrix (Leopold and Loscalzo, 2009). Recent studies with highly sensitive measurements of mitochondrial respiratory flux, showed that mitochondrial respiration was highly coupled with ATP production in primary bovine aortic EC (Davidson 2010). This lead to the speculation that the reliance of EC towards oxidative phosphorylation might be increased under certain conditions. Leopold and Loscalzo (2009) observed that exposure to prolonged periods of hypoxia modified the respiration/ROS generation through enzyme modification involved in electron donor supply among other processes. This could occur via transcriptional activation. 


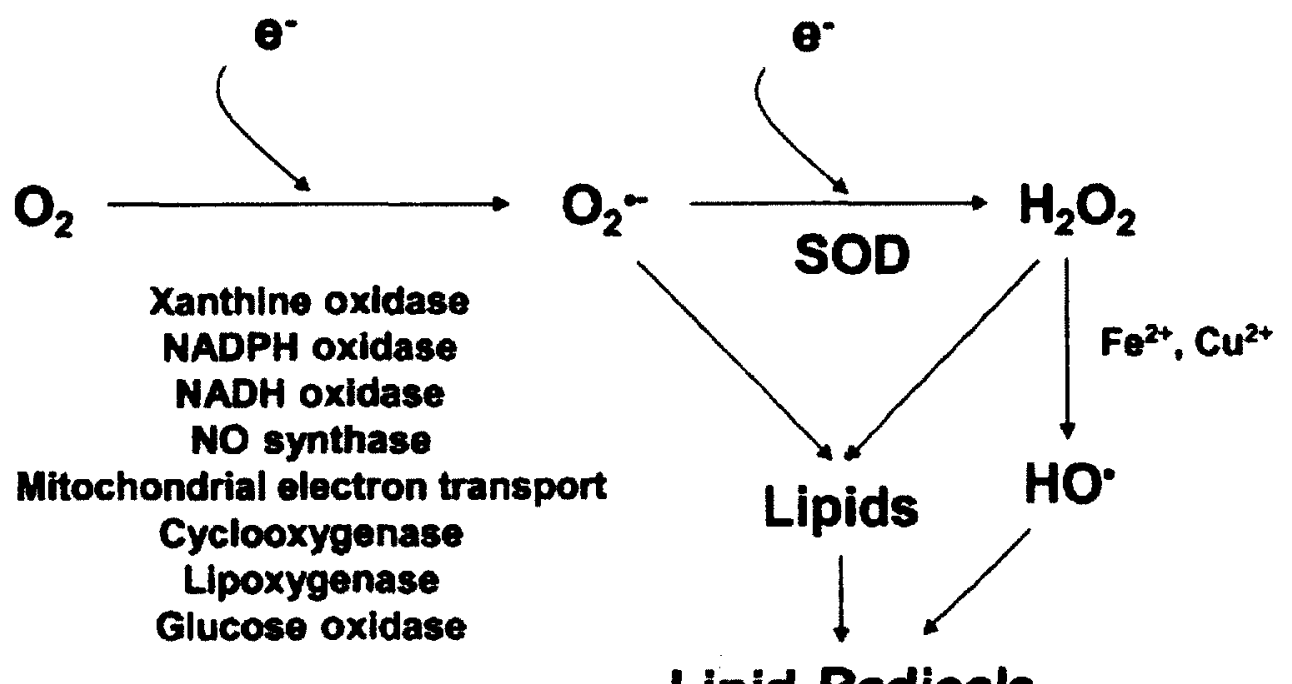

Lipid Radicals

Figure 3: Various reactive oxygen species formation. Reduced oxygen is shown $\left(\mathrm{O}_{2}{ }^{\circ}\right)$ with numerous enzymes which are capable of catalyzing a reduction. SOD can function as a progenitor for numerous other radicals. $\mathrm{SOD}=$ superoxide dismutase; $\mathrm{NADH}=$ reduced nicotinamide adenine dinucleotide; $\mathrm{NADPH}=$ reduced nicotinamide adenine dinucleotide phosphate; $\mathrm{NO}=$ nitric oxide; $\mathrm{e}^{-}=$electron; iron and copper are shown (Harrison et al., 2003). 


\subsection{Nuclear Factor-kB (NF-kB) and Inflammation}

Immunoglobulins can be activated by several stimuli and play a significant role in the production of inflammatory cytokines, such as interleukin- $1 \beta$ and tumor necrosis factor $\alpha$ (Virtanen et al., 2007). NF-kB seems to be particularly important in modulating the expression of immunoregulatory genes with a particular role for regulating cytokines (Sun and Andersson, 2002). This is a pleiotropic transcription factor affecting over 200 known downstream genes in various tissues (Jones et al., 2005). This transcription factor resides in the cytoplasm of the majority of cells as heterodimers or homodimers of a family of related proteins known as the Rel family (Sun and Andersson, 2002; Jones et al., 2005). Within this family, a conserved amino terminal region known as the Rel homology Doman (RHD) exists. RHD is approx. 300 amino acids in length and contains domains and functionality for DNA binding, protein dimerization and the nuclear localization signal (NLS) (Sun and Andersson, 2002; Jones et al., 2005). In mammalian cells, there exist 5 identified NF- $\mathrm{kB}$ encoding genes; RelA or p65, c-rel, RelB, NF- $\mathrm{kB} 1$ (p50/p105) and NF-KB2 (p52/p100). RelA, c-rel and Rel B are transcriptionally active when produced; however, NF- $\mathrm{kB} 1$ and NF- $\mathrm{kB} 2$ have to be processed into smaller active forms. Within the cytoplasm, NF- $\mathrm{KB}$ is inactive and associated with an inhibitory protein termed I-kB. These family members for inhibition regulate DNA binding and subcellular localization of Rel-NF- $\mathrm{KB}$ proteins by covering the NLS. There are numerous genes which could potentially lead to a regulation decision and the outcome varies between cell death/survival or injury/protection within the heart. Table 1 lists numerous genes which are either known to be regulated by, or have DNA binding sites within, their promoter 


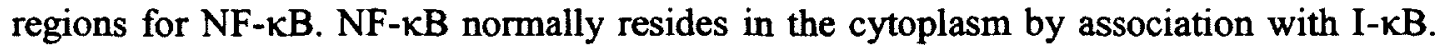
Before transcription of NF-kB dependent genes can be induced, I-KB has to be phosphorylated followed by ubiquitination. It is then degraded via the $26 \mathrm{~S}$ proteasome, allowing the translocation of NF- $\mathrm{kB}$ to the nucleus (Sun and Andersson, 2002; Jones et al., 2005). The involvement of ROS for NF-kB has also been shown in various cell types. It is suggested that ROS potentiate the activity of I-kB phosphorylating kinases. This leads to enhanced degradation of the associated inhibitory protein, I-kB, followed by translocation of NF-kB to the nucleus. A study by Calabro et al. (2011) investigated whether resistin might affect prothrombotic characteristics in HCAEC. Their resultsshowed that (1) resistin induced TF-mRNA transcription and de novo sythesis of functionally active tissue factor (TF) in HCAEC cultures. ROS produced upon the activation of NF-kB pathway was believed to be an effector of this event (Calabro et al., 2011).

Table 1: Various NF-KB-requlated genes*

\begin{tabular}{|l|l|}
\hline GENE TYPE & SPECIFIC GENES \\
\hline Cell death & FasL, FAS[CD95], Bax, Bad, p53, caspase 8, caspase 11 \\
\hline $\begin{array}{l}\text { Genes activated upon injury } \\
\text { or inflammation }\end{array}$ & PAI-1, PPAR $\gamma$ \\
\hline Pro-survival & BclXL, Bc12, IAP1/2, XIAP, A20, IEX-1 \\
\hline $\begin{array}{l}\text { NOS and prostaglandin } \\
\text { biosynthesis }\end{array}$ & iNOS, nNOS, eNOS, Cox1, Cox2 \\
\hline Cytokine-related genes & $\begin{array}{l}\text { TNF- } \alpha, \text { IL-1 } \beta, \text { IL-6, IL-10, IFN- } \gamma, \text { CT-1, LIF, TNFR1 } \\
\text { [p80], TNFR2 [p75], TRAF1, TRAF2, TRAF6 }\end{array}$ \\
\hline NF-kB related genes & p65, p50, Ik $\beta \alpha$, Ik $\beta \beta$, Ik $\beta \varepsilon$, \\
\hline Stress response genes & angiotensin II, cytochrome p450, MAP4K1, MnSOD \\
\hline Cell adhesion genes & fibronectin, ICAM- 1, VCAM-1, P-selectin, E-selectin \\
\hline
\end{tabular}

*(Jones et al., 2005) 


\subsection{Keap1-Nrf2 Cellular Defense Pathway}

The antioxidant response pathway is a multifaceted, highly regulated cell defense system which mammalian cells have evolved in order to maintain a favorable balance between detoxification and bioactivation; enabling cells to protect against harmful effects of exogenous/endogenous reactive species by the transcriptional upregulation of numerous detoxification and antioxidant enzymes (Primiano et al., 1997). The regulatory components of the pathway are comprised of (1) antioxidant response elements (ARE), a DNA motif located within promoter regions of various stress response genes, (2) nuclear factor erythroid 2-related factor (Nrf2), a transcription factor which binds ARE and (3) Kelch-like ECH associated protein 1 (Keap-1), a cytosolic inhibitor of Nrf2.

$N r f 2$ and $A R E$ : Early reporter transgene and electrophoretic mobility shift assay experiments showed that $\mathrm{Nr} 2$ bound ARE and upregulated the expression of target genes (Copple et al., 2010). Nrf2 only binds to ARE with high affinity as a heterodimer with bZip domain-containing Maf proteins. Maf proteins, however, lack transactivation domains. The transactivational ability of $\mathrm{Nrf} 2$ is heavily counted on the formation of the Nrf2-Maf heterodimer to promote transcription of its downstream genes. Activation of Nrf2 promotes cell survival via detoxification and/or elimination of chemical/oxidative stressors. Keap 1: In the absence of cellular stress, Nrf2 is lodged in the cytosol by an inhibitory partner Keap1 resides in the cytosol of mammalian cells and antagonizes Nrf2 activity when there is no stress by binding to $\mathrm{Nrf} 2$ and preventing its association with the

small Mafs. Furthermore, overexpression of Keap1 reduces Nrf2-mediated transactivation of ARE regulated genes. When chemical and oxidative stress is present, 
Nrf2 dissociates from Keapl and translocates to the nucleus, allowing for the transactivation of ARE target genes. Nrfl does not appear to be regulated by Keapl. It is postulated that the activities of $\mathrm{Nrfl}$ and $\mathrm{Nrf} 2$ are distinctly regulated. Nrfl is larger than Nrf2 (741 to 597 AA in mouse), however, the transcriptionally active form of Nrf1 has a slightly lower molecular weight than the inactive form (Copple et al., 2010; Mercado et al., 2011).

\subsection{Endothelial Nitric Oxide Synthase (eNOS) and Nitric Oxide (NO)}

NO is an endogenous vasodilator, platelet inhibitor, antioxidant, and regulator of the vascular endothelium through its ongoing anti-coagulant and anti-thrombogenic properties. It is involved in the maintenance of vasodilation and blood pressure reduction. An increase in superoxide production would result in the loss of NO since these two molecules react to form peroxynitrate, leading tovasoconstriction and increase in peripheral vascular resistance(Harrison et al., 2003; Jones 2008). NO is synthesized by a family of enzymes termed NO synthases. In mammals, there exist 3 isoforms of NOS: inducible (iNOS), endothelial (eNOS) and neuronal (nNOS). Each of these isoforms share between 50 to $60 \%$ homology at amino acid level. Additionally, they all have an Nterminal oxygenase domain with heme, L-arginine, tetrahydrobiopterin $\left(\mathrm{BH}_{4}\right)$ binding domains with a central calmodulin $(\mathrm{CaM})$ binding region. The $\mathrm{C}$-terminal reductase domain with NADPH, FAD and FMN binding sites (Figure 4) (Rafikov et al., 2011; Ducsay and Myers, 2011). eNOS is an approximately $140 \mathrm{kDa}$ homodimeric complex which catalyzes the formation of NO from the oxidation of L-arginine to L-citrulline by utilizing the cofactors NADPH and tetrahydrobiopterin $\left(\mathrm{BH}_{4}\right)($ Leopold and Loscalzo, 
2009) as shown in Figure 5. eNOS undergoes a very complex pattern of intracellular regulation, which includes post translational modifications to the proteins via acylations, calmodulin binding, phosphorylation and S-nitrosylation. This is in addition to eNOS having numerous partners such as caveolin, endoglin, G-protein coupled receptors, Hsp90, P13K, Akt proteins and etc (Jones 2008; Michel and Vanhoutte, 2010; Dudzinski and Michel, 2009).

Post translational modification of eNOS is an essential method of regulating its activity. For example, eNOS has a myristoyl group which is covalently attached at the glycine residue on the second amino acid from the N-terminus. eNOS is localized to cellular membranes when the co-translational addition of this myristoyl group occurs. This action serves 2 basic functions: 1) it localizes eNOS to the cellular membrane and 2) ensures eNOS remains in close proximity with other factors involved in regulating its function (Rafikov et al., 2011). Similarly, palmitoylation is believed to also be involved in stabilizing eNOS to the membrane. However, it is still a debatable topic with no clear answer (Rafikov et al., 2011). The three principle mechanisms involved in controlling eNOS activity are phosphorylation, auto-regulatory properties of eNOS itself and $\mathrm{Ca}^{2+} /$ calmodulin binding (Bird 2011).

Caveolae are considered to be crucial sites involved in the origination and integration of many transduction pathways. Previous studies had discovered that eNOS is located within the caveolae (within the plasma membrane) where it remains inactive due to eNOS interaction with caveolin-1, preventing CaM binding when calcium levels are low (inhibitory effect) (Rafikov et al., 2011). Interestingly, recent data by Tian et al. (2010) showed that under conditions of oxidative stress, eNOS trafficking towards 
plasma membrane is positively regulated. In contrast, its negative regulation by caveolin1 leads to changes in caveolin-1 expression, altering eNOS regulation and subsequently NO production (Tian et al., 2010).

Phosphorylation regulates eNOS at multiple binding sites on residues of tyrosine (Y), serine (S) and threonine (T). Intracellular calcium levels heavily regulate eNOS activity (Rafikov et al., 2011). However, fluid shear stress (FSS) activates eNOS in a different manner. The primary response of eNOS to FSS is calcium dependent, but the long term activation is reduced by tyrosine kinase inhibitors. Recent data has indicated that $\mathrm{Y}$ residue phosphorylation ( $\mathrm{Y} 81$ and $\mathrm{Y} 657$ ) regulate the ability of eNOS to produce NO (Rafikov et al., 2011). Serine and threonine phosphorylation has been studied more in depth. When EC are exposed to FSS, phosphorylation mediated by AKT1 and other kinases occurs on S1177. As intracellular calcium levels increase, CaM is activated, which in turn activates CaM kinase II, causing phosphorylation of S1177. It is very likely that $\mathrm{S} 1177$ phosphorylation renders eNOS more responsive to much lower calcium levels (Rafikov et al., 2011). Prior to recent understanding, phosphorylation of S1177 was considered purely as activating while Thr495 as inhibitory. The most recent understanding suggests that although phosphorylation sites are associated with activation, it alone, is insufficient for complete eNOS activation. The key improvement in understanding eNOS is that in addition to serine/threonine phosphorylation, an elevation in calcium levels above basal $40-60 \mathrm{nM}$ is required for proper activation. Recent studies show that combined phoshphorylations of S1777 and T615 are most effective at sensitizing eNOS to activation by increased intracellular calcium levels with $100 \mathrm{nM}$ being sufficient to induce $50 \%$ eNOS activation, and $300 \mathrm{nM}$ being sufficient for full 
activation (Bird 2011). Interestingly, intact cells do not rely on the initial agonist induced spike in intracellular calcium but more the secondary sustained increase of intracellular calcium that determines output of NO (Bird 2011). More interestingly, recent evidence showed that treatment with (-)-epicatechin (EPI) (most abundant flavanol in cacao) was able to induce NO production in calcium-free HCAEC via eNOS phosphorylatoin at S615, S633 and S1177 (Ramirez-Sanchez et al., 2012). In addition, under calcium free conditions, EPI was able to stimulate NO synthesis independently of calmodulin binding to eNOS and of its translocation into the cytoplasm (Ramirez-Sanchez et al., 2012). This was not the case when the same cells were treated with bradykinin, a well-known calcium-dependent eNOS activator. This study indicated that, with regards to calcium signaling and eNOS activation, it has also been shown in a recent study that adaptive signaling occurs based on the physiological state of the body. For example, Boeldt et al. (2011) demonstrated that pregnancy-specific reprogramming of NO output was determined by a combination of intracellular calcium, eNOS expression and phosphorylation, which is known as the "pregnancy adaptive response" (Boeldt et al., 2011). These findings may not only provide novel targets for future treatments of pregnancy related-diseases but also find application in treating other forms of hypertension.

Basal and stimulated production of NO by eNOS is required for physiological regulation of endothelial function (Atochin and Huang, 2010). eNOS is not limited to being expressed in endothelial cells. It is also available in cardiac myocytes and blood platelets, serving key roles in cardiovascular physiology (Dudzinski and Michel, 2007). It was demonstrated in earlier bioassays that ECs underwent arterial relaxation by the 
release of a vasoactive substance, initially termed as endothelium-derived relaxing factor (EDRF), now known as nitric oxide. When the ability of ECs to release NO is compromised, the ability to cause endothelium-dependent hyperpolarizations is lost. This appears to be the first step in the road leading towards atherosclerosis and coronary heart disease (Michel and Vanhoutte, 2010; Tousoulis et al., 2006). NO can be released in response to shear stress and pressure, aggregating platelets, thrombin, ADP, bradykinin and histamine (Tousoulis et al., 2006). Previous studies showed that cultured EC released NO when exposed to bradykinin (Tousoulis et al., 2006). NO, synthesized by eNOS, is crucial in regulating blood pressure (Tousoulis et al., 2006). Once it is released by the endothelium, NO can diffuse across the extracellular space into smooth muscle cells where it activates soluble guanylate cyclase, which in turn causes an increase in intracellular concentration of cGMP (Tousoulis et al., 2006). Figure 6 indicates the possible mechanisms for the production of NO regulated in EC while Figure 7 illustrates an anticipated G protein-mediated signaling pathway in normal EC (Tousoulis et al., 2006). NO has been found to be a strong stimulus which induces the expression of extracellular superoxide dismutase. NO donors, introduced to vascular smooth muscles cells leads, to a 3-fold increase in mRNA of extracellular superoxide dismutase within 12 hours. This response relies on guanylate cyclase activation as well as the stimulation of protein kinase G (Harrison et al, 2003). Bioavailability of NO is regulated by numerous factors which may either modulate eNOS activity or alter eNOS protein expression. With these systems of regulation, expression and modulation in place (and the relative susceptibility to large scale effects due to slight changes in functionality), the presence of NO ensures the proper functioning of the endothelium. 


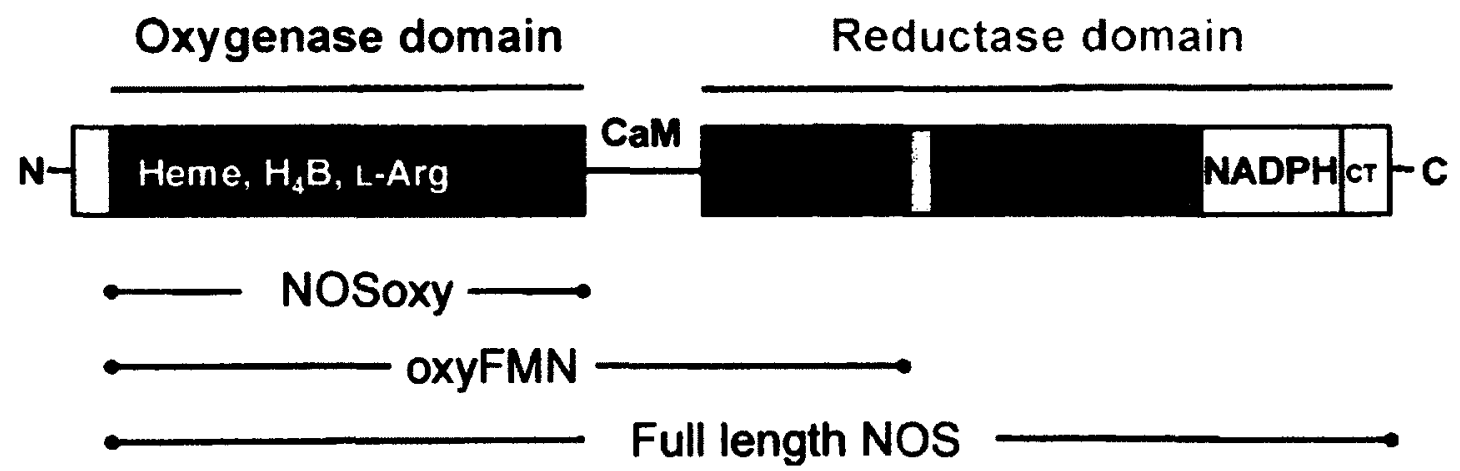

Figure 4: Full length schematic of NOS protein structure showing N-terminal oxygenase and $\mathrm{C}$-terminal reductase domain. The $\mathrm{N}$-terminal oxygenase domain with heme, L-arginine, tetrahydrobiopterin $\left(\mathrm{BH}_{4}\right)$ binding domains with a central calmodulin (CaM) binding region. The C-terminal reductase domain with NADPH, FAD and FMN binding sites are depicted. The NOSoxy and oxyFMN are two typical NOS constructs (artificial). The oxyFMN bi-domain is a designed minimal electron transfer complex which favors FMN and heme domain interactions (Feng 2012). 


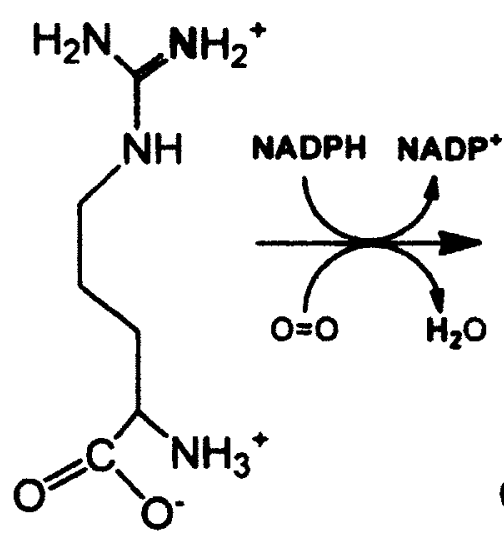

L-Arginine
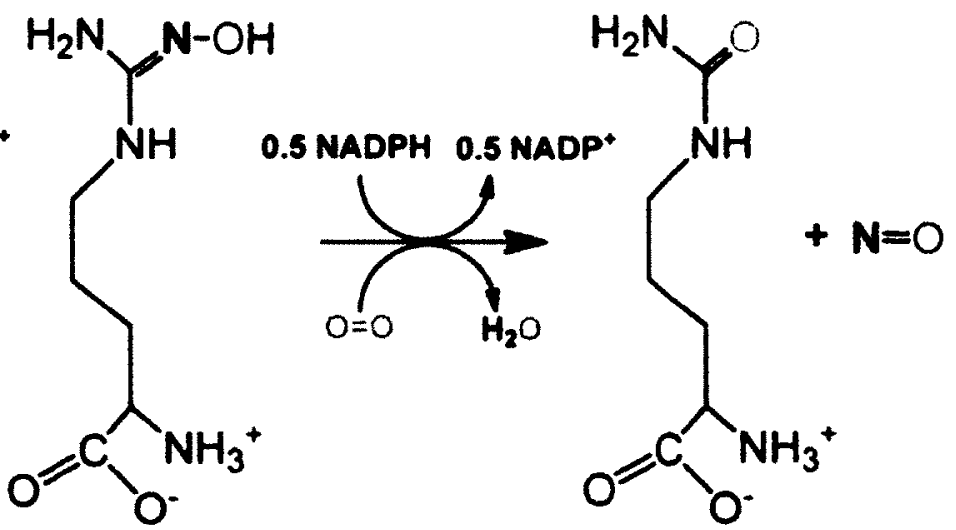

Citrulline

Figure 5: NO production by the NOS enzyme. The NOS catalysis is a two-step process where the substrate, L-arginine, is first converted to N-hydroxy-L-arginine (NOHA), which is then converted on to NO and citrulline. The oxidation mechanism of substrate by NOS heme is an intricate process; the details of the catalytic chemistry mechanism have still yet to be properly understood (Feng 2012). 


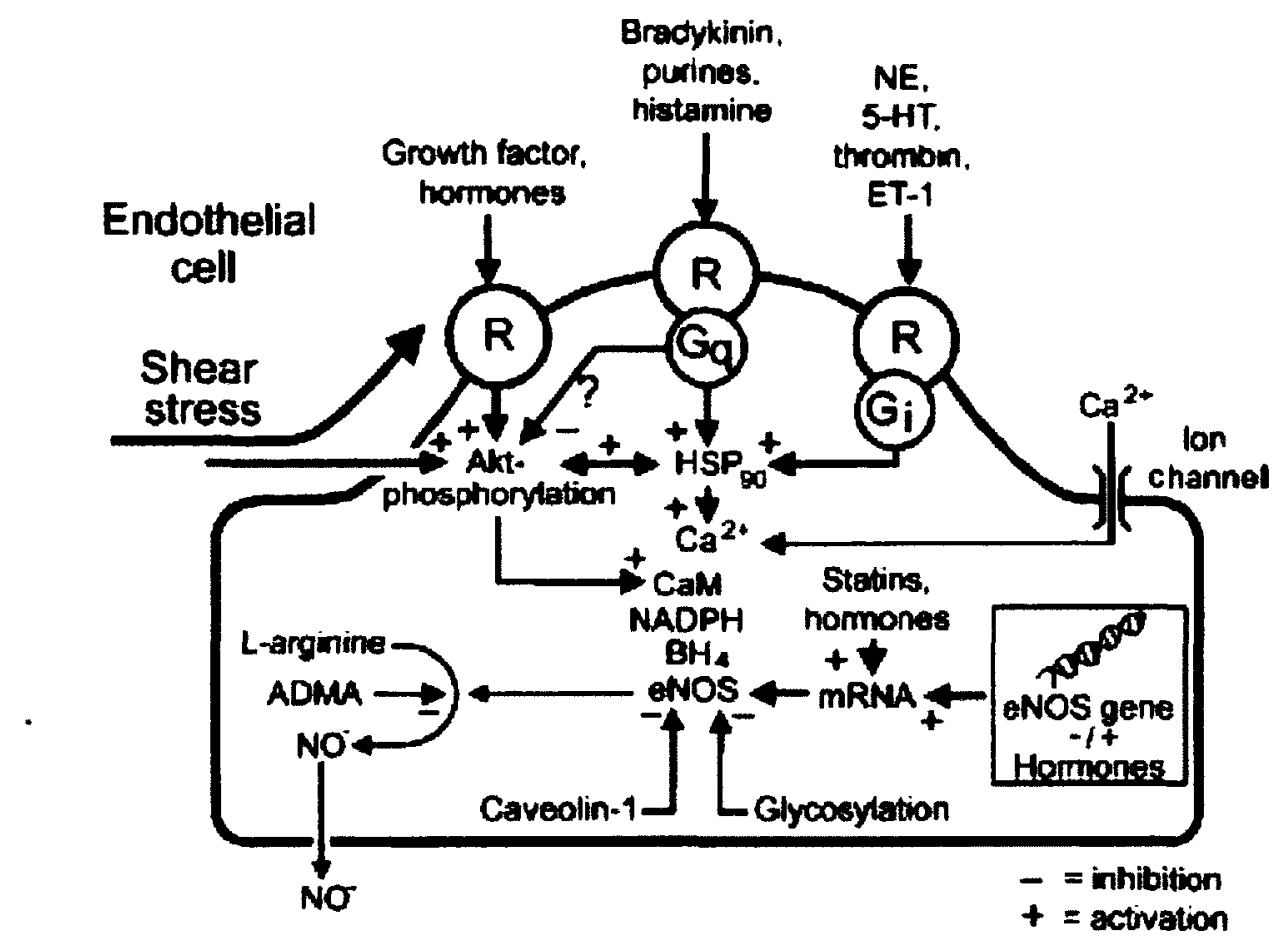

Figure 6: Schematic representation of possible mechanisms by which production of NO is regulated in HCAEC. Transcription of the eNOS enzyme is under genomic regulation via numerous hormones and growth factors. eNOS mRNA is modulated by statins and hormones. $R=$ endothelial surface; $G_{i}=$ pertussis toxin; $G q=$ insensitive to pertussis toxin; "+" = stimulation; "-“ = inhibition; "?" = regulation of pathway is $\begin{array}{llll}\text { currently unknown 2010). } & \text { (Michel and Vanhoutte, }\end{array}$ 


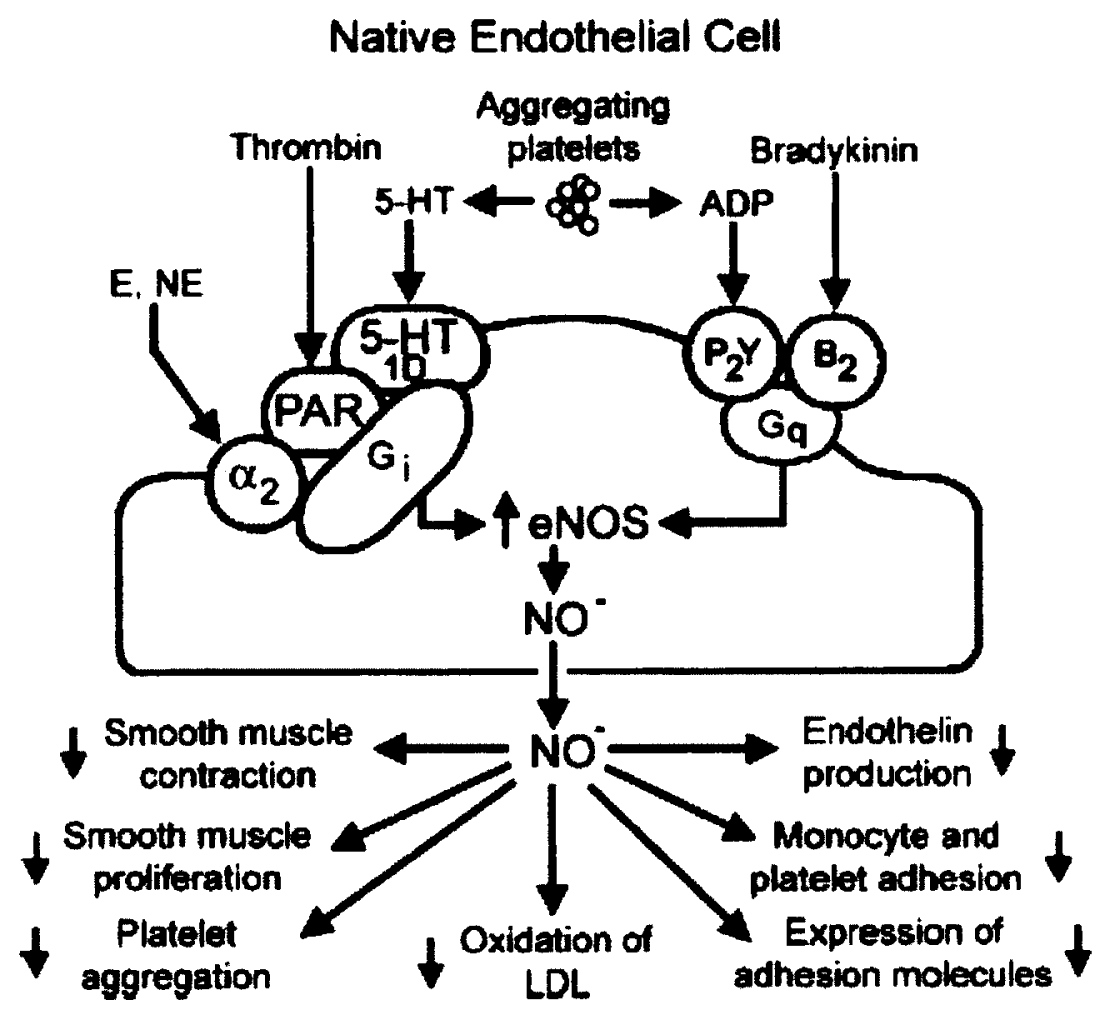

Figure 7: Schematic of a postulated G-protein mediated signal transduction processes found within a normal endothelial cell. The vascular wall confers protective effects by the release of NO upon activation of the cell. 5-HT = serotonin receptor, $\mathrm{B}=$ bradykinin receptor, $\mathrm{P}=$ purinoreceptor, $\mathrm{G}=$ coupling proteins (Michel and Vanhoutte, 2010). 


\subsection{Hypotheses}

A. The exposure of cultured HCAEC in vitro to a mixture of the northern contaminant metals such as lead, cadmium and methylmercury, in combination with lifestyle factors such as alcohol consumption, and changes from a traditional protein-rich to a more Western diet with high levels of dietary fats LDL/VLDL and sugar, will cause adverse changes in biochemical markers such as ET-1, PAI1, IL-6, and eNOS; reflecting endothelial dysfunction.

B. The high use of alcohol will modulate the effects of the metal mixture. The presence or absence of LDL, VLDL and sugar may also alter the effects of the metal mixture on HCAEC in vitro

C. When considering the metals only, individual metals may have differential effects on endothelial functions. As measured in vitro, the metals in the mixture may act additively or antagonistically to influence endothelial functions. 


\section{MATERIALS AND METHODS}

\subsection{Cell Culture}

All cell culture and growth media products were purchased from PromoCell located in Heidelberg, Germany unless otherwise stated. Human coronary artery endothelial cells (HCAEC) (PromoCell, Heidelberg, Germany, catalog no. C-12221) were cultured in Endothelial Cell Basal Medium MV2 (phenol-red-free) supplemented with $0.05 \mathrm{~mL} / \mathrm{mL}$ fetal calf serum, $5 \mathrm{ng} / \mathrm{mL}$ epidermal growth factor, $10 \mathrm{ng} / \mathrm{mL}$ basic fibroblast growth factor, $20 \mathrm{ng} / \mathrm{mL}$ insulin-like growth factor, $0.5 \mathrm{ng} / \mathrm{mL}$ vascular endothelial growth factor $165,1 \mu \mathrm{g} / \mathrm{mL}$ ascorbic acid and $0.2 \mu \mathrm{g} / \mathrm{mL}$ hydrocortisone (PromoCell, Heidelberg, Germany, catalog nos. C-22226 and C-39221, respectively).

Cells were plated in $15 \mathrm{~cm}$ cell culture plates and kept at $37^{\circ} \mathrm{C}$ and $5 \% \mathrm{CO}_{2}$ in a Forma Steri-Cycle $\mathrm{CO}_{2}$ incubator (Thermo Scientific; Marietta, $\mathrm{OH}$ ). Medium was changed every 2 days until cells were considered $70-80 \%$ confluent. Cells were washed with $1 \mathrm{X}$ phosphate buffered saline (PBS) ([-] calcium chloride, [-] magnesium chloride, pH 7.4) (Gibco, Grand Island, NY) followed by trypsinization with $1 \mathrm{~mL}$ of $1 \mathrm{X}$ trypsin (Gibco, Grand Island, NY) for $3 \mathrm{~min}$ at $37^{\circ} \mathrm{C}$. Trypsinization was neutralized using $2 \mathrm{~mL}$ of growth medium and cells were transferred to $15 \mathrm{~mL}$ Becton Dickinson tubes which were centrifuged for $5 \mathrm{~min}$ at $220 \mathrm{~g}$ in an IEC CL31R Multispeed centrifuge (Thermo Electron, France). Supernatants were discarded and cell pellets were resuspended in growth medium. Cell density was determined using a Countess automated cell counter after trypan blue (0.4\%) staining (Invitrogen, Carlsbad, CA). Appropriate dilutions were made to achieve a seeding density of $4 \times 10^{4}$ cells $/ \mathrm{mL}$ before plating. HCAEC cells were only utilized up to a maximum of five passages; after which the cells were discarded. 


\subsection{Preparation of Chemical Dosing Solutions}

Low-density lipoprotein (LDL) and very-low density lipoprotein (VLDL) were purchased from Athens Research and Tech (Athens, GA). The concentrations provided by the supplier were adjusted to obtain $1.5 \mathrm{mg} / \mathrm{mL}$ for $\mathrm{LDL}$ and $1.0 \mathrm{mg} / \mathrm{mL}$ for VLDL. Additionally, lipoprotein buffer $(150 \mathrm{mM} \mathrm{NaCl}, \mathrm{pH} 7.4$ and $0.01 \%$ EDTA; Athens Research and Tech; Athens;GA)

Anhydrous ethyl alcohol (99\%) was purchased from Commercial Alcohols (Brampton, $\mathrm{ON}$ ) and a stock solution of $10 \%$ alcohol was prepared.

Cadmium chloride $\left(\mathrm{CdCl}_{2}\right)$ was purchased from Sigma Aldrich (St. Louis, MO) and a stock solution of $0.0495 \mathrm{mg} / \mathrm{mL}\left(10^{4} \mathrm{X}\right.$ of the working concentration) was prepared in distilled water. Lead chloride $\left(\mathrm{PbCl}_{2}\right)$ was purchased from Sigma Aldrich (St. Louis, $\mathrm{MO})$ and a stock solution of $0.5283 \mathrm{mg} / \mathrm{mL}\left(10^{4} \mathrm{X}\right.$ of the working concentration) was prepared in distilled water.

Methylmercury chloride $\left(\mathrm{CH}_{3} \mathrm{Hg}-\mathrm{Cl}\right.$ or $\left.\mathrm{MeHg}\right)$ was purchased from Sigma Aldrich (St. Louis, MO) and a stock solution of $10 \mathrm{mM}$ was prepared in $5 \mathrm{mM}$ sodium carbonate $\left(\mathrm{Na}_{2} \mathrm{CO}_{3}\right)$.

Glucose was purchased from Sigma Aldrich (St. Louis, MO) and a stock solution of $1 \mathrm{M}$ was prepared in distilled water. 


\subsection{Treatments of HCAEC}

\subsubsection{Cell Preparation}

HCAEC cells were seeded at a density of $4 \times 10^{4}$ cells $/ \mathrm{mL}$ onto $10 \mathrm{~cm}$ cell culture plates $24 \mathrm{hr}$ prior to dosing and incubated at $37^{\circ} \mathrm{C}$ and $5 \% \mathrm{CO}_{2}$ in a Forma SteriCycle $\mathrm{CO}_{2}$ incubator (Thermo Scientific; Marietta, $\mathrm{OH}$ ).

\subsubsection{Experimental Design and Dosing of HCAEC}

Three factors considered in this study were diet, lifestyle and chemical mixture. HCAEC cells were exposed to 12 categories of varying conditions signifying possible combinations of Inuit life situations as reported by Dewailly et al., (2006). A combination of LDL, VLDL and glucose is referred to as LVG and it represents fat as a factor of diet. Alcohol (EtOH) represents the lifestyle factor. The levels of three major heavy metal contaminants detected in Inuit plasma are $\mathrm{Pb}=39,368 \mathrm{ng} / \mathrm{L} ; \mathrm{Cd}=3035 \mathrm{ng} / \mathrm{L}$ and $\mathrm{MeHg}$ $=1,0997 \mathrm{ng} / \mathrm{L}$. The NCM3 refers to a mixture of $\mathrm{Pb}, \mathrm{Cd}$ and methylmercury $(\mathrm{MeHg})$; values in plasma were as $1 \mathrm{X}$ dose. Table 2 describes the various treatment groups and factors.

Table 2: Experimental design of treatment groups and factors

\begin{tabular}{|c|c|c|c|c|c|c|c|c|c|c|}
\hline \multicolumn{2}{|c|}{ Treatment Group } & 1 & 2 & 3 & 7 & 8 & 9 & & & 12 \\
\hline \multirow{3}{*}{$\begin{array}{l}\text { Treatment } \\
\text { factor }\end{array}$} & LVG & - & - & - & + & + & + & + & & + \\
\hline & EtOH & - & - & - & - & - & - & 4 & + & + \\
\hline & NCM3 & VS & $1 \mathrm{X}$ & $100 \mathrm{X}$ & Vs & $1 \mathrm{X}$ & $100 \mathrm{X}$ & $\sqrt{35}$ & 11 & $100 x$ \\
\hline
\end{tabular}


In the case of + LVG; LDL, VLDL and glucose stock solutions were added to obtain $1.5 \mathrm{mg} / \mathrm{mL}, 1.0 \mathrm{mg} / \mathrm{mL}$, and $1.8 \mathrm{mg} / \mathrm{mL}$, concentrations respectively. Both $\mathrm{LDL}$ and VLDL were dissolved in a stabilization buffer containing $150 \mathrm{mM} \mathrm{NaCl}, \mathrm{pH} 7.4$ and $0.01 \%$ EDTA. In the case of - LVG, it is substituted with the same buffer and distilled water. For $+\mathrm{EtOH}$ groups, $10 \% \mathrm{EtOH}$ was added to obtain $0.1 \% \mathrm{EtOH}$ concentration in culture medium, For -EtOH groups, the same amount of distilled and deionized water was added. The vehicle consists of a 1:1 mixture of distilled $\mathrm{H}_{2} \mathrm{O}$ and $\mathrm{Na}_{2} \mathrm{CO}_{3}$. The variable factor is the dosage of the NCM where $1 \mathrm{X}$ is $\mathrm{Pb}=3.9368 \times 10^{4} \mathrm{ng} / \mathrm{L} ; \mathrm{Cd}=3.035$ $\times 10^{3} \mathrm{ng} / \mathrm{L}$ and $\mathrm{MeHg}=1.0997 \times 10^{4} \mathrm{ng} / \mathrm{L}$ : the high dose is $100 \mathrm{X}$ these amounts. The cells were then incubated for $24 \mathrm{~h}$ at $37^{\circ} \mathrm{C}$ and $5 \% \mathrm{CO}_{2}$ in a Forma Steri-Cycle $\mathrm{CO}_{2}$ incubator (Thermo Scientific; Marietta, $\mathrm{OH}$ ).

\subsubsection{Supernatant and HCAEC Lysate Collection}

Following $24 \mathrm{~h}$ exposure, the plates were inspected under a microscope to ensure they were not contaminated; at which point supernatants and cell lysates were collected. Plates were kept on ice and $4.5 \mathrm{~mL}$ of supernatant was collected from each plate. Sample supernatants required for any immediate analysis were used while the rest was frozen at $20^{\circ} \mathrm{C}$ until required. Plates were washed once to remove any dead cells and cell debris with $1 \mathrm{~mL}$ of chilled $1 \mathrm{X}$ PBS ([-] calcium chloride, [-] magnesium chloride, pH 7.4) (Gibco, Grand Island, NY). A $25 \mu \mathrm{L}$ lysis buffer cocktail consisting of 1:98:1: HALT ${ }^{\mathrm{TM}}$ 100X Phosphatase inhibitor; Pierce $®$ RIPA buffer 1 X; HALT ${ }^{\text {TM }} 100$ X Protease inhibitor (all were purchased from Thermo Scientific, Rockford, IL) was added to each plate. Cells were scraped off and collected in $1.5 \mathrm{~mL}$ centrifuge tubes. Volumes of collected lysates were recorded. Lysate samples required for an immediate experiment 
were measured for their protein concentrations while the remaining samples were frozen at $-20^{\circ} \mathrm{C}$ until required.

\subsubsection{Determining Protein Concentration}

In all cases where cell lysates were used for experiments, protein concentration was determined using the Bio-Rad DC Protein Assay Kit (Hercules, CA) using bovine serum albumin as standard according to the manufacturer's protocol (Thermo Scientific, Rockford IL).

\subsection{Individual Metal Dosing and Treatments}

To determine if the individual metal component causes the same effect as the mixture, and if they act synergistically, additively, or antagonistically, HCAEC were treated with $\mathrm{MeHg}, \mathrm{PbCl}_{2}$, or $\mathrm{CdCl}_{2}$ under the same conditions as those used for the NCM3, but only in the absence of LVG and EtOH. Cell lysates and supernatants were collected in the same manner as described before.

\subsection{ELISA}

All assays requiring absorbance, fluorescence or luminescence were measured using a POLARstar OPTIMA spectrophotometer (BMG Labtech, Offenburg, Germany).

\subsubsection{Endothelin-1 (ET-1)}

ET-1 Enzyme Immunometric Assay (EIA) Kit was purchased from ENZO Life Sciences (Plymouth Meeting, PA). The protocol and materials provided by the supplier were used in both cases where samples were either supernatants or cell lysates. Protein concentrations in the cell lysates were measured and used to normalize intracellular ET-1 levels. 
The principle of the assay is that samples and standards are added to a 96-well plate that is precoated with a monoclonal antibody specific for ET-1. After incubation, the plate is washed, leaving only bound ET-1 on the plate. A second anti-ET-1 antibody labelled with horse radish peroxidise (HRT) is added, which binds to ET-1 on the plate. After incubation the plate is washed to remove excess HRT and TMB $(3,3$ ',5,5' tetramethylbenzidine) substrate is added; initiating a color reaction. Stop solution is added resulting in a yellow product, whose absorbance is read at $450 \mathrm{~nm}$.

\subsubsection{Interleukin-6 (IL-6)}

An IL-6 immunoassay kit was purchased from R\&D Systems (Minneapolis, MN). The protocol and materials provided by the supplier were used. The principle of the assay is the same as that described for ET-1. The plate is pre-coated with an IL-6 specific antibody. A polyclonal anti-IL-6 antibody conjugated to HRP is used in the assay.

\subsubsection{Plasminogen Activator Inhibitor-1 (PAI-1)}

A PAI-1 immunoassay kit was purchased from R\&D Systems (Minneapolis, $\mathrm{MN}$ ). The protocol and materials provided by the supplier were used for supernatant samples. The principle of the assay is the same as described for ET-1.

\subsubsection{6-keto Prostaglandin $F_{1 \alpha}$ (6-keto)}

A 6-keto Prostaglandin $F_{1 \alpha}$ kit was purchased from Cayman Chemicals (Ann Arbor, MI). The protocol and materials provided by the supplier were used for supernatant samples. 


\subsubsection{Endothelial Nitric Oxide Synthase (eNOS)}

eNOS has been studied and shown to be a very important regulator for the production of NO and it has been shown to be a very important biochemical marker for endothelial dysfunction (Boeldt et al., 2011; Atochin and Huang, 2010).

An eNOS immunoassay kit was purchased from R\&D Systems (Minneapolis, $\mathrm{MN})$. The protocol and materials provided by the supplier were used in both cases where samples were either supernatants or cell lysates. Protein concentrations of cell lysates were measured and used to normalize eNOS levels.

\subsection{Cell viability assays}

A ToxiLight@ Bioassay kit (Lonza, Rockland, ME) for non-destructive cytoxicity assays was used to determine cell viability in HCAEC exposed to NCM3, $\mathrm{MeHg}, \mathrm{Pb}$ or $\mathrm{Cd}$ for $24 \mathrm{hr}$. The kit is based on the bioluminescent measurement of oxyluciferin generated from reaction of luciferin and ATP, which is produced by adenylate kinase leaked into the medium of cultured cells due to a loss of cell membrane integrity. The 2step reaction is as follows:

$$
\begin{aligned}
& \text { Adenylate kinase } \\
& \mathrm{Mg}^{++} \mathrm{ADP}+\mathrm{ADP} \longrightarrow \mathrm{Mg}^{++} \mathrm{ATP}+\mathrm{AMP}
\end{aligned}
$$

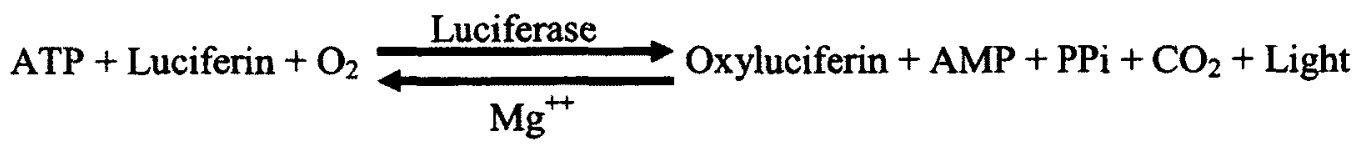




\subsection{Western Blot Analysis}

eNOS protein levels were analyzed in HCAEC lysates exposed to NCM3, MeHg, $\mathrm{Pb}$ and $\mathrm{Cd}$ for $24 \mathrm{hr}$. Protein samples of 27 to $55 \mu \mathrm{g}$ were suspended in Laemmli sample buffer with $\beta$-mercaptoethanol (Sigma, St. Louis, MO). The protein samples were heated at $100^{\circ} \mathrm{C}$ for 10 min and then loaded into a 10 -well precast $4-20 \%$ Precise ${ }^{\mathrm{TM}}$ protein gel (Thermo Scientific, Marietta, OH) in a BupH Tris-HEPES- SDS running buffer (100 mM Tris; $100 \mathrm{mM}$ HEPES; $3 \mathrm{mM}$ SDS; pH $8 \pm 0.5$ Thermo Scientific (Marietta, OH). Protein standards for SDS-PAGE were the Precision Plus Kaleidoscope Standards with a broad molecular weight range of 10 to $250 \mathrm{kDa}$ (Bio-Rad, Hercules, CA). The separation of proteins was performed at $100 \mathrm{~V}$ for 1.5 hours using the X-Cell Sure-Lock Mini-Cell electrophoresis system (Invitrogen, Burlington, ON). Proteins were transferred from gel onto a PVDF transfer membrane in 7 minutes using the iBLOT gel transfer system (Invitrogen, Burlington, ON).

Non specific binding of proteins on PVDF membrane was blocked by incubating membrane with $5 \%$ non-fat powdered skim milk in TBST $(20 \mathrm{mM}$ Tris- $\mathrm{HCl} ; 137 \mathrm{mM}$ $\mathrm{NaCl}$ and $0.1 \%$ Tween-20) for $2 \mathrm{hr}$ at room temperature. Western blot analysis for eNOS protein was performed using purified mouse anti-eNOS antibody (1:1,000 dilution; BD Biosciences, Mississauga, $\mathrm{ON})$ and goat anti-mouse IgG $(\mathrm{H}+\mathrm{L})$ horseradish peroxidise secondary antibody (1:5,000 dilution; Bio-Rad, Hercules, CA). GAPDH was also determined using rabbit anti-GAPDH antibody (1:30,000 dilution; Sigma Aldrich, St. Louis, MO) and goat anti-rabbit IgG $(\mathrm{H}+\mathrm{L})$ horseradish peroxidise secondary antibody (1:5,000 dilution; Bio-Rad, Hercule CA). Membranes were washed with TBST and proteins were detected using Luminol Reagent SuperSignal $\circledast$ West Femto Maximum 
Sensitivity Substrate (Thermo Scientific, Marietta, $\mathrm{OH}$ ) followed by exposure using the Alpha Innotech Fluorchem HD2 Chemidock (Alpha Innotech, San Leandro, CA).

\subsection{Statistical Data Analysis}

Results are expressed as mean \pm S.E.M. of at least three independent experiments unless otherwise stated. Significant differences among treatment factors and groups were identified by running ANOVA and Tukey's test using Sigma Plot (Systat Software Inc, Sigma Plot ver. 12, San Jose, CA). A p value of $<0.05$ was considered statistically significant 


\section{RESULTS}

\subsection{Effects of NCM3 on Markers of Endothelial Function in HCAEC Grown}

Under Varying LVG and EtOH Conditions

\subsubsection{Multitox Data}

Cell viability was measured for HCAEC exposed to various conditions.

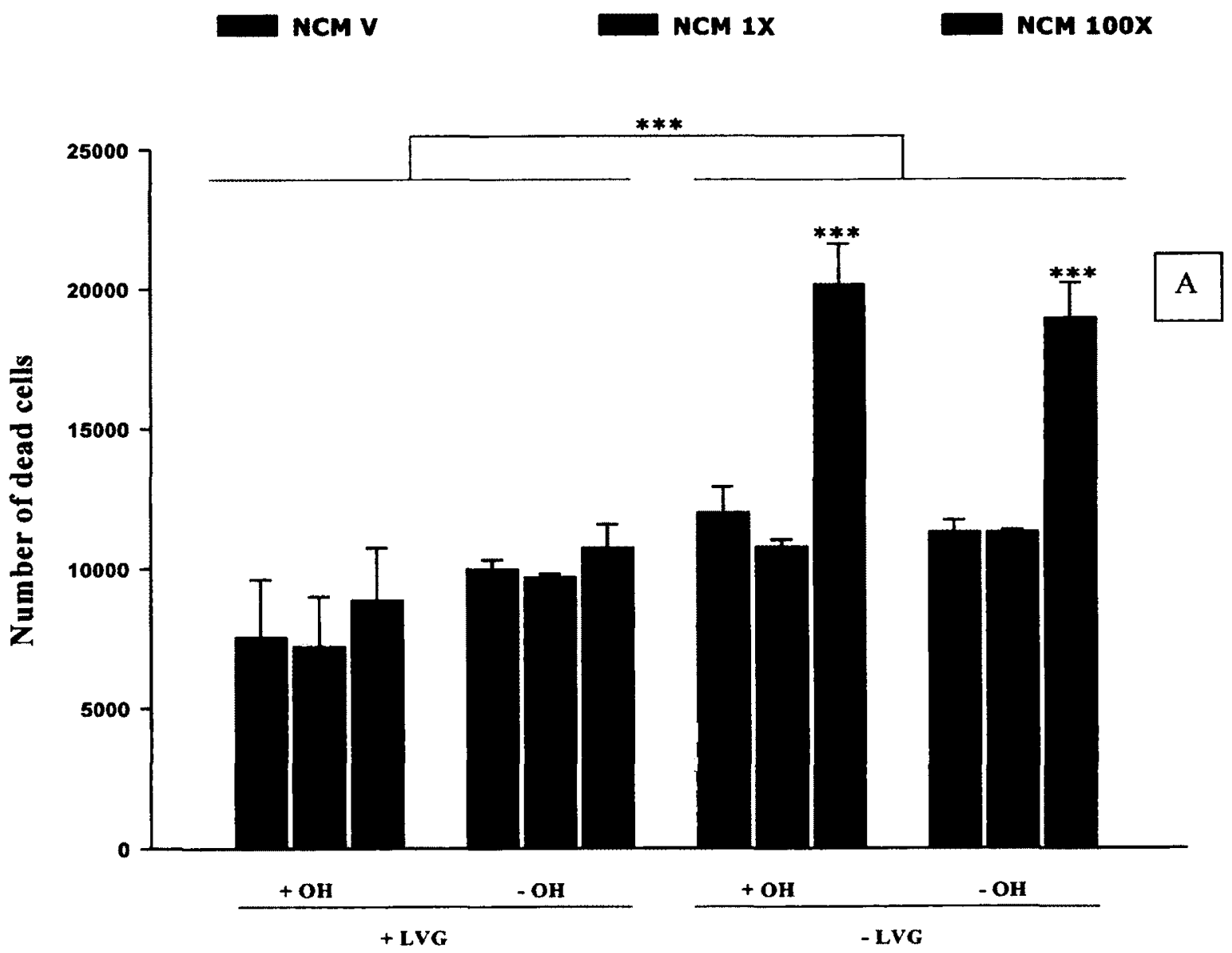




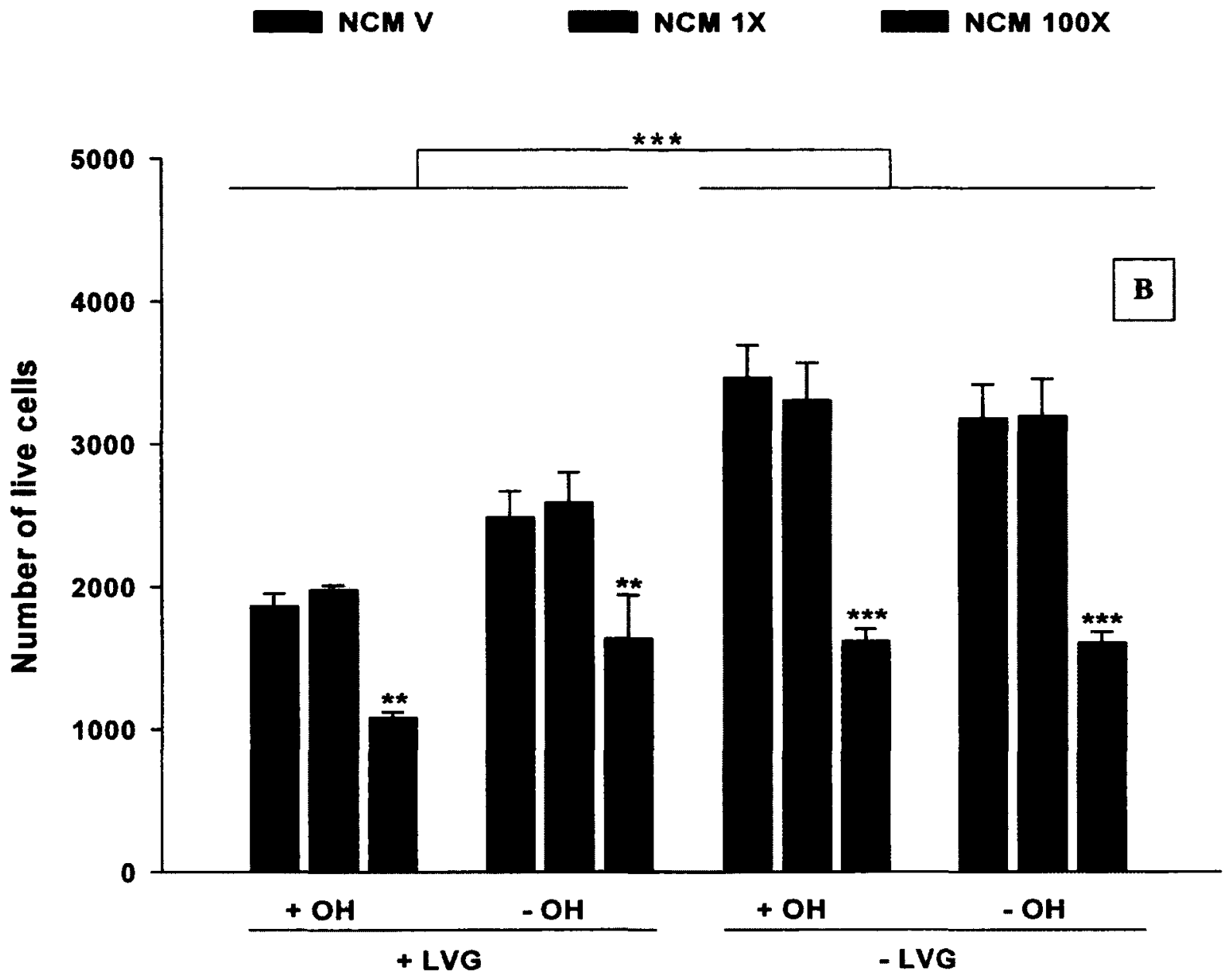

Figure 8: Effects of NCM on cell viability for HCAEC cultured under varying LVG and EtOH conditions for 24 hours. (A) Represents the dead cell assay while (B) represents the live cell assay where $L V G=L D L, V L D L$ and glucose, $O H=E t O H$ and $\mathrm{NCM}=\mathrm{MeHg}, \mathrm{Pb}$ and $\mathrm{Cd}$. Data represent means $\pm \mathrm{SEM}$ from 3 independent experiments. $* * *$ indicates significant differences between the groups of $p<0.001$ and $\begin{array}{llllll}* * & \text { represents } & \mathrm{a} & \text { difference } & \text { of } & \end{array}$ 
Figure 8A shows that when LVG is present, neither the presence/absence of alcohol nor the variations in dose resulted in significant changes to cell death.. The absence of LVG causes a significant increase in cell death. The high dose can be seen to significantly increase cell death independent of the presence or absence of alcohol (Figure 8A). Figure 8B indicates a significant decrease in live cells when LVG is present. In the absence of LVG, a higher number of cells are able to survive in the control and IX dosage groups (independent of either the presence or absence of alcohol) (Figure 8B). However, at the $100 \mathrm{X}$ dose, there is a very significant decrease in viable cells, independent to the factor of alcohol. The live cell assay and dead cell assay both agree and indicate that $100 \mathrm{X}$ dose within the LVG absent conditions very significantly reduce the viability of HCAEC cells. 


\subsubsection{ET-1}

ET-1 a marker primarily involved in vaso-action (constriction) by binding to its receptors. ET-1 was measured in the supernatant of HCAEC treated with or without NCM3 over a $24 \mathrm{hr}$ period. A statistically significant difference $(\mathrm{p}<0.001)$ was found bewteen + LVG and -LVG conditions (Figure 9). The high dose of the NCM3 significantly decreased ET-1 $(\mathrm{p}<0.001)$ when compared to the vehicle. The presence or absence of alcohol had no significant effect on ET-1. It is interesting to note that ET-1 is known to be elevated in instances of arterial and pulmonary hypertensions, atherosclerosis and congestive heart failure.

ET-1 levels in the lysates of HCAEC were significantly lower $(p<0.001)$ in the presence than the absence of LVG (Figure 10). The presence or absence of alcohol had no effect on intracellular ET-1 levels. 


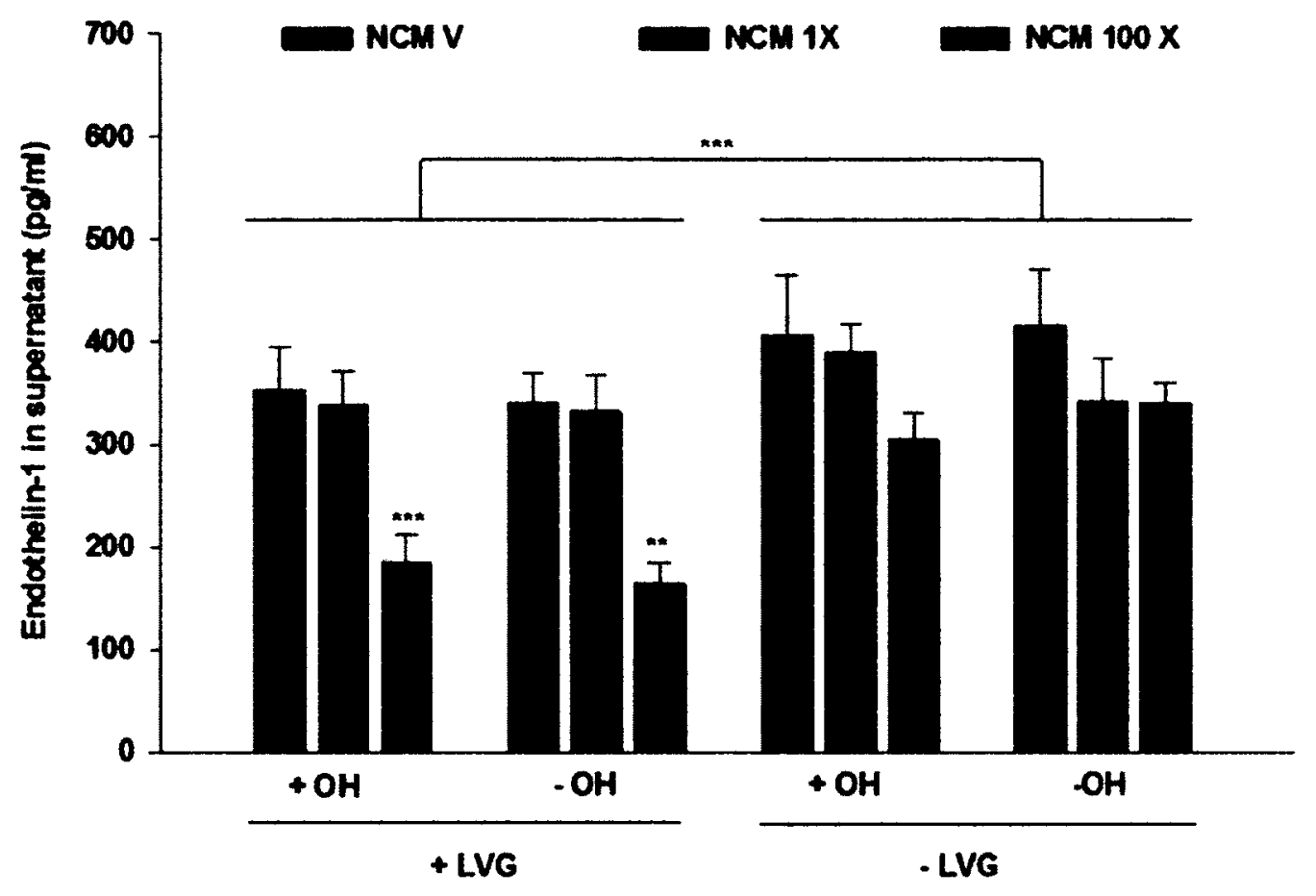

Figure 9: Effects of NCM3 on ET-1 levels in the culture media of HCAEC cultured under varying LVG and EtOH conditions for 24 hours. The figure legends are: LVG $=\mathrm{LDL}, \mathrm{VLDL}$ and glucose, $\mathrm{OH}=\mathrm{EtOH}$ and $\mathrm{NCM}=\mathrm{MeHg}, \mathrm{Pb}$ and $\mathrm{Cd}$ Data represent means \pm SEM from 5 independent experiments.*** indicates significant differences between the groups located under the line at $p<0.001$ and $* *$ indicates a difference of $p$ $<0.05$. 


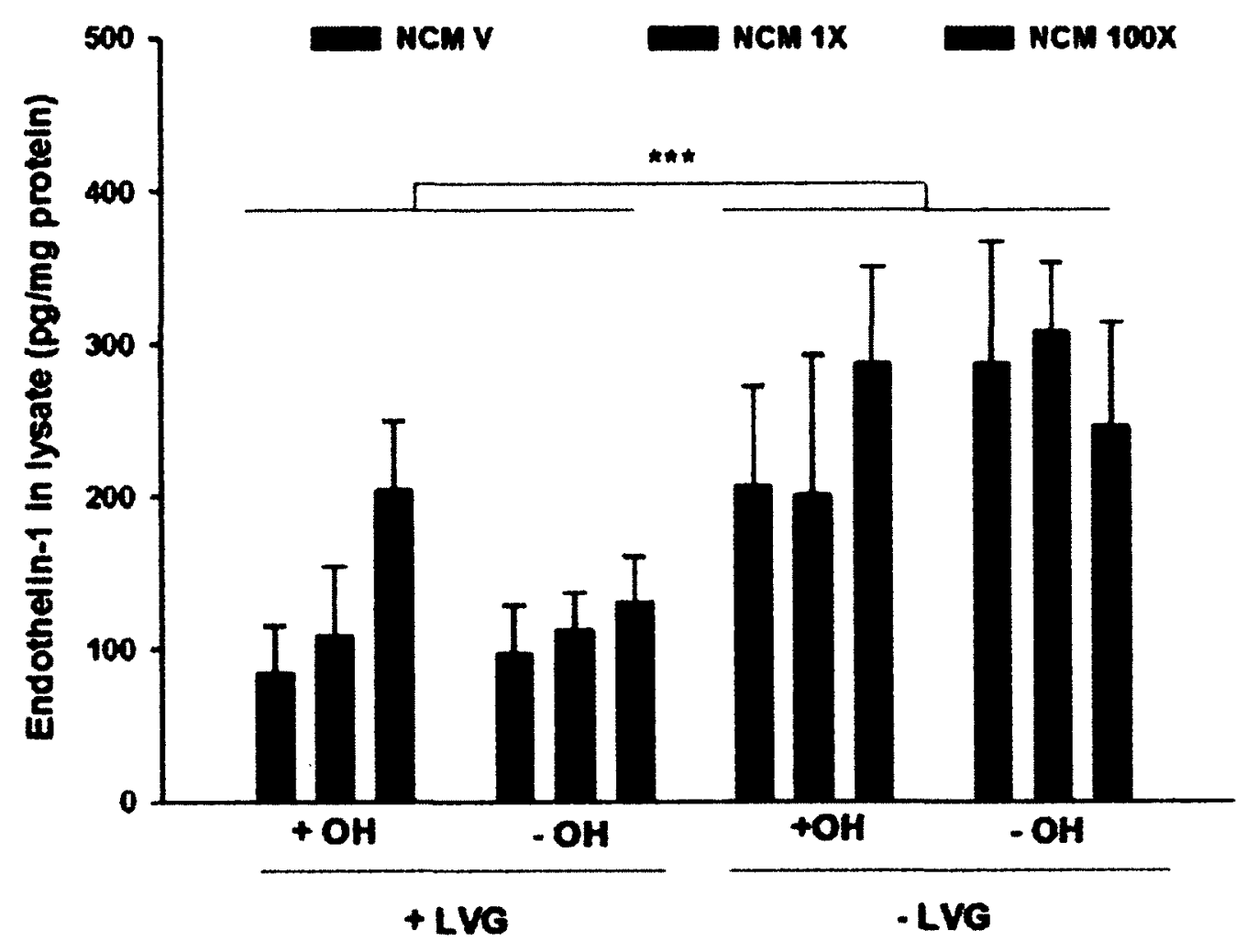

Figure 10: Effects of NCM3 on intracellular ET-1 levels in HCAEC cultured under varying LVG and EtOH conditions for 24 hours. The figure legends are: LVG $=$ LDL, VLDL and glucose, $\mathrm{OH}=\mathrm{EtOH}$ and $\mathrm{NCM}=\mathrm{MeHg}, \mathrm{Pb}$ and $\mathrm{Cd}$ data represent means \pm SEM from 5 independent experiments. 


\subsubsection{IL-6}

The effect of NCM3 on pro inflammatory cytokine, IL-6 was measured in HCAEC supernatants after $24 \mathrm{~h}$ of growth under varying LVG and EtOH conditions (Figure 11). No statistical significance was detected among treatment groups, although a trend of increase in IL- 6 was observed in the high NCM3 dose group as compared to vehicle control group, regardless of LVG and EtOH conditions.

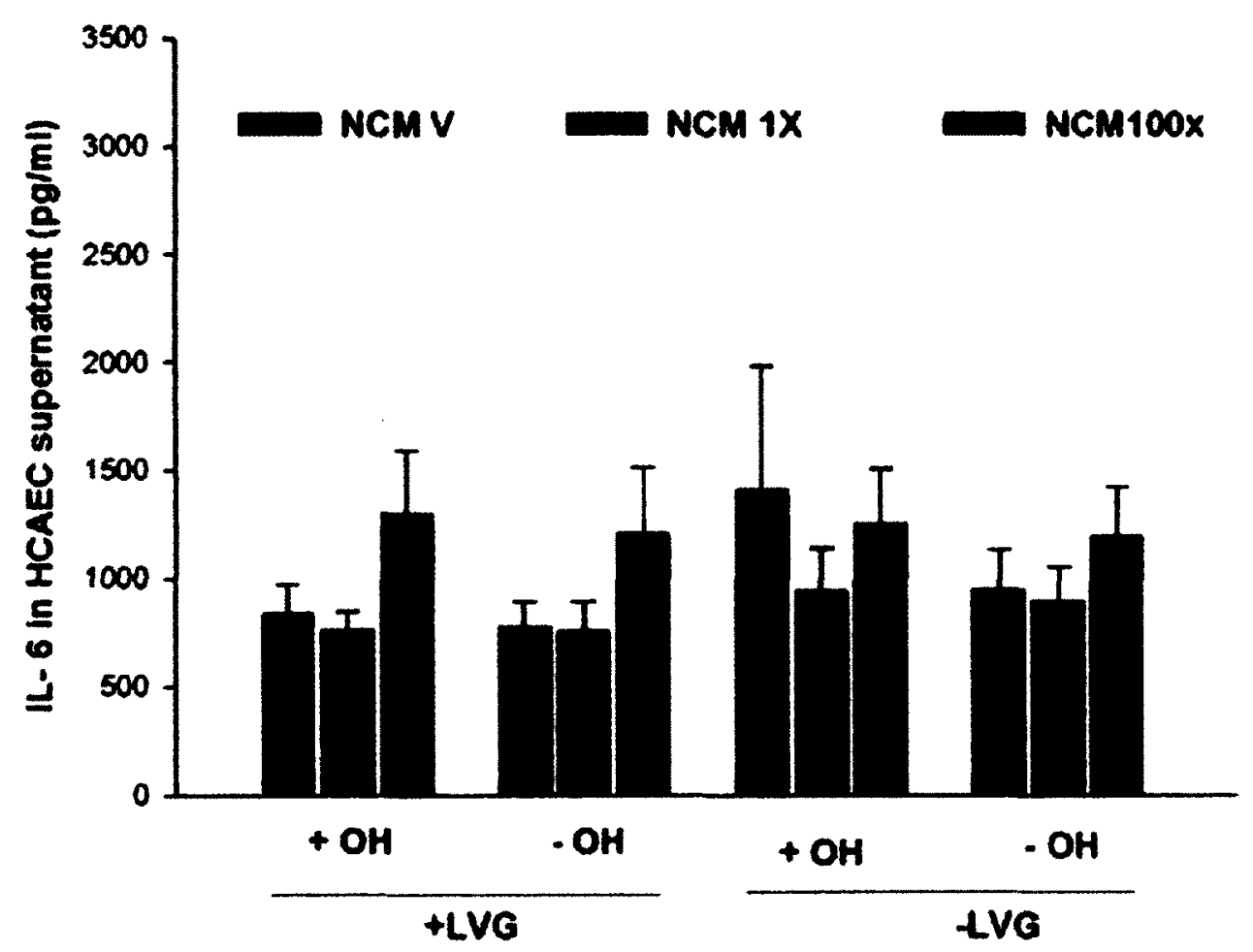

Figure 11: Effects of NCM3 on IL-6 levels in the supernatants of HCAEC cultured under varying LVG and EtOH conditions for 24 hours. The figure legends are: LVG $=\mathrm{LDL}, \mathrm{VLDL}$ and glucose, $\mathrm{OH}=\mathrm{EtOH}$ and $\mathrm{NCM}=\mathrm{MeHg}, \mathrm{Pb}$ and Cd Data represent means \pm SEM from 5 independent experiments. 


\subsubsection{PAI-1}

PAI-1, an inhibitor of fibrinolysis was also measured in the supernatants of HCAEC after $24 \mathrm{~h}$ of exposure to NCM3 in the presence or absence of LVG and EtOH.(Figure 12). In the presence of LVG, NCM3 significantly decreased PAI-1 levels in the supernatants regardless of the EtOH condition. In the presence of LVG, the high dose NCM3 significantly decreased PAI-1 levels in the supernatants of HCAEC as compared to both the control and the low dose groups with or without presence of alcohol. Similar trend was also observed in the absence of LVG,suggesting that that NCM3 is the only mitigating factor for PAI-1. 


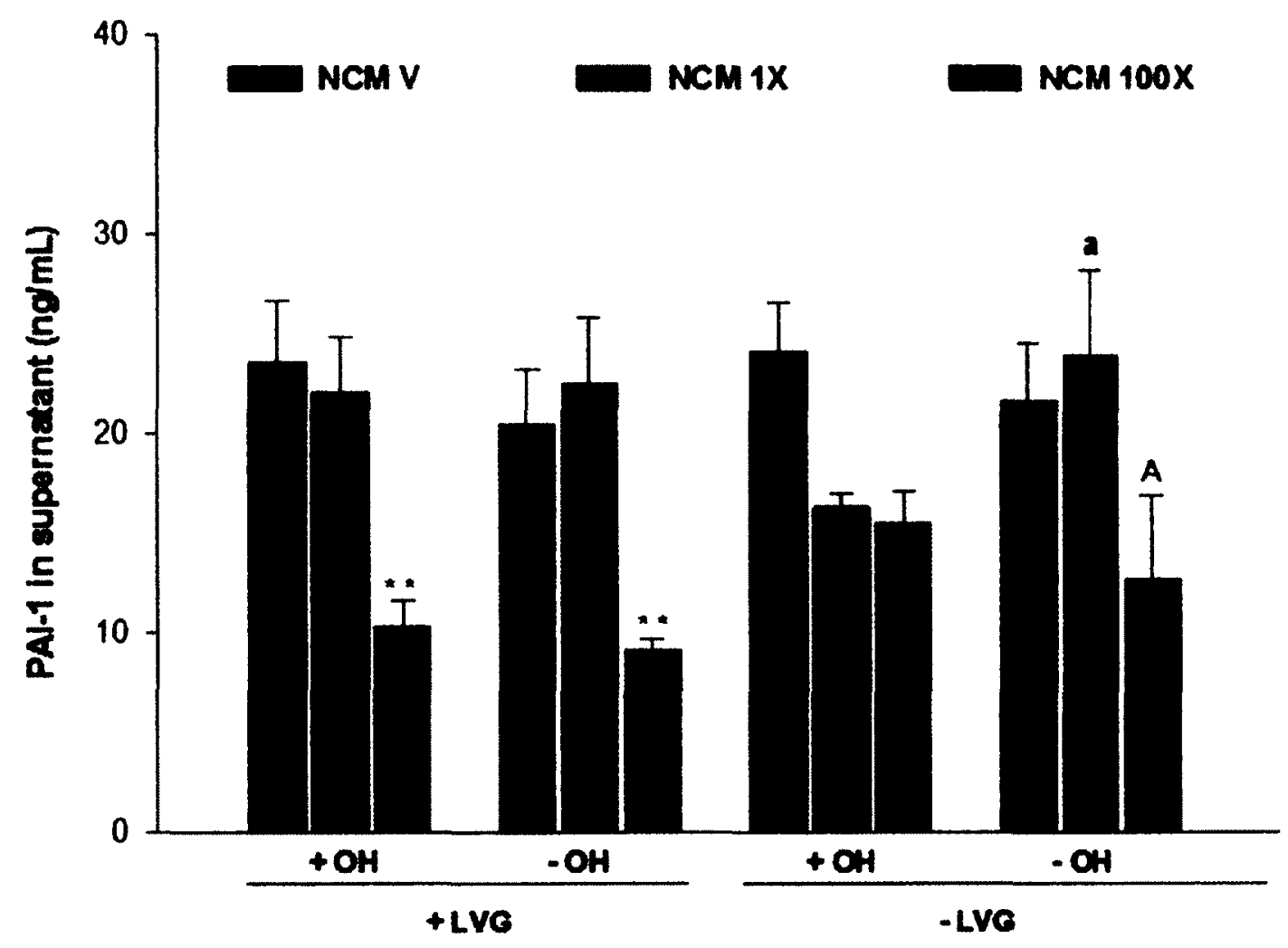

Figure 12: Effects of NCM3 on PAI-1 levels in the supernatants of HCAEC cultured under varying LVG and EtOH conditions for 24 hours. The figure legends are: LVG $=\mathrm{LDL}, \mathrm{VLDL}$ and glucose, $\mathrm{OH}=\mathrm{EtOH}$ and $\mathrm{NCM}=\mathrm{MeHg}, \mathrm{Pb}$ and $\mathrm{Cd}$ Data represent means \pm SEM from 5 independent experiments; $A$ is significantly different from a at $p<0.05$. "**" represents a significant difference of $p<0.05$. 


\subsubsection{6-keto PGF1a}

6-keto $\mathrm{PGF}_{1 \alpha}$ is a non-enzymatically hydrated product of prostacyclin, which is a potent vasodilator and inhibitor of platelet aggregation and is formed primarily by the vascular endothelium. Figure 13 shows the effects of NCM3 on the 6-keto PGF1 levels in the supernatants of HCAEC cultured under varying conditions of LVG and EtOH for 24 h. The levels of 6-keto PGF1 $\alpha$ in the supernatants of HCAEC were significantly lower in the absence than the present of LVG. The presence or absence of alcohol in the samples treated with LVG show no significant differences. Neither NCM3 nor EtOH showed any effects on this parameter in the presence of LVG. In the absence of both LVG and EtOH, NCM3 high dose significantly increased 6-keto PGF1a levels in the supernatants of HCAEC. 


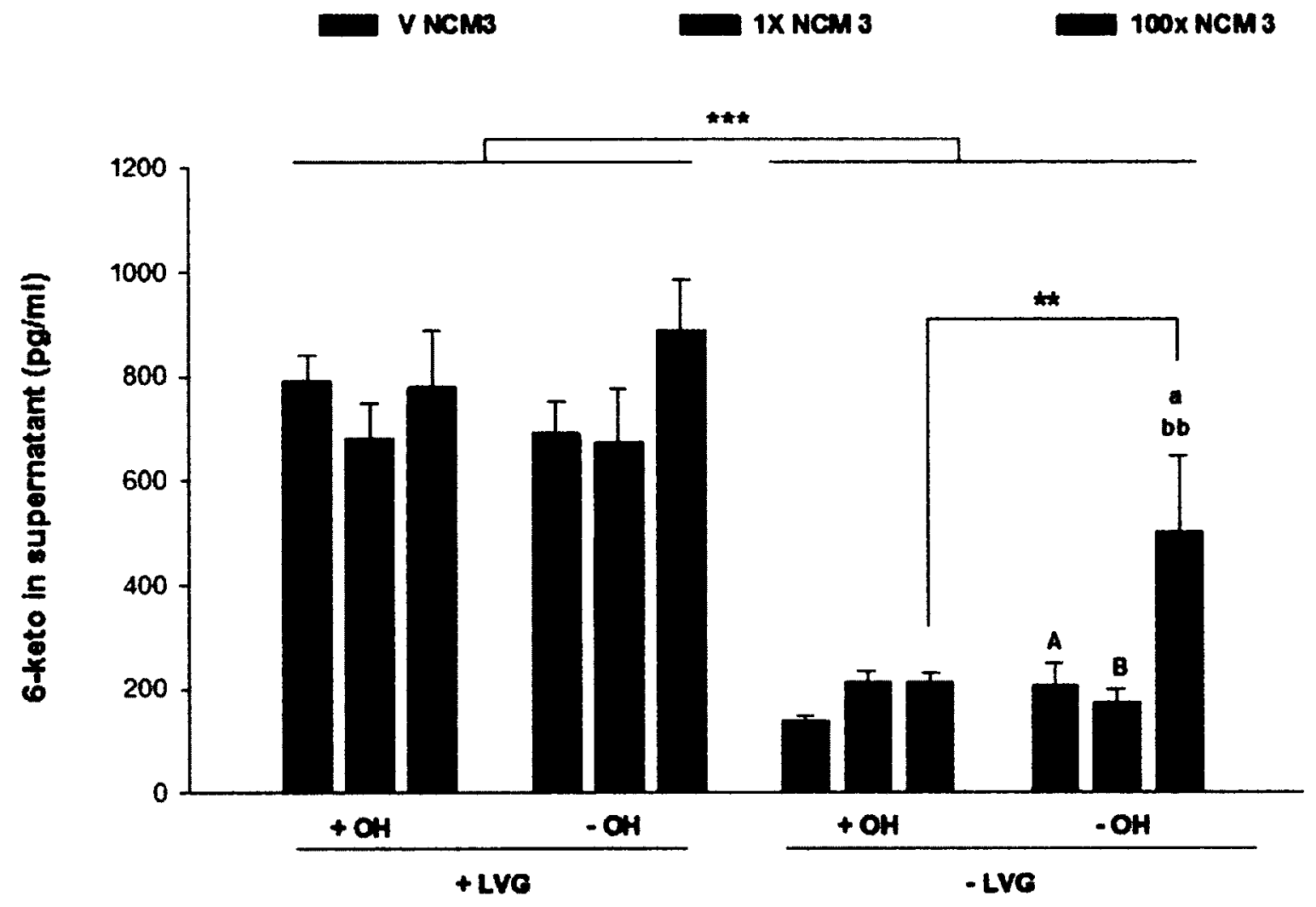

Figure 13: Effects of NCM3 on 6-keto PGF PG $_{1 \alpha}$ levels in the supernatants of HCAEC cultured under varying LVG and EtOH conditions for 24 hrs. The figure legends are: $L V G=L D L, V L D L$ and glucose, $\mathrm{OH}=\mathrm{EtOH}$ and $\mathrm{NCM}=\mathrm{MeHg}, \mathrm{Pb}$ and $\mathrm{Cd}$. Data represent means \pm SEM from 5 independent experiments. “***”and “**” represents significant differences between the two groups of treatments located under the lines at $p<0.001$ and 0.01 , respectively. " $A$ " and " $B$ " are significantly different from " $a$ " and "bb" at $\mathbf{p}<0.05$ and 0.01 , respectively. 


\subsection{6 eNOS}

Vascular endothelial cells express eNOS, an enzyme catalyze NO production. NO is an important vasodilator that regulates blood flow and pressure. Cellular levels of eNOS were significantly higher in the absence than presence of LVG (Figure 14). EtOH had no significant effects on eNOS level. It can be noted that the high NCM3 dose, significantly decreased eNOS under all except $+\mathrm{LVG}+\mathrm{EtOH}$ culture conditions. eNOS levels seem to be affected the most when compared to all the other markers examined. 


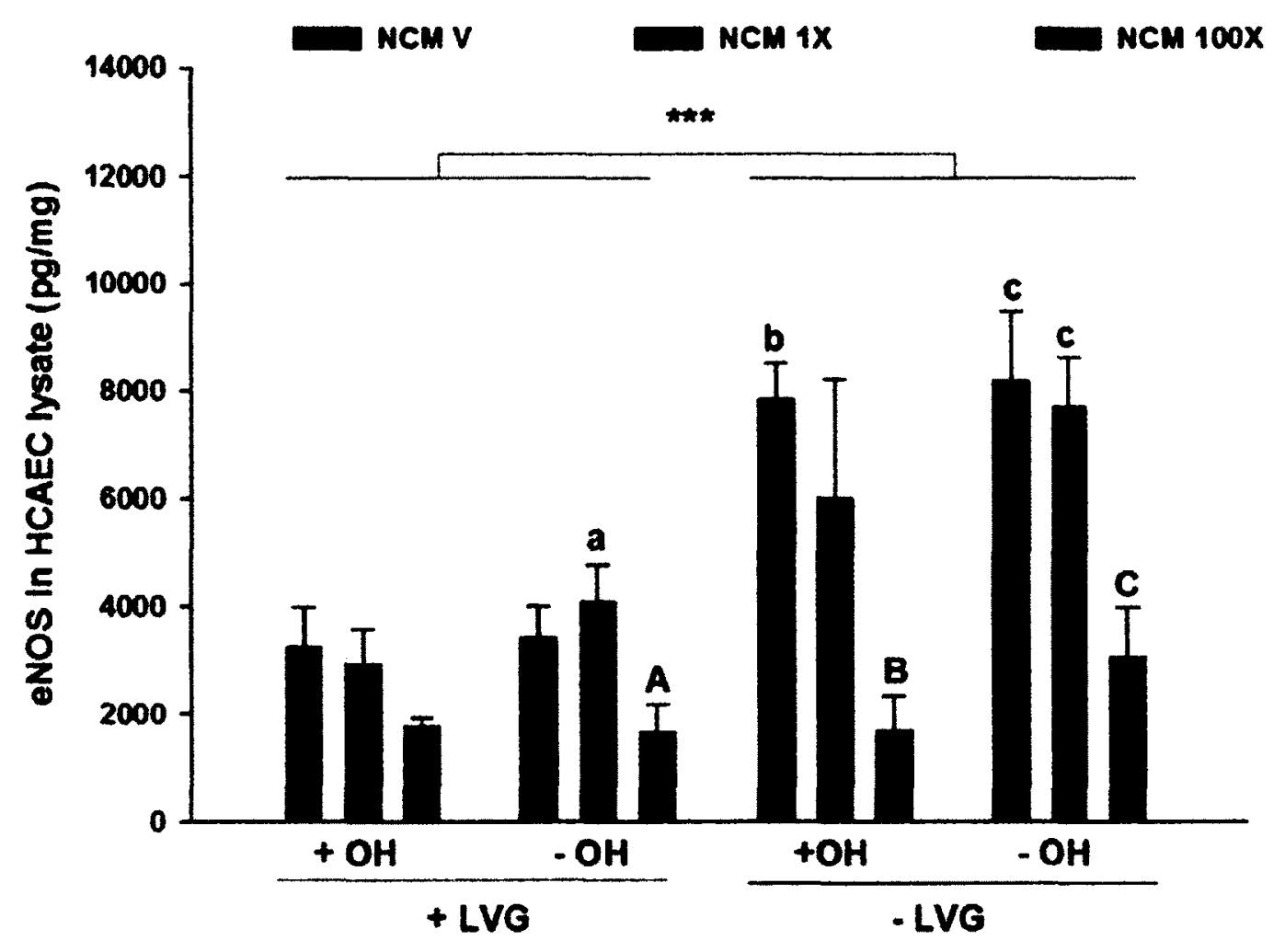

Figure 14: Effects of NCM3 on eNOS levels in cell lysates of HCAEC cultured under varying LVG and EtOH conditions for 24 hrs. The figure legends are: LVG = LDL, VLDL and glucose, $\mathrm{OH}=\mathrm{EtOH}$ and $\mathrm{NCM}=\mathrm{MeHg}, \mathrm{Pb}$ and $\mathrm{Cd}$. Data represent means \pm SEM from 3 independent experiments. A, B, and C are significantly different from a, b and $c$, respectively, at $p<0.05$. “***" indicates significant difference between the two groups located under the lines at $p<0.001$. 
Overall, the results indicate that, in general, the presence of LVG had a significant effect on the overall response of the measured markers; however, the trend of the response remained similar. The presence or absence of alcohol had no significant effect on the measured markers with the exception of 6-keto PGF1 $\alpha$, in which case, NCM3 increased the levels of this marker in the absence, but not presence, of $\mathrm{EtOH}$. The high dose condition in all cases generally accounted for the significant differences measured in the various markers. The trends in the eNOS marker are very interesting since high dose NCM3 decreased eNOS levels under all culture conditions used. To determine the dose effects of NCM3 on eNOS levels, HCAEC were treated with four doses of NCM3, 0, 1X, $10 \mathrm{X}, 100 \mathrm{X}$ for $24 \mathrm{hrs}$ in the absence of LVG and EtOH. 


\subsection{Effects of Individual Metals on eNOS}

\subsection{1 eNOS ELISA}

To understand which chemical component of NCM3 contributed to the effects of the mixture on cellular eNOS levels, cells were treated with individual metals, methylmercury $(\mathrm{MeHg})$, lead $(\mathrm{Pb})$ and cadmium $(\mathrm{Cd})$, in the absence of LVG and EtOH using both ELISA and Western blot. eNOS levels were significantly decreased by $\mathrm{MeHg}$ at the highest dose used after $24 \mathrm{~h}$ of exposure (Figure 16). The degree of decrease in eNOS caused by MeHg was similar to that by NCM3 (Figure 15).

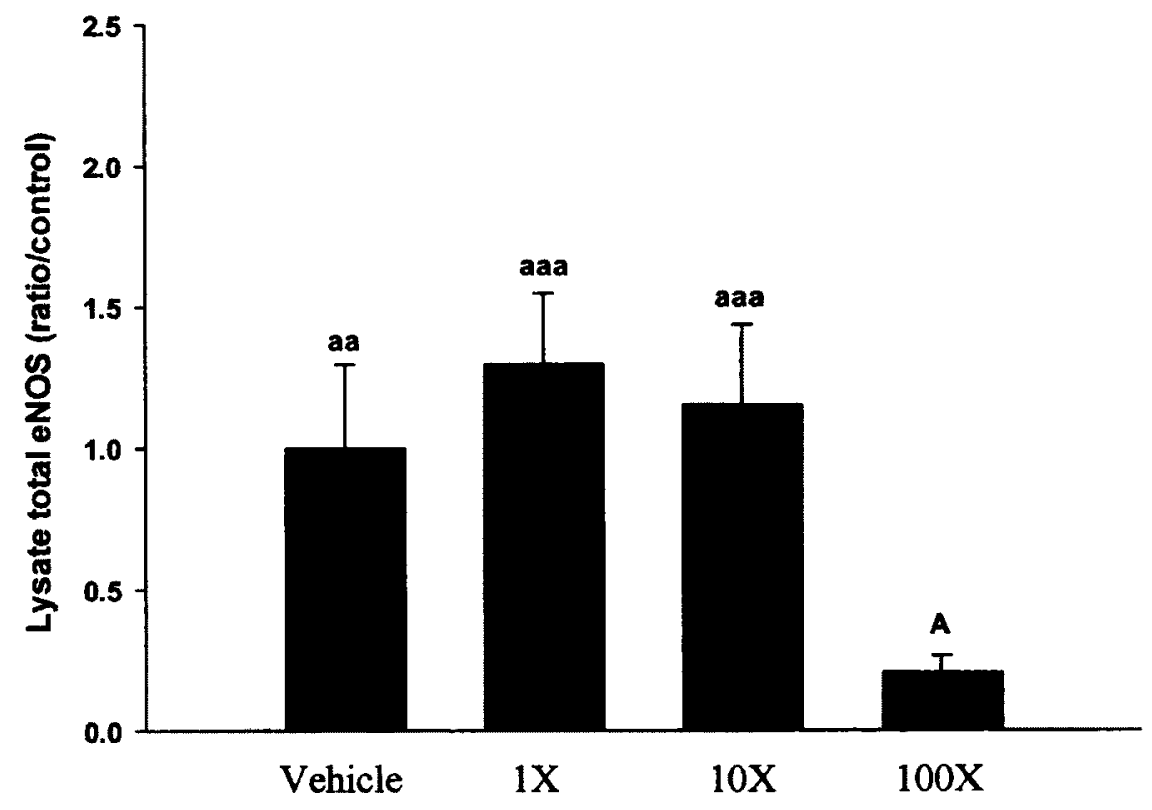

Figure 15: Dose effects of NCM3 on eNOS protein levels in HCAEC after $24 \mathrm{hr}$ of exposure in the absence of $\mathrm{LVG}$ and EtOH. The data is presented as ratios to control. " $\mathrm{A}$ " is significantly different from "aa" and "aaa" and $\mathrm{p}<0.01$ and 0.001 , respectively. Data represent means \pm SEM for 5 individual experiments. 


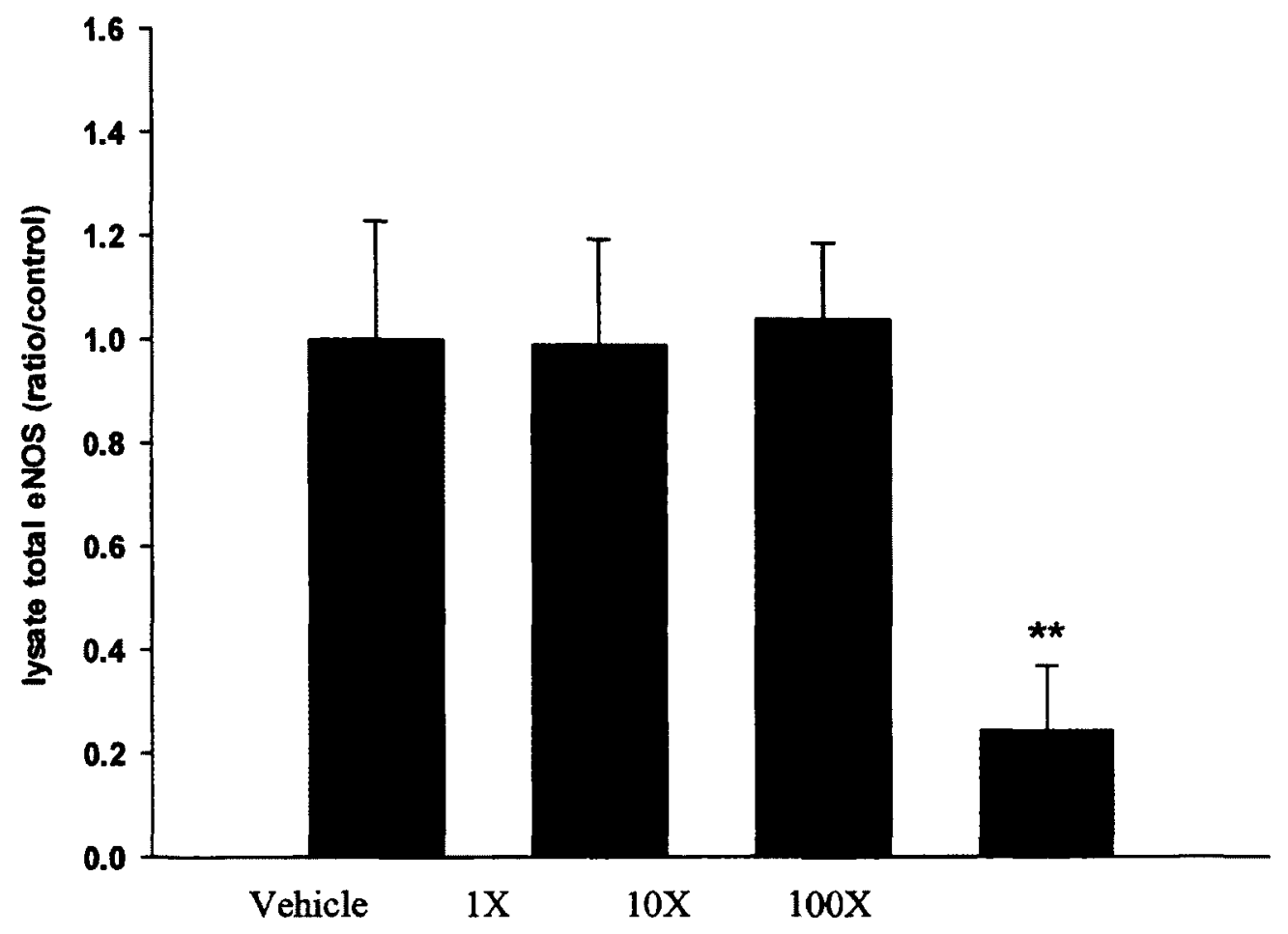

Figure 16: Effects of MeHg on eNOS levels in HCAEC after $24 \mathrm{hr}$ of exposure. The data is presented as ratios to control. Data represent means \pm SEM for 5 individual experiments. “**” represents a significant difference of $\mathrm{p}<0.05$. 
Figures 17 and 18 show the effects of $\mathrm{Pb}$ and $\mathrm{Cd}$, respectively, on eNOS protein levels. In both cases, eNOS was not significantly affected at any of the four dosages or $\mathrm{Pb}$ or $\mathrm{Cd}$. This suggests that $\mathrm{MeHg}$ was the causative agent of eNOS decrease induced by NCM3 while $\mathrm{Pb}$ and $\mathrm{Cd}$ had no effect.

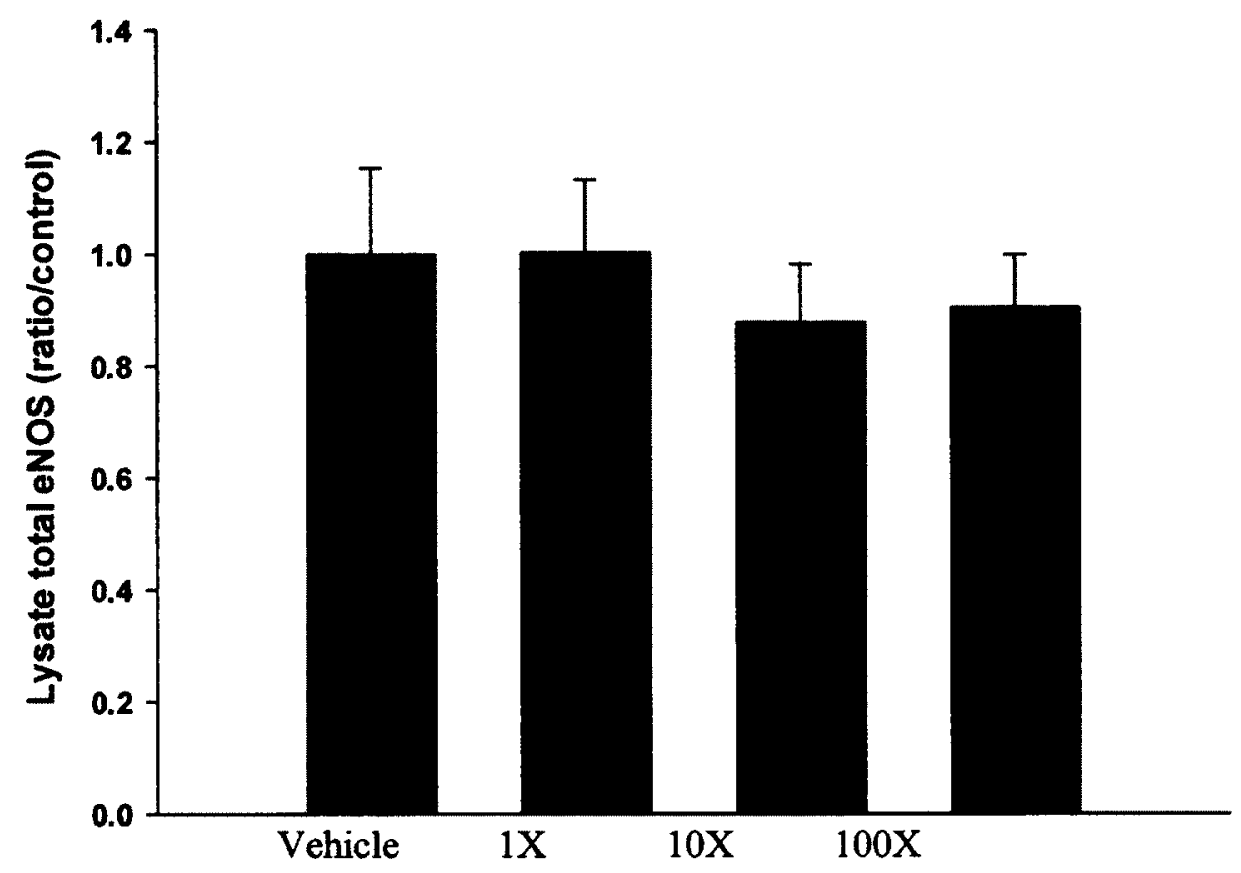

Figure 17: Effects of Pb on eNOS protein levels in HCAEC after $24 \mathrm{hr}$ of exposure. The data are presented as ratios to control. Data represent means \pm SEM of 4 individual experiments. 


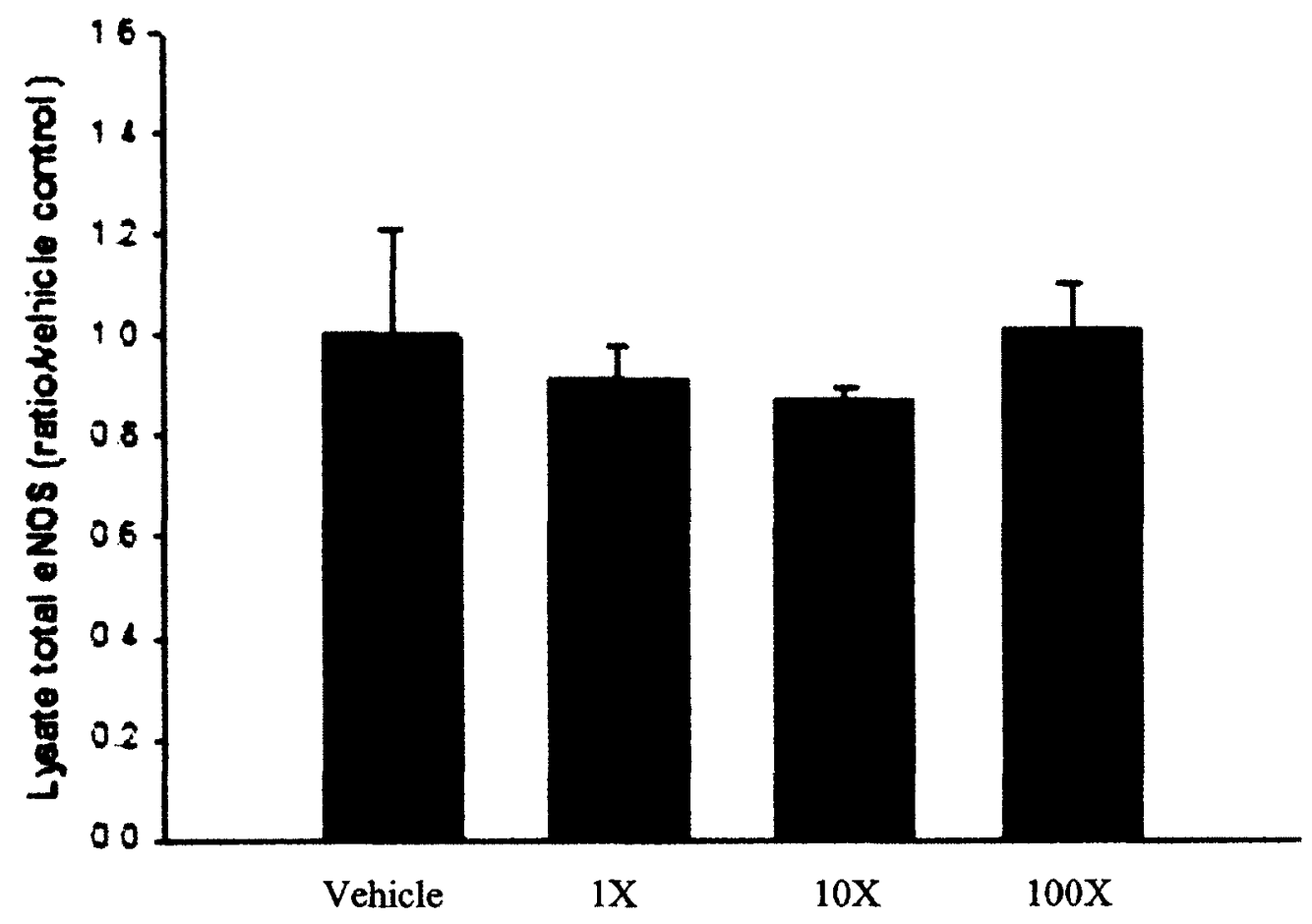

Figure 18: Effects of Cd on eNOS protein levels in HCAEC after 24 hr of exposure. The data are presented as ratios to control. Data represent means \pm SEM of 4 individual experiments. 


\subsection{2 eNOS Protein}

To verify further that the eNOS changes observed were actual changes in protein levels, Western blot analyses were performed using a rabbit antibody which recognized a band at 130-140 kDa. GAPDH was used as a loading control. It can be seen in Figure 19 that eNOS levels were decreased markedly by the $100 \mathrm{X}$ NCM3 whereas GAPDH was uniform throughout all treatment groups. This shows that the decrease in eNOS was not due to unequal loading.

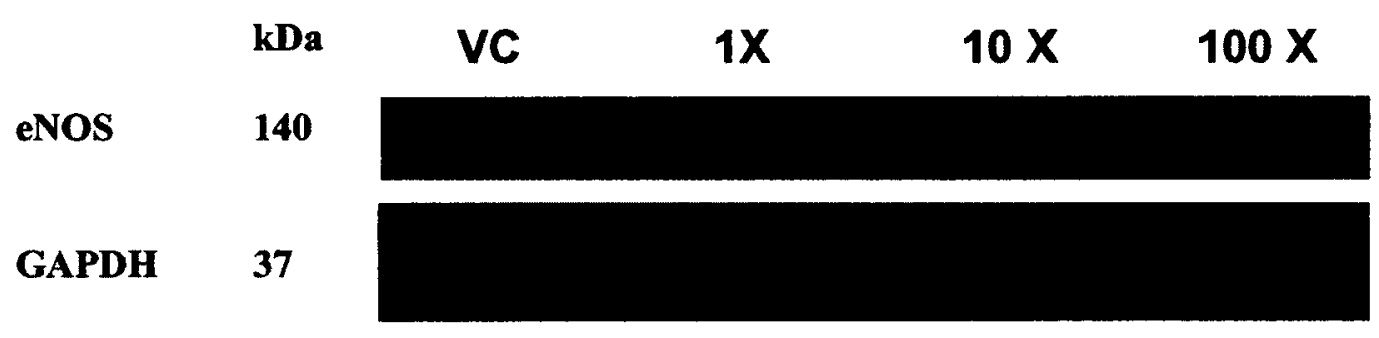

Figure 19: Western blot of protein extracts of HCAEC exposed to varying doses of NCM3 for $24 \mathrm{hr}$. The protein bands of total eNOS is shown in the top row with a MW $140 \mathrm{kDa}$, and GAPDH in the bottom row with a MW $37 \mathrm{kDa}$. 
Figure 20 shows that $100 \mathrm{X}$ MeHg decreased the band intensity of eNOS while the GAPDH band remained relatively consistent across the treatment groups. This is consistent with the ELISA results presented above.

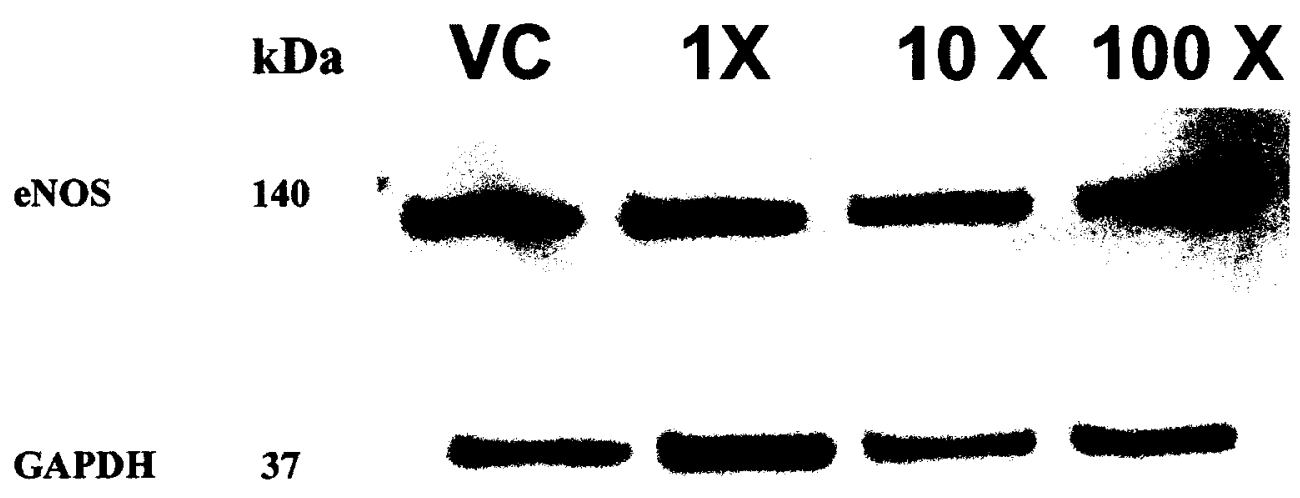

Figure 20: Western blot of protein extracts of HCAEC exposed to MeHg for $24 \mathrm{hr}$. The top 4 bands at $140 \mathrm{kDa}$ are for eNOS and the bottom 4 bands at $37 \mathrm{kDa}$ are for GAPDH. 
Western blots of protein extracts of HCAEC exposure to $\mathrm{Pb}$ and $\mathrm{Cd}$ are indicated in Figures 21 and 22 respectively. In both instances, it can be noted that the eNOS and GAPDH band intensities are similar between treatment groups. This further verifies that eNOS protein levels in HCAEC are not significantly affected by exposure to either $\mathrm{Pb}$ or Cd.

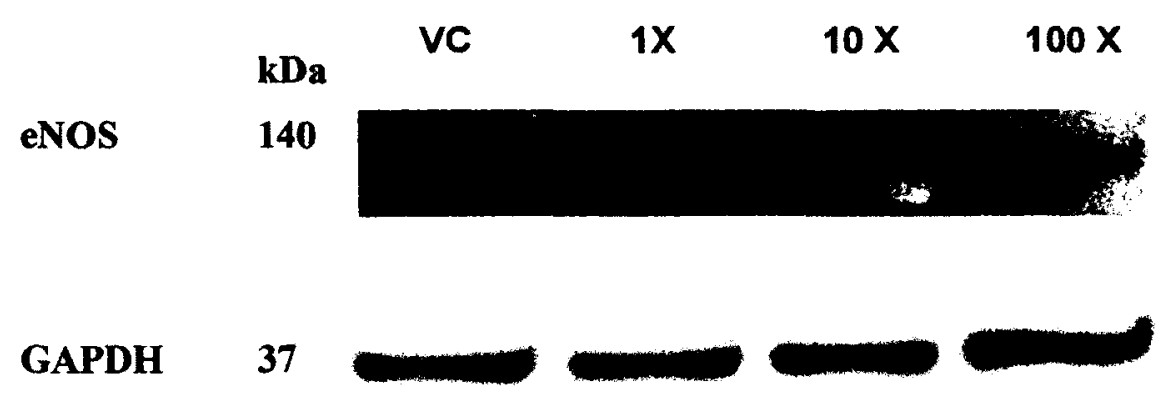

Figure 21: Western blot of protein extracts of HCAEC exposed to Pb for $24 \mathrm{hr}$. The top 4 bands at $140 \mathrm{kDa}$ are for eNOS and GAPDH have molecular weights of 140 and and the bottom 4 bands at $37 \mathrm{kDa}$ are for GAPDH. 


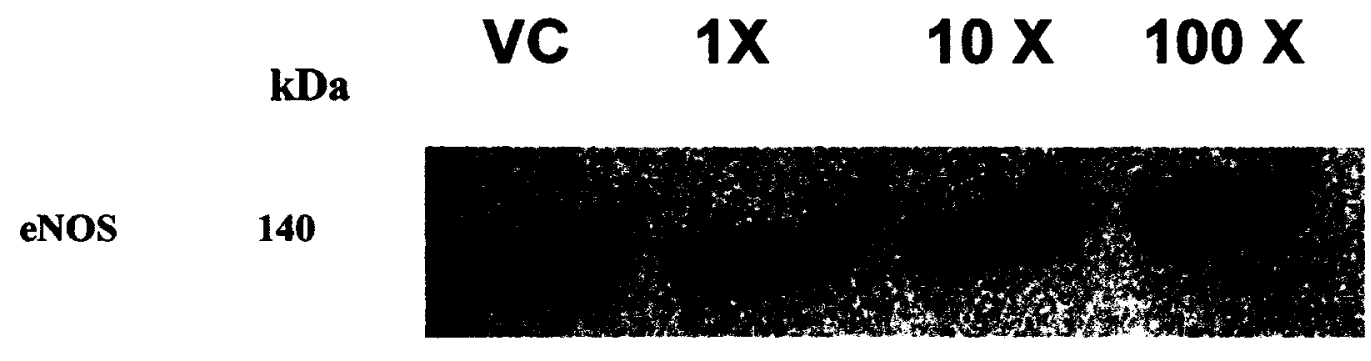

GAPDH $\quad 37$

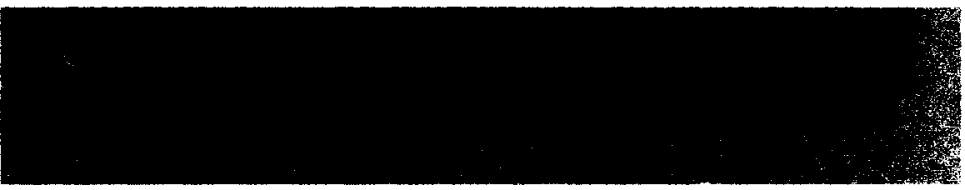

Figure 22: Western blot of protein extracts of HCAEC exposed to Cd for $24 \mathrm{hr}$. The top 4 bands at $140 \mathrm{kDa}$ are for eNOS and GAPDH have molecular weights of 140 and and the bottom 4 bands at $37 \mathrm{kDa}$ are for GAPDH. 


\subsection{Effects of NCM3 and Individual Metals on Cell Morphology}

In order to verify if changes in eNOS and NO induced by NCM3 and $\mathrm{MeHg}$ were associated with any physiological changes cell morphology was examined in HCAEC exposed to NCM3 or MeHg for $24 \mathrm{hr}$. Figure 23 shows that the control cells are in close contact and appear in their characteristic spindle shape (Figure $23 \mathrm{~A}$ ). The 1X (Figure 23 $\mathrm{B}$, and 10X NCM (Figure $23 \mathrm{C}$ ) had no obvious effects on cell morphology showing characteristic spindle shape, although the cells were farther apart with lesser cell-to-cell contact. Cell debris is not very apparent and the cell density looked slightly lower than the control group. The $100 \mathrm{X}$ NCM3 caused dramatic changes in cell morphology with much fewer cells separated far apart and lack of contact (Figure $23 \mathrm{D}$ ). The characteristic spindle shape also disappeared. The cells appeared very jagged and serrated. It can be assumed that the cell membrane integrity had been compromised and that cell-to-cell communication as well as functions may be severely altered by exposure to the high dose of NCM3. Although the cells appeared quite damaged physically, there did not appear to be much cell debris present, which would indicate apoptosis or necrosis. Most, if not all of the cells, are still attached to the plate and are not free floating. 


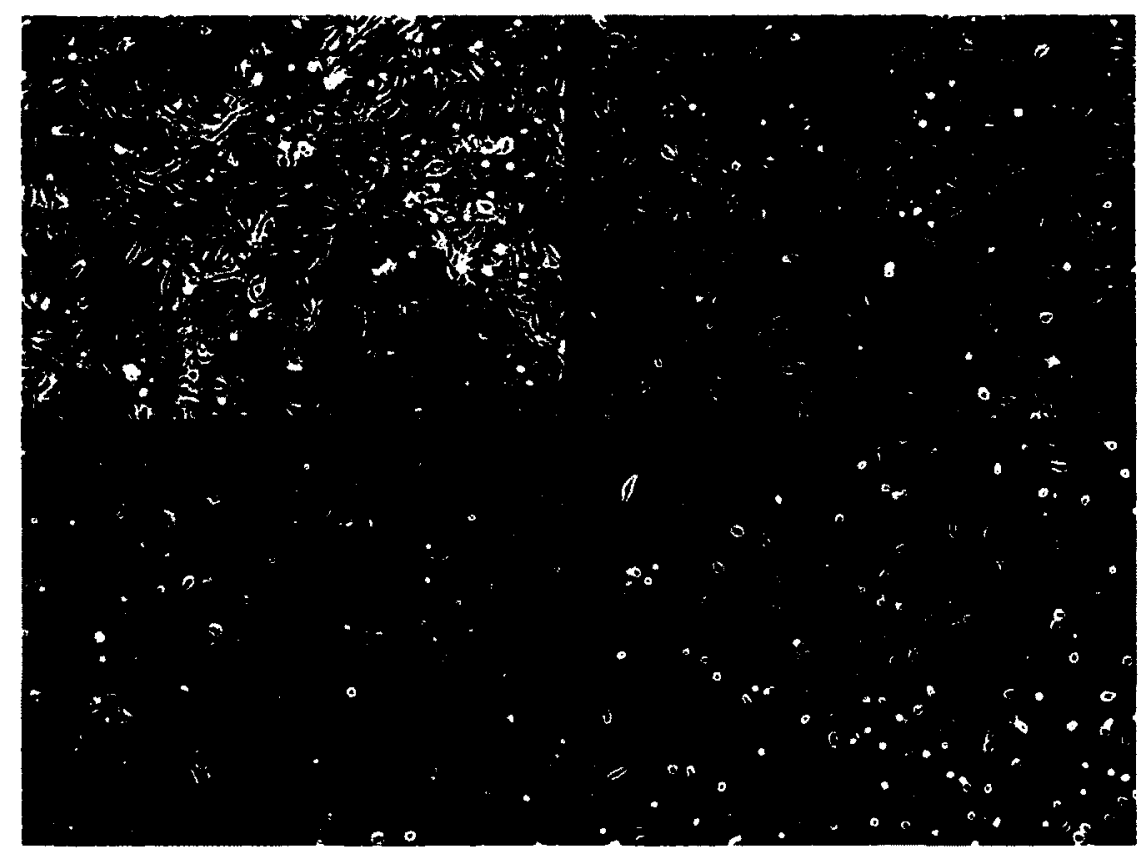

Figure 23: Effects of NCM3 on morphology of HCAEC after $24 \mathrm{hr}$ of exposure. The different panels are indicative of different doses with $\mathrm{A}=$ Sodium carbonate and water vehicle, $\mathrm{B}=1 \mathrm{X} \mathrm{NCM} 3, \mathrm{C}=10 \mathrm{X} \mathrm{NCM} 3$ and $\mathrm{D}=100 \mathrm{X}$ NCM3. All pictures were taken under a light microscope at a magnification of $10 \mathrm{X}$. 
Changes in morphology were also observed in cells exposed to $100 \mathrm{X} \mathrm{MeHg}$, with close resemblance to the patterns observed in the cells exposed to NCM3 (Figure 24). Pb and Cd did not cause obvious morphological changes in the exposed cells regardless of the doses used (Figures 25 and 26). In all cases, the treated cells appear in their normal characteristic spindle shape and density as their control cells. Overall, the $100 \mathrm{X} \mathrm{MeHg}$ and $\mathrm{NCM} 3$, but not $\mathrm{Pb}$ and $\mathrm{Cd}$, caused dramatic morphological changes in exposed cells, which correlated well with the observed eNOS decrease in these cells. 


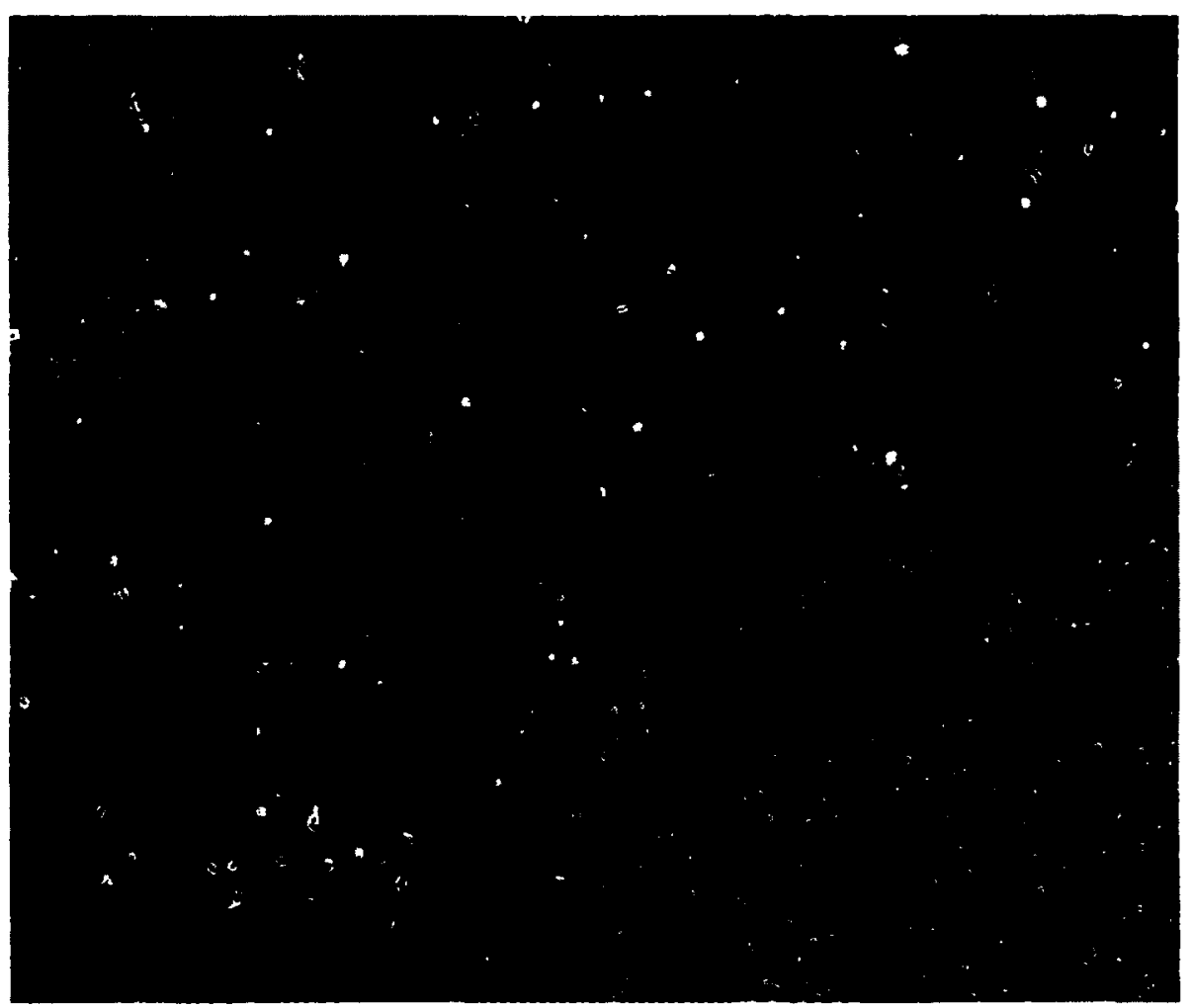

Figure 24: Effects of MeHg on morphology of HCAEC after 24 hr of exposure. The different panels are indicative of different doses with $A=$ Sodium carbonate vehicle, $B=$ 1X $\mathrm{MeHg}, \mathrm{C}=10 \mathrm{X} \mathrm{MeHg}$ and $\mathrm{D}=100 \mathrm{X} \mathrm{MeHg}$. All pictures were taken under a light microscope at a magnification of $10 \mathrm{X}$. 


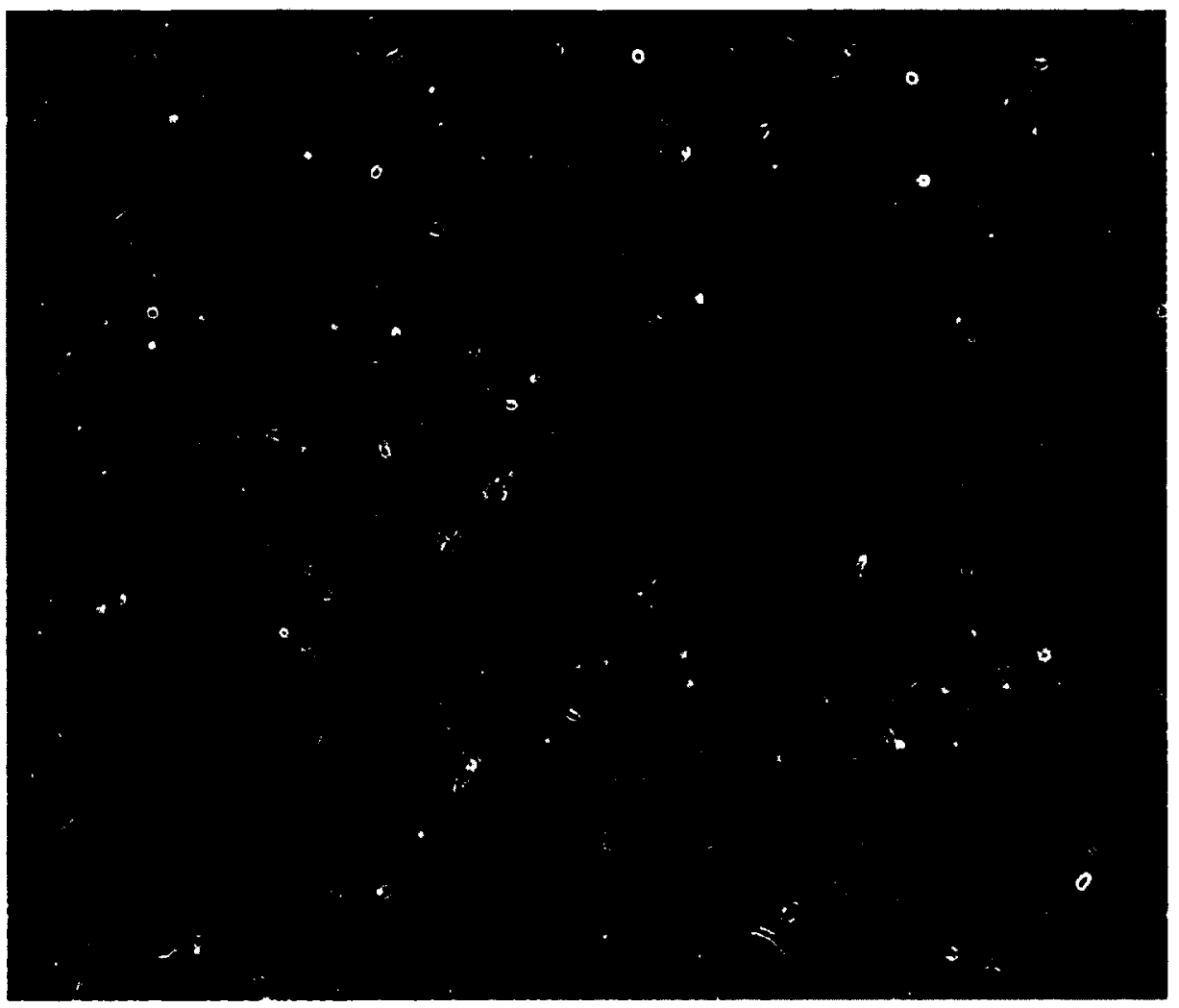

Figure 25: Effects of $\mathrm{Pb}$ on morphology of HCAEC after $24 \mathrm{hr}$ of exposure. The different panels are indicative of different doses with $A=$ water as vehicle control, $B=1 \mathrm{X}$ $\mathrm{Pb}, \mathrm{C}=10 \mathrm{X} \mathrm{Pb}$ and $\mathrm{D}=100 \mathrm{Xb}$. All pictures were taken under a light microscope at a magnification of $10 \mathrm{X}$. 


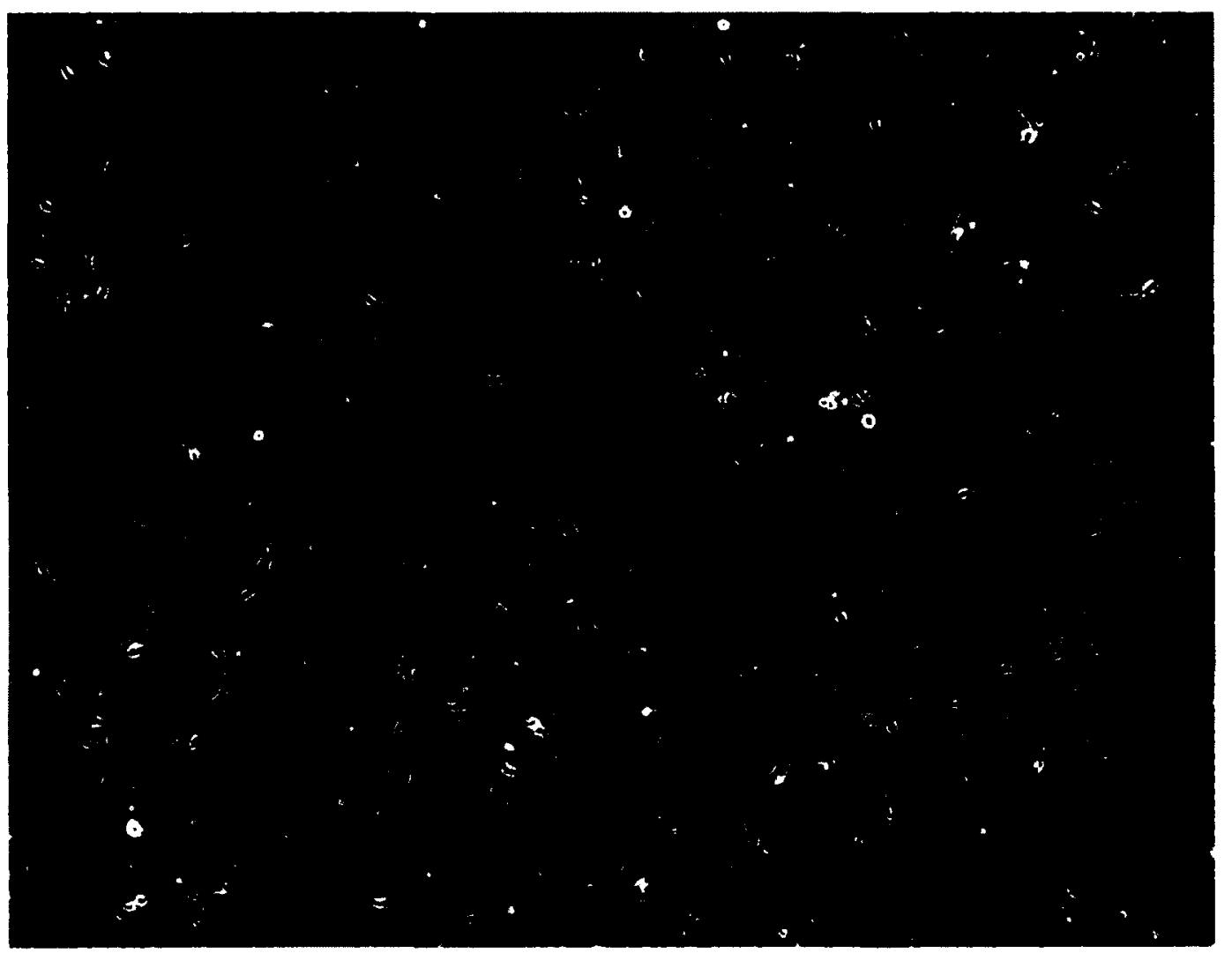

Figure 26: Effects of Cd on morphology of HCAEC after $24 \mathrm{hr}$ of exposure. The different panels are indicative of different doses with $A=$ water as vehicle control, $B=1 \mathrm{X}$ $\mathrm{Cd}, \mathrm{C}=10 \mathrm{X} \mathrm{Cd}$ and $\mathrm{D}=100 \mathrm{X} \mathrm{Cd}$. All pictures were taken under a light microscope at a magnification of $10 \mathrm{X}$. 


\subsection{Cell Viability For Exposure to $\mathrm{M3}, \mathrm{MeHg} \mathrm{PbCl}_{2}$ and $\mathrm{CdCl}_{2}$}

The morphology changes from figures 23 and 24 in panel $d$ the high dose, showed a decrease in cell number due to cell death. The same pattern does not hold true for figures 25 and 26 as the high dose present does not indicate a large variation in cell number. Figure 27 verifies increased cell death by the high dose for $\mathrm{M} 3$ and $\mathrm{MeHg}$ exposure.

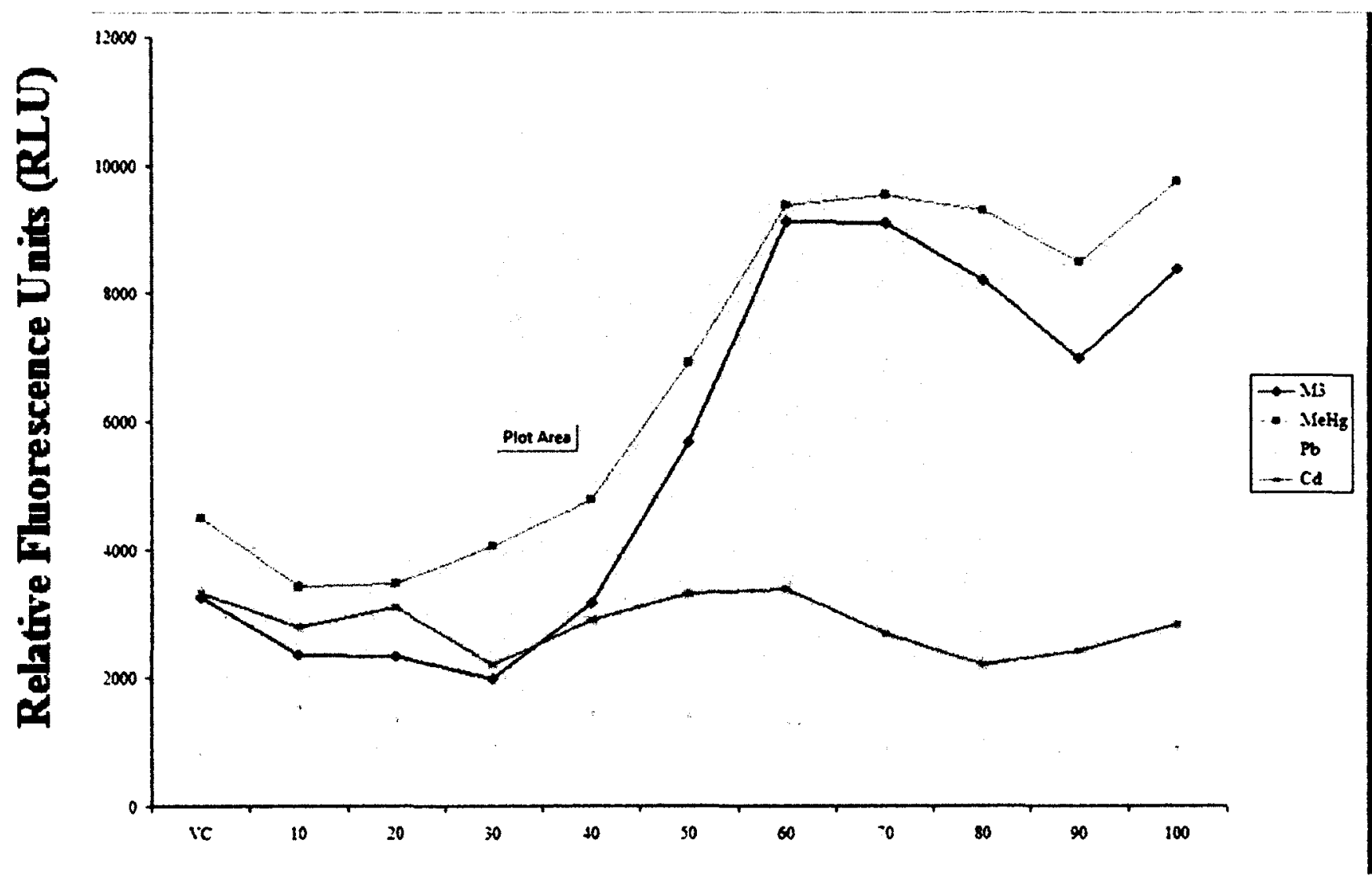

Figure 27: Dose response cell viability of $\mathrm{HCAEC}$ exposed to $\mathrm{M3}, \mathrm{MeHg}, \mathrm{PbCl}_{2}$ and $\mathrm{CdCl}_{2}$ over 24 hrs. Note that $\mathrm{PbCl}_{2}$ and $\mathrm{CdCl}_{2}$ remain relatively unchanged in overall numbers while $\mathrm{M} 3$ and $\mathrm{MeHg}$ undergo numerous fluctuations. 


\section{DISCUSSION}

There are numerous persistent environmental contaminants which move from the southern towards the northern arctic via atmospheric and oceanic transport; many of these contaminants are biomagnified within the arctic food web (Fontaine et al., 2008; Var Oostdam et al. 2005; Sharp 2009; Pelletier et al. 2009; Dellaire et al., 2003). This poses a problem for the local human population. The Northern populations of Canada rely heavily on the marine life for sustenance; a traditional diet high in monounsaturated and polyunsaturated fatty acids. Their eating habits were thought to afford them with lower incidences of $\mathrm{CHD}$, but recently this has been found not to be the case (Jorgensen and Borch-Johnsen 2008). The problem is magnified when we consider that it is a mixture of contaminants rather than a single contaminant. The study by Dewailly et al. (2006) showed that the levels of $\mathrm{MeHg}, \mathrm{Cd}$ and $\mathrm{Pb}$ in Inuit plasma are significantly higher than the national averages for Canada. These increased levels of exposure lead to the hypothesis that it may cause endothelial dysfunction and ultimately lead to metabolic and cardiovascular diseases. There is little information regarding the compounded effects of the contaminant metal mixture, and what effects these would have when combined with a change towards a more western diet and lifestyle (along with use of alcohol). Considering all three factors may shed new light into how endothelial function is affected and how they could lead towards metabolic and cardiovascular diseases.

\subsection{Human Coronary Artery Endothelial Cells}

The endothelium serves as the primary interface between blood and body tissues and is very important in regulating important aspects of vascular responses such as 
maintaining vessel tone and modulating adhesion and aggregation of platelets affecting thrombosis (Davidson 2010; Versari et al 2008; Atochin and Huang 2010; Deanfield et al 2007). Endothelial dysfunction occurs when this system is upset and there have been numerous in vitro studies which have used cultured HCAEC to determine its cause. HCAEC have been used to determine the changes which occur in various biochemical markers of endothelial dysfunction when introduced to stress. A study by Briones et al in 2001 showed that various chemokines were expressed differently when comparing HCAEC and Human Umbilical Vein Endothelial Cells (HUVEC) which could contribute to or influence site-specific recruitment of subsets of leukocytes (Briones et al, 2001). The vascular endothelium is a very important interface serving to keep endothelial function normal and any changes within this system could introduce changes that lead to cardiovascular diseases.

\subsection{Effects of NCM3, Dietary Fat/Sugar and Alcohol on HCAEC Cell Viability}

The multitox-glo multiplex cytoxicity assay uses the sequential addition of fluorescent and luminescent reagents that measure the relative number of live and dead cells within a given cell population. The luminogenic cell-impermeant peptide substrate is used to measure dead cell protease activity; these proteases are released from cells which have lost membrane integrity. The dead cell protease activity graph is shown in Figure 8 indicating a significant difference between the presence versus absence of LVG; however, the presence or absence of alcohol made no difference on cell viability when we compare the vehicle controls under all conditions. The number of dead cells from $100 \mathrm{X}$ NCM3 in the LVG absent system was significantly higher when compared to the 
vehicle and $1 \mathrm{X}$ dose. The observations could be explained by considering that the presence of LVG may be hindering the capability of protease to properly function and generate luminescence due to the reaction at any of the varying doses. The LVG environment may block the active site of the protease or interfere with the substrate to allow proper binding by the enzyme. It may also be possible that the presence of LVG allows HCAEC cells to maintain cell membrane integrity which would prevent the deadcell protease from being released into the medium and causing a luminescent signal, suggesting that the cells are more viable. The LDL which is added in this case is in the native form, and not the oxidized form. An earlier study found evidence that native LDL ( $\mathrm{n}-\mathrm{LDL}$ ) binding to the $\mathrm{LDL}$ receptor within a concentration of 100 to $700 \mu \mathrm{g} / \mathrm{mL}$ was able to trigger an increase in intracellular calcium to act as second messengers to induce vascular cell adhesion molecule-1 expression in HCAEC and pig aortic endothelial cells. The induction of this allows for various monocytes to bind vessel walls as an initiation for atherosclerosis (Allen et al., 1998). There are numerous studies which show that oxidized LDL (ox-LDL) is more harmful to endothelial cells than n-LDL, as it can initiate the processes of atherosclerosis, whereas $\mathrm{n}-\mathrm{LDL}$ may require some time before it can be oxidized (Li and Mehta, 2005; Stocker and Keaney, 2004). It may be possible that $\mathrm{n}$-LDL, in this study, allows HCAEC some form of a protective barrier from the harsh effects of heavy metals. It may be that similar mechanisms are being used when LDL and VLDL are present in the levels according to this study. The study by Srimahachotra et al (2010) showed that a lifestyle modification approach, where patients with an LDL level of $9.872 \pm 2.72 \mathrm{mg} / \mathrm{ml}$ were instructed to follow a low-fat, high antioxidant and fiber 
diets, improved HCAEC viability along with lipid profiles, decreased oxidative stress and hence reduced risk of future cardiovascular events (Srimahachota et al, 2010).

The decreased cell viability by $100 \mathrm{X}$ NCM3 in the LVG absent categories can be explained by considering the following information: It was shown in a previous study that endothelial cell death occurred when exposed to Cd concentrations of 1-5 $\mu \mathrm{M}$ for 24 72 hours (Prozialeck et al., 2006). The concentration of $\mathrm{Cd}$ in the 100X NCM3 was 2.7 $\mu \mathrm{M} \mathrm{Cd}$, which is within the range of what was used in the study by Prozialeck et al., (2006). Fujiwara and Kaji (2000) showed that $\mathrm{Pb}$ inhibited the repair of injured monolayers of vascular endothelial cells as well as the proliferation of vascular endothelial cells, while lead did not destroy vascular endothelial cell monolayers. Mazerick et al. (2007) measured the release of arachidonic acid from cellular membrane phospholipids. A dose dependent cytotoxic effect of $\mathrm{MeHg}(5-15 \mu \mathrm{M})$ was found in cultured bovine pulmonary artery endothelial cells after 30 and 60 minutes of exposure (Mazerick et al., 2007). Phospholipases are enzymes which specifically hydrolyze membrane phospholipids and generate second messengers which play important roles in cellular signaling. Phospholipase $A_{2}$ is one such enzyme that was found to be activated by $\mathrm{MeHg}$, causing release of arachidonic acid (Mazerick et al., 2007). $\mathrm{Pb}, \mathrm{Cd}$ and $\mathrm{MeHg}$ are heavy metals known to have relatively high affinities for sulfhydryl (thiol) groups (Gurer and Ercal, 2000; Cuypers et al., 2010). Mazerick et al. (2007) also found that $\mathrm{MeHg}$ caused a loss of cellular thiols which in turn activated phospholipase $\mathrm{A}_{2}$ and eventually lead to endothelial dysfunction. Therefore, the significant increase in cell death by $100 \mathrm{X}$ NCM3 may be explained as that in the absence of LVG, metals of NCM3 
were able to reach the cells more easily and interact with and decrease cellular thiol levels, which in turn activated phospholipase $A_{2}$ leading to increased cell death.

\subsection{Effects of NCM3 on Markers of Endothelial Dysfunction}

Little is known about the effects of exposure to LVG, alcohol and environmental contaminants all together in HCAEC for determining endothelial dysfunction. There exists the possibility that various biochemical markers may be affected differently when exposed to various combinations of these factors. However, there is a relatively high level of inter-connectivity between markers as each one may be regulated relative to how the other is affected. ET-1 is a peptide which is responsible for vasoconstriction and can be used as a biochemical marker of endothelial dysfunction. Active ET-1 binds to G-

protein coupled endothelin receptors $\mathrm{A}$ or $\mathrm{B}$, leading to activation of phospholipase $\mathrm{C}$, which hydrolyses phosphatidylinositol 4,5-bisphosphate ( Ptdins(4,5)P2 ) to generate diacylglycerol (DAG) and inositol trisphosphate ( IP3 ). DAG and IP3 stimulate protein kinase C, delta and epsilon (PKC-delta and PKC-epsilon) and mobilize intracellular $\mathrm{Ca}^{2+}$, promoting vasoconstriction (Niemann et al., 2005). Endothelin-converting enzyme -1 (ECE-1) is required to proteolytically cleave big-ET-1 to activate it. ECE-1 is membrane bound within endothelial cells (Niemann et al., 2005). Basal circulating levels of ET-1 in human plasma are reported at $0.7-5 \mathrm{pg} / \mathrm{mL}$ (Mazzuca and Khalil 2012). However, it is known to be elevated in atherosclerosis and pulmonary hypertensions. (Rubanya and Botelho, 1991; Inoue and et al., 1989; Rubanyi and Polokoff, 1994; Rossi et al., 2000). Niemann et al. (2005) showed that HUVEC cells exposed to n-LDL at a concentration of $100 \mu \mathrm{g} / \mathrm{mL}$ significantly increased ET-1 release into the supernatant. They also showed a 
dose dependent increase in ECE-1 mRNA expression by the same dose of LDL. However, ox-LDL was more potent than $\mathrm{n}-\mathrm{LDL}$ in inducing ECE-1 expression. Their results suggested that circulating $\mathrm{n}-\mathrm{LDL}$ are important stimuli for both ECE-1 and endothelin synthesis. This in turn potentiates a vicious cycle which allows n-LDL to get increasingly oxidized via ET-1-induced down-stream changes including activation of NADPH oxidase. As increases in ox-LDL occurs, it serves as a positive feedback which allows for uptake of more ox-LDL into endothelial cells, leading to increased oxidative stress (Niemann et al., 2005; Lubrano et al., 2008).

In this study, the levels of ET-1 in supernatants were significantly higher in the absence than the presence of LVG. The same pattern of results was also observed in cell lysates, with lower supernatant ET-1 levels in the presence than absence of LVG. It remains to be clarified if this was a result of altered protein synthesis processes by LVG leading to a decreased ET-1 production, or simply due to an inhibited cell proliferation by LVG. There was a trend of increase in lysate ET-1 levels adjusted for protein yield with NCM3 doses in the presence of LVG, suggesting that 100X NCM3 did not inhibit ET-1 synthesis in the cells. The significant decrease in the supernatant ET-1 levels by $100 \mathrm{X}$ NCM3 under the same LVG condition could be attributed to the decreased cell proliferation by NCM3 as shown by the cytotoxicity assays, or inhibited release of ET-1 into supernatants as a result of disrupted cell membrane or inhibited ECE function. The presence or absence of alcohol had no significant effect on either supernatant or lysate ET-1 levels under any of the treatment conditions used.

The pro-inflammatory cytokine IL-6, which favors vasoconstriction at increased levels, is an indication for the prognosis of atherosclerosis (Esteve et al., 2007). Lee et al. 
(2005) showed that elevated IL-6 levels, during the first 48 hours of acute coronary syndromes, were strongly associated with 30-day major cardiovascular end points $(\mathrm{p}=$ $0.1)$. It can be seen in Figure 11 that IL-6 levels were not significantly altered under either the presence or absence of LVG. Lubrano et al. (2008) showed that IL-6 supernatant concentrations measured in human microvascular endothelial cells increased according to LDL concentrations and were also directly proportional to the degree of LDL oxidation. However, $200 \mu \mathrm{g} / \mathrm{mL}$-LDL did not increase IL-6, whereas $200 \mu \mathrm{g} / \mathrm{mL}$ of med-oxidized LDL did (Lubrano et al., 2008). In this study, I used much higher concentrations of LDL and did not observe effects of LDL on IL-6 release, suggesting that the LDL molecules remained to be in native form during the $24 \mathrm{~h}$ of exposure period. A trend of increase in supernatant IL-6 concentration with $100 \mathrm{X}$ NCM3 was observed, especially in the presence of LVG, although not to a significant degree. This increase was significant after adjusting for cell density as this dose of NCM3 significantly decreased cell density. These suggested that $100 \mathrm{X}$ NCM3 promoted an inflammatory response in the dosed cells. IL-6 is not only a well-known marker of vascular inflammation, but also plays a central significant role in regulating cardiovascular homeostasis by mediating hepatic acute response, thrombosis, monocyte activation, stress response, endothelial dysfunction and insulin resistance (Hou et al. 2008). Increase in circulating IL-6 is known to be associated with atherosclerosis, cardiomyopathies, and metabolic syndromes. IL-6 exerts its action by at least two signaling pathways. In the classical membrane signaling pathway, IL-6 binds to its receptor subunit IL-6R $\alpha$ at the cell surface. The IL-6-IL-6R $\alpha$ complex then triggers ligand-mediated oligomerization with transmembrane gp130 $\beta$ subunit, inducing gp130 homodimerization and formation of a hexameric IL-6-IL-6R $\alpha$ - 
gp130 complex, which in turn induce a cascade of phosphorylation and signal transduction to the nucleus, resulting in transcription of target genes. In the transsignaling pathway, IL- $6 \alpha$ exists as a plasma soluble form, lacking a transmembrane domain, and requires no gpl30 for signal transduction (Hou et al., 2008). The endothelium does not express the transmembrane receptor and therefore, IL-6 exerts action through the trans-signaling pathway. One of the specific inducers of IL- 6 is TNF- $\alpha$ (Hou et al., 2008). However it remains to be confirmed if NCM3 also increased TNF- $\alpha$ expression in the dosed cells. Nevertheless, the increased IL- 6 release by $100 \mathrm{X}$ NCM3 points to an increased risk in developing cardiovascular and metabolic diseases if it happens in the Northerners exposed to these metals.

The endothelium produces many components of the extracellular matrix regulatory chemical modulators, including NO, ET-1, and PAI-1 for maintenance of vascular homeostasis (Oever et al., 2010). The endothelium maintains blood fluidity and restores vessel wall integrity to avoid bleeding. It regulates fibrinolysis by producing tissue-type plasminogen activator and PAI-1 (inhibitor) which limits the cascade of coagulation; PAI-1 levels are increased in obesity and metabolic syndrome in addition to being known as an important factor in the pathogenesis of atherosclerosis and thrombosis (Oever et al., 2010; Sodergren et al., 2010). In epidemiological studies, endothelial dysfunction is indicated by increased levels of PAI-1 (Meigs et al., 2006). In this study, PAI-1 release was not affected by the presence/absence of either LVG or alcohol at the levels used. Latron et al. (1991) incubated HUVEC cells for $24 \mathrm{hrs}$ with n-LDL at varying doses and showed that PAI-levels were not significantly increased even at high doses whereas ox-LDL did cause significant increases (Latron et al., 1991). Another 
study by Ren et al. (2000) found that HUVECs incubated with native and oxidized LDL showed significant increases in PAI-1 in both cases; however, it required a concentration of $10 \mathrm{nM}$ ox-LDL and $100 \mathrm{nM}$ native-LDL (n-LDL) to show the effect. They suspected that the prolonged $48-\mathrm{hr}$ period might have allowed for $\mathrm{n}-\mathrm{LDL}$ to be oxidized due to interactions within the cellular environment, and that oxidative modification might have contributed to $\mathrm{n}-\mathrm{LDL}$ and $\mathrm{Lp}(\mathrm{a})$ induced PKC activation and PAI-1 production in treated endothelial cells (Ren et al., 2000). In this study, the basal levels of PAI-1 released into supernatants for all vehicle control groups were comparable to the results of Termoli et al. (1993); approximately $20 \mathrm{ng} / \mathrm{L}$ (Tremoli et al., 1993). This is also consistent with the findings of Allison et al. (1999) where HUVECs incubated with n-LDL over an $18 \mathrm{hr}$ period showed no significant increases in PAI-1 levels while ox-LDL did show significant increases. Zhao et al. (2008) showed that HCAEC treated with VLDL did not induce significant increases in PAI-1 whereas oxidized VLDL showed a significant increase. Norata et al. (2003) demonstrated that HUVEC incubated with VLDL upregulated numerous genes which were involved in intracellular signaling and transcriptional regulation suggesting endothelial cell activation. Additionally, ox-VLDL levels were significantly higher than n-VLDL levels. It was concluded that the overall response of endothelial cell might depend on the micro-environment which promoted conversion of VLDL to ox-VLDL (Norata et al., 2003). It is possible that the lack of increasing effects of LVG on PAI-1 release was due to low levels of ox-LDL or oxVLDL. Alcohol, at the concentrations administered, did not affect PAI-1 levels. PAI-1 release was significantly decreased by $100 \mathrm{X}$ NCM3 especially in the presence of LVG. Yamamoto et al. (1996) exposed VSMC to $\mathrm{Pb}, \mathrm{Cd}$, and $\mathrm{Hg}$ for $24 \mathrm{hr}$ and showed that all 
these metals significantly decreased PAI-1; specifically, Cd was the most potent inhibitor with a dose dependent response (Yamamoto et al., 1996). It remains to be determined if the decreased supernatant PAI-1 by $100 \mathrm{X}$ NCM3 was attributed to the decreased cell density or direct inhibition of PAI-1 expression and/or release by this dose of NCM3.

Decreased levels of prostacyclin are one of the biochemical markers associated with endothelial dysfunction (Zou et al., 2002). Smith et al. (2002) showed that HUVEC incubated with LDL caused a dose dependent decrease in 6-keto PGF $1_{\alpha}$ where the maximal decrease occurred at their highest dosage of $90 \mathrm{mg} / \mathrm{dL}$ producing approximately $1000 \mathrm{pg} / \mathrm{mL}$ 6-keto PGF $1_{\alpha}$. However, Triau et al. (1988) showed that $24 \mathrm{~h}$ exposure of human saphenous vein endothelial cells to $0-0.2 \mathrm{mg} / \mathrm{mL} \mathrm{n}$-LDL did not increase 6-keto $P G F 1_{\alpha}$ release whereas ox-LDL caused a dose dependent significant increase reaching above $1000 \mathrm{pg} / \mathrm{mL}$ 6-keto $\mathrm{PGFl}_{\alpha}$. In another study, it was shown that $\mathrm{PGI}_{2}$ production in cultured bovine aortic endothelial cells was significantly reduced in the presence of high glucose $(3 \mathrm{mg} / \mathrm{mL})$ when compared with physiological glucose concentrations of 1 $\mathrm{mg} / \mathrm{mL}$ (Ono et al., 1988). Similarly, another study showed that HCAEC exposed to a high dose of glucose at $30 \mathrm{mmol} / \mathrm{L}$ significantly decreased $\mathrm{PGI}_{2}$ levels when compared to $5 \mathrm{mmol} / \mathrm{L}$ (Zou et al., 2002). For this study, the levels of 6 -keto $P G F 1_{\alpha}$ released into supernatants in the absence of LVG were comparable to those released by cultured human aortic endothelial cells exposed to $5 \mathrm{mM}$ glucose (Zou et al., 2002). Recent studies have shown that $\mathrm{PGI}_{2}$ may in fact paradoxically induce vasoconstriction rather than vasodilation under certain circumstances. Studies with rat aortic strips have indicated that $\mathrm{PGI}_{2}$ induces relaxation via a $\mathrm{PGI}_{2}-\mathrm{PGE}_{1}$ receptor; however, higher concentrations of $\mathrm{PGI}_{2}$ can act at the $\mathrm{Tx} \mathrm{A}_{2}-\mathrm{PGH}_{2}$ receptor which decreases $\mathrm{PGI}_{2}$ induced 
relaxation (Giles et al., 2012). It remains to be investigated if under the conditions used in this study, the combination of high glucose, LDL and VLDL affected the cells through the same pathway. The dosage and the presence or absence of alcohol did not affect 6 keto $P G F 1_{\alpha}$ released under the + LVG condition. However, under the LVG absent condition, the presence or absence of alcohol had significant influence on the effects of $100 \mathrm{X}$ NCM3 on 6-keto PGF $1_{\alpha}$ release. This suggested that when LVG was absent, alcohol modulated cellular response to metal exposure. It has been previously shown that $\mathrm{MeHg}$ can induce the formation of $\mathrm{COX}$ - related eicosanoids in endothelial cells while $\mathrm{Pb}$ is able to promote the release of arachidonic acid (which is required for prostaglandin synthesis) via phospholipase $\mathrm{A}_{2}$ (PLA2) activation (Vaziri 2008; Azevedo et al, 2012). It is possible that the MeHg and/or Pb present in the $100 \mathrm{X}$ NCM3 caused COX and PLA2 activation leading to increased 6-keto $P G F 1_{\alpha}$ release.

eNOS is an important regulator of the production of NO and a very important biochemical marker for endothelial dysfunction (Boeldt et al., 2011; Atochin and Huang, 2010). eNOS undergoes numerous post-translational modifications such as phosphorylation, palmitoylation and myristoylation. These are involved in controlling eNOS activity as well as localizing the eNOS protein primarily to the cell membrane (Rafikov et al. 2011; Bird 2011). In this study, eNOS levels were greatly reduced by the $100 \mathrm{X}$ NCM3 especially in the absence of LVG. The presence of LVG caused an overall significant decrease in eNOS levels when compared to the absence of LVG. These results are comparable to previous studies where HUVEC treated with n-LDL as well as ox-LDL were both able to decrease eNOS in a concentration dependent manner whereas the absence of any form of LDL maintained normal synthesis and function of eNOS (Ji et al., 
2006). The glucose component of LVG might also contributed to the reduction in eNOS production since a study by Srinivasan et al. (2004) showed that human aortic endothelial cells exposed to a high level of glucose $(25 \mathrm{mmol} / \mathrm{L})$ for $24 \mathrm{~h}$ significantly decreased eNOS protein expression when compared to a normal glucose level $(5 \mathrm{mmol} / \mathrm{L})$ (Srinivasan et al., 2004). Therefore, the results of this study agrees with previous studies in that eNOS protein levels are significantly decreased by LVG. Similar to the other markers tested in this study, the presence or absence of alcohol did not affect eNOS levels regardless of NCM3 and LVG conditions used. However, it is interesting to note that compared to all the other markers tested in this study, eNOS was decreased by $100 \mathrm{X}$ NCM3 independent of other factors. Additionally, eNOS levels were significantly decreased by $100 \mathrm{X}$ NCM3 as compared to the vehicle, $1 \mathrm{X} \mathrm{NCM} 3$, and 10X NCM3 doses under conditions lacking LVG and alcohol, suggesting that high doses of the metal mixture significantly decreases eNOS protein expression level. eNOS levels were decreased by $100 \mathrm{X}$ NCM3 across all conditions used, suggesting that eNOS may be a primary target of NCM3.

\subsection{Effects of Individual Metals on eNOS Protein Expression in HCAEC}

The $100 \mathrm{X}$ NCM3 has so far been responsible for causing statistically significant changes for the various biochemical markers indicative of endothelial dysfunction. However, it remained unclear which component metal or metals were responsible for the observed effects. A comparison made for the same dosages of $\mathrm{MeHg}, \mathrm{Pb}$ and $\mathrm{Cd}$ showed that only $\mathrm{MeHg}$ decreased eNOS protein expression level, pointing $\mathrm{MeHg}$ as the effector within this metal mixture. The levels of eNOS remained unchanged by $\mathrm{Pb}$ and $\mathrm{Cd}$ 
exposure as compared to the vehicle control groups. This was also confirmed using Western blot, in which $100 \mathrm{X}$ NCM3 caused a decrease in eNOS protein expression at the $140 \mathrm{kDa}$. The same is true for the eNOS protein expression in HCAEC exposed to $100 \mathrm{X}$ $\mathrm{MeHg}$, but not $\mathrm{Pb}$ or $\mathrm{Cd}$. It can be stated that $\mathrm{MeHg}$ lowered the protein expression of eNOS and that it is the causative contaminant in NCM3. There were distinct morphological changes associated with $\mathrm{MeHg}$ exposure, which were not observed in $\mathrm{Pb}$ and Cd exposed cells. The changes in cell shape and size associated with 100X NCM3 exposure were similar to those observed in 100X MeHg exposed cells. The morphological comparison also validated the idea that $\mathrm{MeHg}$ was independently responsible for the observed effects of NCM3. The changes in morphology caused by $100 \mathrm{X}$ NCM3 were in agreement with the results obtained using ToxiLight cell viability assay, in which both NCM3 and $\mathrm{MeHg}$, but not $\mathrm{Pb}$ and $\mathrm{Cd}$ decreased cell viability in a dose dependent manner.

\subsection{Conclusion}

The emphasis of this study was to determine whether the factors of diet, lifestyle and contaminant metal mixture adversely affected biochemical markers indicative of endothelial dysfunction. It can be seen that at the levels used, which reflect the levels of concern for increased risk of developing cardiovascular disease in humans, LVG caused various changes indicative of endothelial dysfunction while alcohol at the level used did not seem to be a modulating factor. The NCM3 at the highest dose used was able to induce endothelial dysfunction, especially by decreasing eNOS protein expression, which was independent of the factor LVG or alcohol. Furthermore, it was MeHg as a 
component of the NCM3 metal mixture that was the effector of NCM3-induced endothelial dysfunction. The decreased eNOS protein expression will likely cause changes in the ability of HCAEC to properly regulate vascular activity by causing a reduction in NO production/bio-availability.

The relevance of these findings on the development of cardiovascular disease in Northern populations may be summarized by considering the effects of $\mathrm{MeHg}$ exposure at high doses. The decrease in cell viability due to high $\mathrm{MeHg}$ concentrations is one factor which directly affects the overall number of functional cells. In this study, the responses of a few important biochemical markers for endothelial dysfunction to NCM3 exposure were shown to be consistent with literature findings; especially concerning high concentrations of MeHg. Specifically, the significant decrease of eNOS protein by exposure to high concentrations of $\mathrm{MeHg}$ is relevant because it is so important in vascular regulation of NO production (important for vascular relaxation). A study by Valera et al. (2009) observed a positive correlation between mercury levels and measured blood pressure levels among Nunavik Inuit adults at an exposure concentration of $\mathbf{5 0 . 2}$ $\mathrm{nmol} / \mathrm{L}$ (Valera et al., 2009). However, a review by Mozaffarian in 2009 outlined observations from numerous studies on the effects of $\mathrm{Hg}$ and $\mathrm{MeHg}$ on cardiovascular risk with varying results. A study among men in Kuopio, Finland revealed that hair mercury contents of $>2.03 \mu \mathrm{g} / \mathrm{g}$ were correlated with a $66 \%$ higher risk of coronary syndromes whereas two other prospective studies involving higher blood mercury levels were not significantly associated with increased CVD risk (Mozzafarian 2009). The overall conclusion of his review stated that the effect of $\mathrm{Hg}$ exposure on CVD risk had not been adequately studied. An updated and more recent study by Mozaffarian et al. 
(2011) found that $\mathrm{Hg}$ measured from toenails at a concentration of $0.95 \mu \mathrm{g} / \mathrm{g}$ were not significantly linked to increased risk of CVD (Mozaffarian et al., 2011). Similarly, Mozaffarian et al., (2012) reported that two separate large prospective cohort studies in US men and women did not support any clinically apparent adverse effect of $\mathrm{MeHg}$ exposure to the rsk of hypertension in either men or women (Mozaffarian et al., 2012). Although it seems that there is no clear answer when considering MeHg dosage and CVD risk, our results suggest that exposure to high concentrations of $\mathrm{MeHg}$ adversely affects biochemical markers indicative of endothelial dysfunction on HCAEC in vitro. Considering the "simplifying assumptions" made at the beginning of this thesis would therefore indicate that similar effects may manifest themselves in an in vivo condition where high doses of $\mathrm{MeHg}$ may cause various alterations in pathways and processes associated with human cardiovascular disease. 
Allen S, Khan S, Al-Mohanna F, Batten P and Yacoub M. Native Low-Density Lipoprotein- induced Calcium Transients Trigger VCAM-1 and E-selectin Expression in Cultured Human Vascular Endothelial Cells. J Clin Invest 1998; 101:1064-1075

Allison BA, Nilsson L, Karpe F, Hamsten A and Eriksson P. Effects of Native, Triglyceride-enriched and oxidatively modified LDL on plasminogen activator inhibitor-1 in human endothelial cells. Arterioscler Throm Vasc Biol 1999; $19: 1354-1360$.

Amonpatumrat S, H Sakurai H, P Wiriyasermkul P, N Khunweeraphong N, S Nagamori S, H Tanaka H, P Piyachatuwarat P and Y Kanai Y. L-glutamate enhances methylmercury toxicity by synergistically increasing oxidative stress. $J$ Pharmacol Sci 2008; 108:280-289

Atochin DN and Huang PL. Endothelial nitric oxide synthase transgenic models of endothelial dysfunction. Pflugers Arch - Eur J Physiol 2010; 460: 965-974.

Azevedo BF, Furieri LB, Pecanha FM, Wiggers GA, Vassallo PF, Simoes MR, Fiorim J, Rossi de Batista P, Fioresi M, Rossoni L, Stefanon I, Alonso MJ, Salaices M and Vassallo DV. toxic effects of mercury on the cardiovascular and central nervous systems. J Biomed Biotechnol 2012; 2012

Bird IM. Endothelial nitric oxide synthase activation and nitric oxide function: new light through old windows. J Endocrinol 2011; 210: 239-241

Boeldt DS, Yi FX and Bird IM. eNOS activation and NO function: Pregnancy adaptive programming of capacitative entry responses alters nitric oxide (NO) output in 
vascular endothelium - new insights into eNOS regulation through adaptive cell signaling. $J$ Endocrinol $2011 ; 210$ : 243-258

Bond $\mathrm{AL}$ and Diamond AW. Total and methyl mercury concentrations in seabird feathers and eggs. Arch Environ Contam Toxicol 2009; 56:286-291

Bose-O'Reilly S, McCarthy KM, Steckling N, and Lettmier B. Mercury exposure and children's health. Curr Probl Pediatr Adolesc Health Care 2010; 40: 186-215

Briones MA, Phillips DJ, Renshaw MA and Hooper WC. Expression of chemokine by human coronary-artery and umbilical-vein endothelial cells and its regulation by inflammatory cytokines. Coron Artery Dis 2001; 12(3): 179-86

Cai $\mathrm{H}$ and Harrison DG. Endothelial dysfunction in cardiovascular diseases: The role of oxidant stress. Circ Res $2000 ; 87: 840-844$

Calabro P, Cirillo P, Limongelli G, Maddaloni V, Riegler L, Palmieri R, Pacileo G, De Rosa S, Pacileo M, De Palma R, Golino P and Calabro R Tissue factor is induced by resistin in human coronary artery endothelial cells by the NF- $\mathrm{KB}$ dependent pathway. $J$ Vasc Res $2011 ;$ 48:59-66

Ceccatelli S, Dare E and Moors M. Methylmercury-induced neurotoxicity and apoptosis. Chem Biol Interact 2010; 188: 301-308.

Celermajer DS, Sorensen KE, Gooch VM, Spiegelhalter DJ, Miller OI, Sullivan ID, Lloyd JK, Deanfield JE: Non-invasive detection of endothelial dysfunction in children and adults at risk of atherosclerosis. Lancet 340: 1111-1115, 1992

Copple IM, Goldring CE, Kitterinham NR and Park BK. The Keap1-Nrf2 cellular defense pathway: mechanisms of regulation and role in proetction against drug- 
induced toxicity. Uetrech J (ed), Adverse Drug Reactions, Handb of Exp Pharmacol 2010: 196.

Cuypers A, Plusquin M, Remans T, Jozefczak M, Keunen E, Gielen H, Opdenakker K, Nair AR, Munters E, Artois TJ, Nawrot T, Vangronsveld $J$ and Smeets $K$. Cadmium stress: an oxidative challenge. Biometals 2010; 23:927-940.

Davidson SM. Endothelial mitochondria and heart disease. Cardiovasc Res 2010;88:5866

Deanfield JE, Halcox JP and Rabelink TJ. Endothelial function and dysfunction: Testing and clinical relevance. Circulation 2007; 115: 1285-1295

Dellaire F, Dewailly E, Muckle G and Ayotte P. Time trends of persistent organic pollutants and heavy metals in umbilical cord blood of Inuit infants born in Nunavik (Quebec, Canada) between 1994 and 2001. Environ Health Perspect $2003 ; 111(13) ; 1660-1664$.

Dewailly E, Ayotte P, Pereg D and Dery S. Exposure to heavy metals and persistent organic pollutants in Nunavik: the Nunavik health study (human health). Synopsis of Research, 2005-2006. NCP 2006: 44-64

Ducsay CA and Myers DA. eNOS activation and NO function: Differential control of steroidogenesis by nitric oxide and its adaptation with hypoxia. $J$ Endocrinol 2011; 210: 259-269

Dudzinski D and Michel T. Life History of eNOS: Partners and pathways. Cardiovasc Res 2007; 75(2): 247-260.

Durackova Z. Some current insights into Oxidative stress. Physiol Res 2010; 59:459-469 
Ekino S, Susa M, Ninomiya $T$, Imamura $\mathrm{K}$ and Kitamura $\mathrm{T}$. Minamata disease revisited: An update on the acute and chronic manifestations of methyl mercury poisoning. J Neurol Scis 2007; 262: 131-144

Endemann DH and Schiffrin EL. Endothelial dysfunction. J Am Soc Nephrol 2004; 15(8): 1983-1992

Esteve E, Castro A, Lopez-Bermejo A, Vendrell J, Ricart W and Fernandez-Real JM. Serum interleukin-6 correlates with endothelial dysfunction in healthy men independently of insulin sensitivity. Diabetes Care 2007; 30: 939-945

Faria M, Lopez MA, Fernandez-Sanjuan M, Lacorte S and Barata C. Comparative toxicity of single and combined mixtures of selected pollutants among larval stages of the native freshwater mussels (Unio elongatulus) and the invasive zebra mussel (Dreissena polymorpha); Sci Total Environt 2010; 408: 2452-2458

Feng C. Mechanism of nitric oxide synthase regulation: Electron transfer and interdomain interactions. Coordin Chem Rev 2012; 256:393-411.

Fontaine J, Dewailly E, Benedetti JL, Pereg D, Ayotte P and Dery S. Re-evaluation of blood mercury, lead and cadmium concentrations in theInuit population of Nunavik (Quebec): a cross-sectional study. Environ Health 2008; 7:25.

Fujiwara Y and Kaji T. Inhibition of the repair of injured endothelial cell monolayers by lead and its possible mechanisms. J Health Sci $2000 ; 46(1): 1-4$.

Giles TD, Sander GE, Nossaman BD and Kadowitz PJ. Impaired vasodilation in the pathogenesis of hypertension: Focus on nitric oxide, endothelial-derived hyperporalizing factors, and prostaglandins. J Clin Hypertens 2012; 14:198-205

Goyer RA. Toxic and essential metal interactions. Annu Rev Nutr 1997;17:37-50. 
Goyer RA. Nutrition and metal toxicity. Am J Clin Nutr 1995; 61 (suppl):646S-50S

Grandjean P, Satoh H, Murata K and Eto K. Adverse effects of methylmercury:

Environmental health research implications; Environ Health Perspect 2010; August 118 (8)

Gurer $\mathrm{H}$ and Ercal N. Can antioxidants be beneficial in the treatment of lead poisoning?

Free Radic Biol Med 2000; 29(10):927-945

Guzik TJ, Chen W, Gongora MC, Guzik B, Lob HE, Mangalat D, Hoch N, Dikalov S, Rudzinski P, Kapelak B, Sadowski J and Harrison DG. Calcium-dependent NOX5 nicotinamide adenine dinucleotide phosphate oxidase contributes to vascular oxidative stress in human coronary artery disease. $J$ Am Coll Cardiol 2008; 52:1803-1809.

Harrison D, Griendling KK, Landmesser U, Hornig B and Drexler H. Role of oxidative stress in atherosclerosis. Am J Cardiol 2003; 91(suppl):7A-11A.

Hou T, Tieu BC, Ray S, Recinos III A, Cui R, Tilton RG and Brasier AR. Roles of IL-6gp130 signaling in vascular inflammation. Curr Card Rev 2008; 4:179-192

Ji Y, Diao J, Han Y, Huang Y, Bai H, Chen Q, Fan L and Ferro A. Pyridoxine prevents dysfunction of endothelial cell nitric oxide synthase production in response to low-density lipoprotein. Atherosclerosis 2006; 188:84-94

Jones DP. Radical-free biology of oxidative stress. Am J Cell Physiol 2008; 295: C849C868.

Jones WK, Brown M, Wilhide M, He S and Ren X. NF-kB in cardiovascular disease: diverse and specific effects of a "general" transcription factor. Cardiovasc Toxicol 2005; 5:183-201. 
Jorgensen MA, Bjerregaard P, Kjergaard JJ and Borch-Johnsen K. High prevalence of coronary heart disease among Greenland Inuit. Atherosclerosis 2008; 196: 772778

Kondo $T$, Hirose $M$ and Kageyama $K$. Roles of oxidative stress and redox regulation in atherosclerosis. $J$ Atherscler Thromb 2009; 16:532-538.

Lassegue B and Griendling KK. NADPH Oxidases: Functions and pathologies in the vasculature. Arteriscler Thromb Vasc Biol; 2010; 30:653-661

Latron Y, Chautan M, Anfosso F, Alessi MC, Nalbone G, Lafont H and Juhan-Vague I. Stimulating effect of oxidized low density lipoproteins on plasminogen activator inhibitor-1 synthesis by endothelial cells. Arterioscler Thromb Vasc Biol 1991; 11:1821-1829

Lee KW, Lip GYH, Tayebjee M, Foster W and Blann AD. Circulating endothelial cells, von Willebrand factor, interleukin-6, and prognosis in patients with acute coronary syndromes. Blood $2005 ; 105: 526-532$

Lener B, Koziel R, Pircher H, Hutter E, Greussing R, Herndler-Brandstetter D, Hermann M, Unterluggauer $\mathrm{H}$ and Jansen-Durr $\mathrm{P}$. The NADPH oxidase Nox 4 resticts the replicative lifespan of human endothelial cells. Biochem J 2009; 423:363-374.

Leopold JA and Loscalzo J. Oxidative risk for atherothrombotic cardiovascular disease Free Radic Biol Med. 2009; 47:1673-1706.

Li D and Mehta JL. Oxidized LDL, a critical factor in atherogenesis. Cardiovasc Res $2005 ; 65: 353-354$ 
Lubrano V, Baldi S, Ferrannini E, L'abbate A and Natali A. Role of thromboxane A2 teceptor on the effects of oxidized LDL on microvascular endothelium nitric oxide, endothelin-1 and IL-6 production. Microcirculation 2008; 15:543-553

Mahaffey K. Mercury Exposure: Medical and public health issues. Trans Am Clin Climatol Assoc 2005; 116

Mazerick JN, Hagele T, Sherwani S, Ciapala V, Butler S, Kuppusamy ML, Hunter M, Kuppusamy P, Marsh CB and Parinandi NL. Phospholipase A2 activation regulates cytotoxicity of methylmercury in vascular endothelial cells. Int $J$ Toxicol 2007; 26:553-569

Mazzuca MQ and Khalil RA. Vascular endothelin receptor type B: Structure, function and dysregulation in vascular disease. Biochem Pharmacol 2012; 84:147-162

McAlpine D and Araki S. Minamata Disease: An unusual neurological disorder caused by contaminated fish. Lancet 1958 ; September 20

Mercado N, Thimmulappa R, Thomas CMR, Fenwick PS, Chana KK, Donnelly LE, Biswal S, Ito $\mathrm{K}$ and Barnes PJ. Decreased histone deacetylase 2 impairs Nrf2 activation by oxidative stress. Biochem Biophys Res Commun 2011; 406(2): 292-298.

Michel T and Vanhoutte PM. Cellular signaling and NO production. Pflugers Arch - Eur J Physiol 2010; 459:807-816.

Montezano AC, Burger D, Ceravolo GC, Yusuf H, Montero M and Touyz RM. Novel Nox homologues in the vasculature focusing on Nox 4 and Nox 5. Clin Sci 2011; 120:131-141 
Moulis JM and Thevenod F. New Perspectives in cadmium toxicity: an introduction. Biometals 2010; 23:763-768.

Mozaffarian D. Fish, mercury, selenium and cardiovascular risk: Current evidence and unanswered questions. Int J Environ Res Public Health 2009; 6:1894-1916

Mozaffarian D, Peilin S, Morris JS, Grandjean P, Siscovick DS, Spigelman D, Willet WC, Rimm EB, Curran GC and Forman JP. Mercury exposure and risk of hypertension in US men and women in 2 prospective cohorts. Hypertension 2012; 60:645-652.

Mozaffarian D, Peilin PH, Shi P, Morris JS, Spigelman D, Grandjean P, Siscovick DS, Willet WC and Rimm EB. Mercury exposure and risk of cardiovascular disease in rwo U.S. cohorts. $N$ Engl J Med 2011; 364:1116-1125

Niemann B, Rohrbach S, Catar RA, Muller G, Barton M and Morawietz H. Native and oxized low-density lipoproteins stimulate endothelin-converting enzyme-1 expression in human endothelial cells. Biochem Bioph Res Co 2005; 334:747753

Norata GD, Pirillo A, Callegari E, Hamsten A, Catapano AL and Eriksson P. Gene expression and intracellular pathways involved in endothelial dysfunction induced by VLDL and oxidised VLDL. Cardiovasc Res 2003; 59:169-180

Nordberg GF. Historical perspectives on cadmium toxicology. Toxicol and app Pharmacol 2009: 238:192-200.

Oever IAMVD, Raterman HG, Nurmohamed MT and Simsek S. Endothelial dysfunction, inflammation, and apoptosis in diabetes mellitus. Mediat Inflamm 2010 
Ono H, Umeda F, Inoguchi I and Ibayashi H. Glucose inhibits prostacylcin production by cultured aortic endothelial cells. Thromb Haemost 1988; 60(2): 174-177

Pelletier G, Masson S, Wade MJ, Nakai J, Alwis R, Mohottalage S, Kumarasathan P, Black P, Bowers WJ, Chu I and Vincent R. Contribution of methylmercury, polychlorinated biphenyls and organochlorine pesticides to the toxicity of contaminant mixture based on Canadian Arctic population blood profiles. Toxicol Lett; 2009; 184:176-185.

Perez-Vizcaino F, Cogolludo A and Moreno L. Reactive oxygen species signaling in pulmonary vascular smooth muscle. Resp physiol and Neurobiol 2010; 174:212220

Primiano T, Sutter TR, Kensler TW. Antioxidant-inducible genes. Adv Pharmacol 1997; 38:293-328

Prozialeck WC, Edwards JR and Woods JM. The vascular endothelium as a target of cadmium toxicity. Life Sci 2006; 79:1493-1506.

Rafikov R, Fonseca FV, Kumar S, Pardo D, Darragh C, Elms S, Fulton D and Black SM. eNOS activation and NO function: Structural motifs responsible for the posttranslational control of endothelial nitric oxide synthase activity. $J$ Endocrinol 2011; 210: 271-284

Ramirez-Sanchez I, Aguilar H, Ceballos G and Villarreal F. (-)-Epicatechin- induced calcium independent eNOS activation: roles of HSP90 and AKT. Mol Cell Biochem 2012; 368

Reriani MK, Lerman LO and Lerman A. Endothelial function as a functional expression of cardiovascular risk factor. Biomark Med 2010; 4(3): 351-360 
Rubanyi GM and Botelho LH. Endothelins. FASEB J 1991; 5(12):2713-2720

Rubanyi GM and Polokoff MA. Endothelins: molecular biology, biochemistry, pharmacology, physiology, and pathophysiology. Pharmacol Rev 1994; 46(3): $325-415$

Sanders T, Y Liu, Buchner V and Tchounwou PB. Neurotoxic effects and Biomarkers of Lead Exposure: A Review. Rev Environ Health 2009; 24(1): 15-45.

Schroder K. Isoform specific functions of Nox protein-derived reactive oxygen species in the vasculature. Curr Opinion Pharmacol. 2010; 10:122-126

Sodergren A, Karp K, Boman K, Eriksson C, Lundstrom E, Smedby T, Soderlund L, Rantapaa-Dahlqvist $\mathrm{S}$ and Wallberg-Jonsson S. Athersclerosis in early rheumatoid arthritis: very early endothelial activation and rapid progression of intima media thickness. Arthritis Res Ther 2010; 12: R1 58

Stocker R and Keaney JF. Role of Oxidative Modifications in Atherosclerosis. Physiol $\operatorname{Rev} 2004 ; 84: 1381-1478$

Suvorava T and Kojda G. Reactive oxygen species as cardiovascular mediators: Lessons from endothelial-specific protein overexpression mouse models. Biochimica et Biophysica Acta 2009; 1787:8002-810

Sharp D. Environmental toxins: A potential risk factor for diabetes among canadian aboriginals. Int J Circumpolar Health 2009; 68

Smith LH, Boutaud O, Breyer M, Morrow JD, Oates JA and Vaughan DE. Cyclooxygenase-2-dependent prostacyclin formation is regulated by low density lipoprotein cholesterol in vitro. Arterioscler Thromb Vasc Biol 2002; 22:983988 
Sun $\mathrm{Z}$ and $\mathrm{R}$ Andersson. NF-kB activation and inhibition: A review. SHOCK 2002; 18(2):99-106.

Suwaidi JA, Hamasaki S, Higano ST, Nishimura RA, Holmes DR Jr, Lerman A: Longterm follow-up of patients with mild coronary artery disease and endothelial dysfunction. Circulation 101: 948-954, 2000

Tesfamariam B, Brown ML and Cohen RA. Elevated glucose impairs endotheliumdependent relaxation by activating protein Kinase C. J Clin Invest 1991; 87:1643-1648.

Thijssen S, Cuypers A, Maringwa J, Smeets K, Horemans N, Lambrichts I and Kerkhove EV. Low cadmium exposure triggers a biphasic oxidative stress response in mice kidneys. Toxicol 2007;236: 29-41.

Tian J, Hou Y, Lu Q, Wiseman DA, Vasconcelos FF, Elms S, Fulton DJ and Black SM. A novel role for caveolin-1 in regulating endothelial nitric oxide synthase activation in response to $\mathrm{H}_{2} \mathrm{O}_{2}$ and shear stress. Free Radic Biol Med 2010; 49: $159-170$

Tousoulis D, Antoniades C and Stefanadis C. Nitric oxide in coronary artery disease: effects of antioxidants. Eur J Clin Pharmacol 2006; 62:101-107.

Tremoli E, Camera M, Maderna P, Sironi L, Prati L, Colli S, Piovella F, Bernini F, Corsini A and Mussoni L. Increased synthesis of plasminogen activator inhibitor- 1 by cultured human endothelial cells exposed to native and modified LDLs. An LDL receptor-independent phenomenon. Aterioscler Thromb Vasc Biol 1993; 13:338-346 
Triau JE, Meydani SN and Schaefer EJ. Oxidized low density lipoprotein stimulates prostacyclin production by adult human vascular endothelial cells. Arterioscler Thromb Vasc Biol 1988; 8:810-818.

Ushio-Fukai $M$ and Nakamura Y. Reactive oxygen species and angiogenesis: NADPH oxidase as a target for cancer therapy. Can Lett 2008; 266:37-52

Valera B, Dewailly E and Poirier P. Environmental mercury exposure and blood pressure among Nunavik Inuit adults. Hypertension 2009; 54:981-986.

Van Oostdam J, Donaldson SG, Feeley M, Arnold D, Ayotte P, Bondy G, Chan L, Dewaily E, Furgal CM, Kuhnlein H, Loring E, Muckle G, Myles E, Receveur O, Tracy B, gill G and Kalhok S. Human health implications of environmental contaminants in Arctic Canada: A review. Sci Total Environ 2005; 351352:165-246

Vaziri ND. Mechanisms of lead-induced hypertension and cardiovascular disease. $A m J$ Physiol Heart Circ Physiol 2008; 295:H454-H465

Versari D, Daghini E, Virdis A, Ghiadoni L and Taddei S. The ageing endothelium, cardiovascular risk and disease in man. Exp Physiol 2008; 943: 317-321

Virtanen JK, Rissanen TH, Voutilainen S and Tuomainen TP. Mercury as a risk factor for cardiovascular diseases. J Nutr Biochem 2007; 18:75-85.

Wassmann S, Stumpf M, Strehlow K, Schmid A, Schieffer B, Bohm M and Nickenig G. Interleukin-6 induces oxidative stress and endothelial dysfunction by overespression of the angiotensin II Type 1 receptor. Circ Res 2004; 94:534-541

Wiggers GA, Pechana FM, Briones AM, Perez-Giron JC, Miguel M, Vassallo DV, Cachofeiro V, Alonso MJ and Salaices M. Low mercury concentrations cause 
oxidative stress and endothelial dysfunction in conductance and resistance arteries. Am J Physiol Heart Circ Physiol 2008; 295:H1033-H1043.

Wind S, Beuerlein K, Armitage ME, Taye A, Kumar AHS, Janowitz D, Neff C, Shah AM, Wingler $\mathrm{K}$ andSchmidt HHHW. Oxidative stress and endothelial dysfunction in aortas of aged spontaneously hypertensive rats by NOX1/2 is reversed by NADPH oxidase inhibition. Hypertension; $2010 ; 56: 490-497$

Writh JJ and Mijal RS. Adverse effects of low level heavy metal exposure on male reproductive function. Sys Biol in Reprod Med 2010; 56:147-167.

Yamamoto C, Kaji T, Sakamoto M and Kozuka H. Effects of cadmium on the release of tissue plasminogen activator and plasminogen activator inhibitor type 1 from cultured human vascular smooth muscle cells and fibroblasts. Toxicol 1996; 106:179-185

Yorifuji T, Tsuda T, Kashima S, Takao S and Harada M. Long-term exposure to methylmercury and its effects on hypertension in Minamata. Environ Res 2010; 100: $40-46$.

Zhang C, Zhang Nannan and BT Andresen. Inflammation and reactive oxygen species in cardiovascular disease . World J Cardiol 2010; 2(12): 408-410

Zhao $\mathrm{R}, \mathrm{Ma} \mathrm{X}$ and Shen GX. Transcriptional regulation of plasminogen activator inhibitor-1 in vascular endothelial cells by oxidized very low density lipoproteins. Mol Cell Biochem 2008; 317:197-204

Zou MH, Shi C and Cohen RA. High glucose via peroxynitrite causes tyrosine nitration and inactivation of prostacyclin synthase that is associated with thromboxane/ prostaglandin $\mathrm{H} 2$ receptor-mediated apoptosis and adhesion molecule 
expression in cultured human aortic endothelial cells. Diabetes 2002; 51:198- 